Portland State University

PDXScholar

Dissertations and Theses

Dissertations and Theses

$1-1-1983$

\title{
Causes and consequences of divorce in late life
}

Keren Brown Wilson

Portland State University

Follow this and additional works at: https://pdxscholar.library.pdx.edu/open_access_etds Let us know how access to this document benefits you.

\section{Recommended Citation}

Wilson, Keren Brown, "Causes and consequences of divorce in late life" (1983). Dissertations and Theses. Paper 402.

https://doi.org/10.15760/etd.402

This Dissertation is brought to you for free and open access. It has been accepted for inclusion in Dissertations and Theses by an authorized administrator of PDXScholar. Please contact us if we can make this document more accessible: pdxscholar@pdx.edu. 


\title{
CAUSes AND CONSEQUenCES OF DIVORCE IN LATE LIFE
}

\author{
by \\ REREN BROWN WILSON
}

A dissertation submitted in partial fulfillment of the requirements for the degree of

\author{
DOCTOR OF PEILOSOPEY \\ in \\ ORBAN STUDIES
}

Portland State University

(C) 1983 keren Brown Wilson 
TO THE OFFICE OF GRADUATE STUDIES AND RESEARCH:

The members of the Committee approve the dissertation of Keren Brown Wilson presented December 8, 1982.

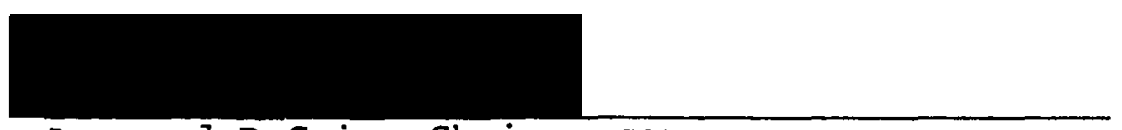

Leonard D Cain, Chairperson

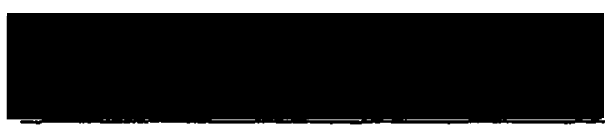

Kristena LaMar
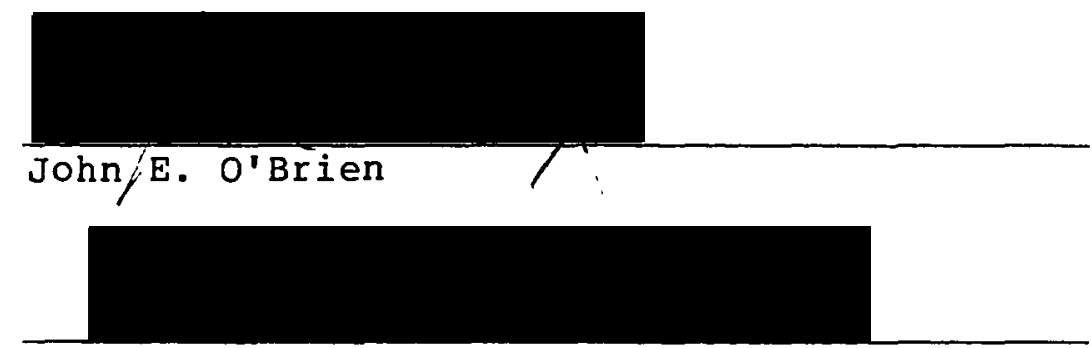

Cathleen L. Smith

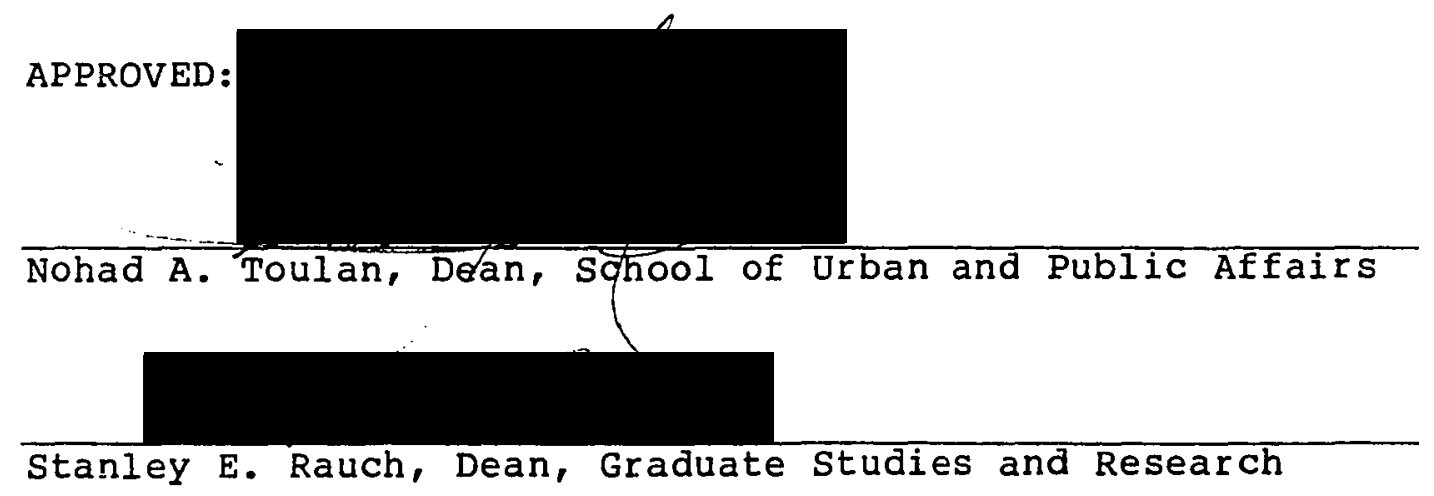


AN ABSTRACT OF THE DISSERTATION OF Keren Brown Wilson for the Doctor of Philosophy in Urban Studies presented December 8,1982 .

Title: Causes and Consequences of Divorce in Late Life

APPROVED BY MEMBERS OF THE DISSERTATION COMMITTEE:

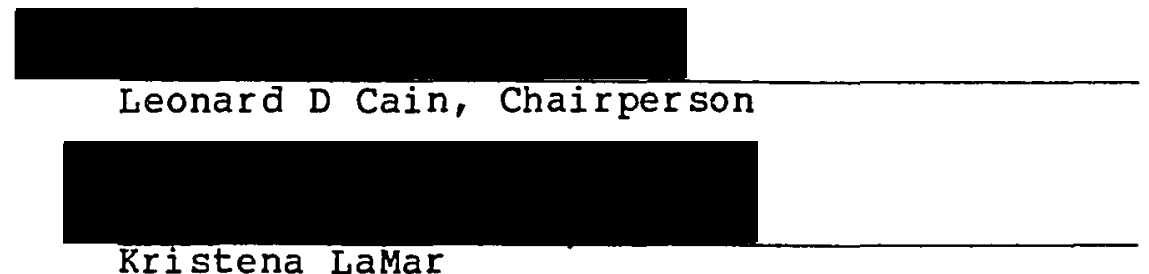

Kristena LaMar

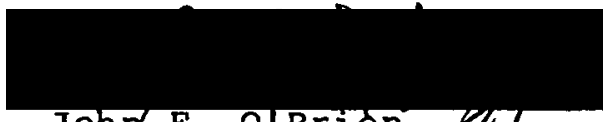

Johp E. OBrien YYT

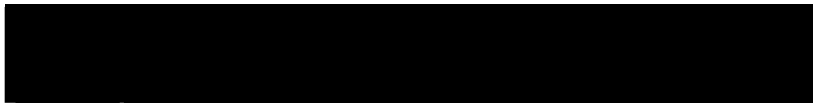

Cathleen L. Smith

The purpose of this study was to develop a framework in which the effect of divorce in late life could be examined. Statistics indicate a growing number of persons who occupy the divorce status in late life. Many of these persons enter late life in the divorced status, others are divorced after age 60. This study focuses upon those who divorce after age 60. Although previous work does not shed much light upon late life divorce, it yields a clear picture of the characteristics, process and consequences of 
divorce for younger persons. Assumptions derived from work with younger divorcing populations provide a basis for the conceptual framework used in this study.

A description of who gets divorced, causes, process and consequences of divorce in late life is provided. Stage in the life cycle and birth cohort are used to determine whether significant age related differences existed in the study sample. A model which predicts post divorce adjustment also is tested. The model's components--anticipated cost, type of divorce experienced, consequences, time and sex--are derived from studies of post divorce adjustment in younger populations.

Data for the study come from two sources--court records of 240 older individuals filing for divorce and interviews with 81 individuals involved in those actions. Sample selection criteria required at least one of the parties to the divorce action be over the age of 60 . In addition to the descriptive statistics used in the study, analysis of variance and multiple linear regression techniques were used to test hypotheses related to the divorce adjustment model.

Findings affirm similarities between younger and older divorcing persons. Persons divorcing in late life generally had low occupational status, few assets and weak religious ties. They were urban residing, had weak ties with kin and were married and had children at an earlier 
than average age for their birth cohort. Generally, the marriage being terminated had endured for at least 20 years. The collapse (i.e., "cause" of the divorce) resulted from a long-standing lack of emotional gratification aggravated by some type of precipitating event.

Few subjects perceived themselves to be victims of the divorce; most had ambivalent feelings about getting divorced and mixed experiences during the divorce. The data show clearly the consequences of having negative feelings about the termination of the marriage and being involved in a highly conflicted divorce process. Not only were the legal, economic, social and psychological consequences greater, but subjects were less successful in resolving problems and exhibited high levels of stress subsequent to the divorce.

Age was not found to be associated with personal and marital characteristics, cause of divorce, type divorce experienced or consequences endured as a result of divorce. The findings do suggest, however, the possibility of a curvilinear relationship between age and post divorce adjustment, with those in mid life (45-65) being more adversely affected than those in later life.

Fifty-four percent of the variance in post divorce adjustment was accounted for by five predictor variables. of these, sex, consequences and type of divorce experienced 
accounted for nearly all (49\%) of the differences found. The study also found that with the exception of sex, single variables such as health status, were not useful in explaining variance in post divorce adjustment. Overall, the data suggest that: 1) females have more negative divorce experiences and suffer greater negative consequences than do males; 2) managed conflict is an important part of successful adjustment; and 3 ) society does not recognize the complications presented by late life divorce. 


\section{ACRNOWLEDGMENTS}

This dissertation was made possible by a grant from the AARP Andrus Foundation. I should like to thank Dr. Frederick Ferris of the Andrus Foundation for his support of this work. Special thanks are due Dr. Michael Deshane, Susan Whitney and Dawn Kuenle for their unfailing help at various stages in the preparation of this dissertation. Nor could I have completed the task without the uniquely humane encouragement offered by Dr. Leonard Cain, Chair of my Committee, and the diligence displayed by other members of my Committee, Dr. Cathleen L. Smith, Kristena LaMar, Esq., and Dr. John O'Brien. But most of all I should like to thank Jessie Richardson wilson, who had enough courage to dream as only a mother can for her child. 
TABLE OF CONTENTS

PAGE

ACKNOWLEDGMENTS . . . . . . . . . . . . . . . . iii

LIST OF TABLES • • • • • • • • • • • • • • • • • • v viii

LIST OF FIGURES . . . . . . . . . . . . . . . . xii

CHAPTER

I INTRODUCTION • . . . . . . . . . . . . . 1

I I REVIEW OF THE LITERATURE . . . . . . . . . 8

Historical Trends in Divorce . . . . . 8

Divorce Rates Among the Elderly . . . . 14

Characteristics of Divorcing Individuals • 22

Causes of Divorce . . . . . . . . 32

The Divorce Process and Adjustment . . . 36

III DESIGN AND METHODOLOGY . . . . . . . . . . 45

Stage I: Divorce in Late Life. . . . . 46

Personal Characteristics and Late Life Divorce

Explaining the Cause of Late Life Divorce

The Divorce Process

The Role of Age . . . . . . . . . 51

Stage II: A Model of Divorce Adjustment . 53

Anticipated Cost

The Types of Divorce Experience

Consequences of Divorce

Interactive Nature of the Divorce

Adjustment Model 
PAGE

Study Sample........... 61

Rationale for selection Criteria

Data Collection and Preparation . . . 64

Reliability of Interview Data

Sample Representativeness . . . . . . 68

Operationalization of the Variables . . 70

Glossary of Terms . . . . . . . . 73

IV FINDINGS AND INTERPRETATIONS . . . . . . . 83

Profiles of Divorcing older Persons . . 83

Differences Between Younger and Older Divorcing Persons

Similarities Between Younger and

Older Divorcing Persons

Causes of Late Life Divorce . . . . . 90

Cause of Divorce and Personal Characteristics

Cause of Divorce and the Divorce Process

Expectations and Reactions to Divorce • 95

Divorcing Behaviors

Consequences of Late Life Divorce . . . 106

Correlations Between Types of

Consequences Experienced

Coping strategies Used for Problem Resolution

Factors Influencing Adjustment subsequent

to Divorce.............. . . 113

Divorce in Two Stages of the

Life Cycle . . . . . . . . . . . . II7

Personal Characteristics of Divorcing

Individuals of Pre and post

Retirement Age 


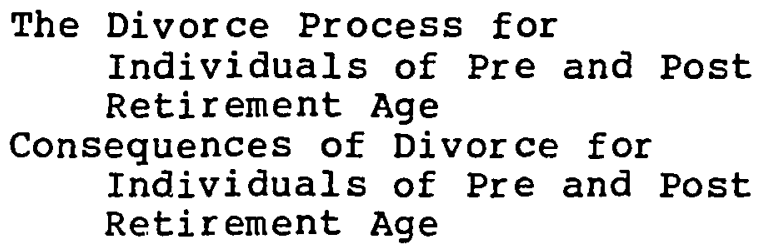

Divorce in Two Birth Cohorts... . . . 124

Characteristics of Divorcing Individuals in Two Birth Cohorts

Anticipated Cost and the Type of Divorce Experience . . . . . . . . . . . 128

Type of Divorce Experience and Resulting

Consequences ............. 133

Consequences of and Adjustment to

Divorce . . . . . . . . . . . . 137

Intervening Variables and Adjustment . . 138

Testing the Divorce Adjustment Model . . 141

V. DISCUSSION AND CONCLUSIONS . . . . . . . . 144

Stage I: The Phenomenon of Late Life

Divorce . . . . . . . . . . . . . I 144

Profiling Causes of Late Life

Divorce

Reaction and the Type of

Divorce Experience

Consequences and Post Divorce Adjustment

Age and Divorce . . . . . . . . . 151

Relationship Between Age and Sex

Stage II: Predicting Adjustment to

Divorce ............... 154

Discussion of the Divorce Adjustment Model

Limitations of the study . . . . . . 160 
vii

PAGE

Implications of the Study . . . . . . 163 FOOTNOTES . . . . . . . . . . . . . . . 167

BIBLIOGRAPHY . . . . . . . . . . . . . . . 169 


\section{LIST OF TABLES}

TABLE

PAGE

I Number of Divorced Persons Per 1,000 Married Couples by Age for Selected Years . . . . . 16

II Sample Loss from Selected Causes . . . . . . 63

III Information Collected for each Member of the Divorcing Couple from Pre-Interview Information Provided by subject and Court Files in Multnomah and Clackamas Counties, oregon . . 65

IV Comparison of Interview with Initial

Sample on Selected Personal and Divorce Characteristics from Court Records . . . 69

$\mathrm{V}$ Items Used to Construct Scales Describing

Personal Characteristics of the study Population . . . . . . . . . . 77

VI Items Used to Construct Scales of

Marital Risk, Marital Quality and

Life Stress.............. 78

VII Items Used to Construct Measures of

Conflict in the Divorce Process . . . . . 79

VIII Items used to Construct scales of

Psychological, Social, Legal Consequences

and Measure of Economic Loss Caused by

Divorce . . . . . . . . . . . 80 
PAGE

IX Langner Psychiatric Checklist Items . . . . . 81

$x$ Items used to Create Predictor and

Criterion Variables in the Divorce

Adjustment Model . . . . . . . . . 82

XI Personal Characteristics in a Sample of

Divorcing older Persons . . . . . . . . 84

XII Causes of Divorce in a sample of 81

Divorcing older Persons . . . . . . . . 91

XIII Distribution of Subject Scores on

Marital Risk, Marital Quality, Life Stress

and Anticipated Cost Score . . . . . . 97

XIV Level of Conflict in the Divorce Process . . . 101

XV Subject Divorce Experience Based on Reaction

to Divorce and Conflict Exhibited During

the Divorce Process . . . . . . . . 103

XVI Consequences of Divorce in a sample of

81 Divorcing older Persons . . . . . . 108

XVII Coping strategies in a Sample of 81

Divorcing older Persons . . . . . . . . 111

XVIII Adjustment in a Sample of 81 Divorcing

Older Persons............ . . . 114

XIX Comparisons of Personal Characteristics of

Sample Subjects in Two Stages of the Life

Cycle • . . • . • . . . . . . . 119 
$\mathrm{xx}$ Comparisons of Divorce Characteristics of Sample Subjects in Two stages of the Life Cycle . . . . . . . . . . . . . . 121

XXI Comparisons of Consequences Experienced by Sample subjects in Two stages of the Life Cycle . . . . . . . . . . . . . 123

XXII Comparisons of Adjustment of Sample

Subjects in Two Stages of the Life Cycle • . 125

XXIII Comparisons of Personal Characteristics

of Sample Subjects in Two Birth Cohorts . . 127

XXIV Comparisons of Divorce Characteristics

of Sample Subjects in Two Birth Cohorts. . . 129

XXV Comparisons of Consequences Experienced

by Sample Subjects in Two Birth Cohorts . . 130

XXvI Comparisons of Adjustment of Sample

Subjects in Two Birth Cohorts.. . . . . 131

XXVII Analysis of Variance of Marital Risk, Marital Quality and Life stress Scores for Negative, Ambivalent and Positive Divorce Experience Groups . . . . . . . . . . 134 XXVIII Analysis of Variance of Consequences for Negative, Ambivalent and Positive Divorce Experience Groups . . . . . . . . . 136 XXIX Summary Results from Three Regression Equations for the Criterion Variable Adjustment . . . . . . . . . . . . . 140 
PAGE

XXX Summary Statistics for Divorce Adjustment

Model Multiple Regression Equation with Five

Predictor Variables . . . . . . . . 142 


\section{LIST OF FIGURES}

F IGURE

PAGE

1. Divorces Per 1,000 U.S. Population, $1870-1981$. . . . . . . . . . 12

2. Divorces/Annulments Per 1,000 U.S.

Population, 1950-1981 . . . . . . . 15

3. Divorce Adjustment Model . . . . . . . . 54 
CHAPTER I

\section{INTRODUCTION}

Whether urbanization has a positive or negative effect on individual behavior and social institutions is a topic around which considerable debate has occurred. Urbanization is presumed to have weakened kinship bonds, increased specialization, escalated the movement away from teritorially based commitments, encouraged the growth of secularism and generated higher tolerance for diversity (c.E., Milgram, 1970; Park, 1952; Reissman, 1964; Wirth, 1938). In the course of these events, the function of the family also has been altered and the social utility of marriage has been questioned. The questioning presumably has resulted in rising divorce rates.

Industrialization and urbanization have been linked to the emergence of a conjugal marriage pattern more susceptible to dissolution by means other than death of a spouse than the marriage pattern reinforced by external kinship pressures (Goode, 1968; Nye \& Berardo, 1973; Ogburn, 1968).1 The susceptibility of the conjugal marriage to dissolution purportedly stems from an increased emphasis on autonomy of decision-making, consumption as opposed to production, non-territorially based commitments 
and free mate selection. Familial responsibilities in the areas of education, socialization, recreation and economic production have been reduced, with the affectional role remaining as the strongest bond between spouses. Hence, marriage increasingly has come to be based on romantic love. Even though romantic love is a fragile bond easily broken, its value in the conjugal family has become so high that its absence often is reason enough for the dissolution of a marriage. Such dissolutions are achieved through desertion, separation and divorce.

Permission to dissolve a marital relationship traditionally has been governed by religious tenets and/or the social codes a society uses to control itself. These "laws" have traditionally acted as a brake to slow down the rate of divorce until the conflict between the new conditions of family life and the old values still cherished by society's members abated (Litwak, 1956). Despite a relaxation of the laws governing divorce in the past twenty years or so, marital dissolution continues to be viewed as problematic for individuals and for society.

The view of divorce as problematic undoubtedly stems partially from continuing strain to accommodate variations in social norms held about the form and function of the family. Furthermore, the research carried out with divorcing persons indicates clearly that divorce represents a major life transition with many consequences for 
individuals who are exposed to it. The need to reduce social strain and alleviate negative consequences for individuals most likely accounts for the tremendous efforts expended in the past decade studying the phenomenon of divorce.

These research efforts have been focused in three areas. First, much of the effort has been directed at gaining an understanding of the demographic trends involved so that projections about future divorce rates could be made (c.f., Carter \& Glick, 1976; Carter \& Plateris, 1968; Cherlin, 1979; Crosby, 1980; England \& Kunz, 1975; Glick \& Norton, 1973, 1977; Michael, 1978; Norton \& Glick, 1976; Schoen \& Nelson, 1974). Second, other efforts have been directed at discovering explanations for divorcing behavior (Becker et al., 1977; Burr et al., 1979; Deckert \& Langelier, 1978; Lewis \& spanier, 1979; McKenry et al., 1978; Nye \& Berardo, 1973; Scanzoni, 1972; walster et al., 1973). Finally, considerable effort has been focused on the consequences of divorce and the process by which people adjust to the dissolution of a marriage (Berman \& Turk, 1981; Chiriboga, 1979; Chiriboga et al., 1978; Chiriboga \& Cutler, 1979; Goode, 1956; Hunt \& Hunt, 1977; Raschke, 1977; Raschke \& Barringer, 1978; Spanier \& Casto, 1979; Weiss, 1975).

To date, however, almost no attention has been paid to divorce among persons in the later stages of the family 
life cycle. While the lack of attention to divorce among older people may have been justified in the past by the small number of individuals occupying that status, such arguments can no longer be justified. The rate of divorce among older Americans has increased steadily over the past 50 years and a steepening of the upward curve in the rate of divorce for older persons has been predicted (Deshane \& Wilson, 1981a). Even if the rate of divorce among older persons does not increase, the absolute number of older persons who are divorced is expected to climb sharply in the next several decades. Indeed, in 1977 the U.S. Bureau of the Census reported that approximately 600,000 persons over age 65 were divorced; by 1979 this figure had increased to 767,000 persons. While some of the increase is due to the movement of divorced individuals into old age, changes in age-specific divorce rates indicate that not all of the increase can thus be attributed (Carlson, 1979).2 These increases suggest that divorce will become a more important issue in late life adjustment.

Late life adjustment involves confronting a series of major life transitions. Most of these transitions are experienced, to some degree, by all older persons. Indeed, some, such as the post-parental role or retirement from work, are anticipated and are duly heralded as special accomplishments. Yet, even approved transitions such as these are often extremely stressful events, particularly if 
they occur prematurely or in rapid succession. Divorce is neither approved, nor widely experienced. It is, in fact, a non-normative event (McCubbin et al., 1980; Pearlin \& Schooler, 1978). As such, the level of stress associated with late life divorce might be expected to be quite high, and as with divorce in younger populations, might be expected to impact negatively upon the well-being of those who experience it in late life.

This study seeks to develop a framework in which the effect of late life divorce on the well-being of older persons can be explored. The paucity of available information on late life divorce necessitates the use of a two-stage approach. Stage I reflects a descriptive study designed to answer four fundamental questions:

1) What are the characteristics of individuals experiencing a late life divorce;

2) What reasons are given as the cause of late life divorce:

3) What events characterize the divorce process in late life; and

4) What consequences are experienced as a result of the decision to divorce?

Taken together, the answers to these four questions are anticipated to provide a framework to test a model of divorce adjustment in the second stage of the study.

Stage II focuses on examining relationships among several sets of factors and well-being subsequent to late life divorce. Ideally, the results of the analysis will 
yield information with implications for social policy as well as a more definitive theoretical framework within which future studies of late life divorce may be undertaken.

Two terms require definition at the outset to avoid confusion over their meanings in the context of this study. "Late life divorce" will refer to a divorce action filed in a court of law which involves individuals 60 years of age or older. Age 60 was chosen because it represents a commonly used legal definition of old age. The definition, however, is designed primarily as a means of distinguishing clearly between those who become divorced in late life and those who enter old age in the divorced status. Such a distinction is necessary given the differences likely between those who divorce before 60 and remain unmarried, and those who divorce after age 60. This study focuses upon those individuals involved in a divorce action in which one or both parties are 60 years of age or older.

Although "well-being" has been used to describe several dimensions of individual functioning, in this study the term will be limited in its application. For the purposes of this study, well-being is defined as the degree of adjustment exhibited subsequent to the initiation of a late life divorce. Other frequently studied indicators of well-being including health, housing, economic security, interpersonal distress and social involvement, are viewed 
in this study as independent or intervening variables whose relationship to well-being as defined above will be subject to testing in this study. 
CHAPTER II

\section{REVIEW OF THE LITERATURE}

Great value traditionally has been placed on the marriage relationship in the United states. Parsons has proposed that this value stems from the central role the marital couple plays in the conjugal family system (Parsons \& Bales, 1955). Others have suggested that urban culture has contributed to the prominence of the marriage relationship in contemporary American society.

In a society often characterized by impersonal
relationships, one in which a given individual is
important to only a few, the most 'significant
other takes on great importance in giving the
individual a sense of personal value. Society
helps contribute to the belief that the marriage
relationship has something special in it that
cannot be found in any other relationship. (Bell,
1967:279)

The marriage relationship historically has been so valued that to remain single or to get divorced often was to invite social censure. Indeed, couples constituted the basic social unit (Babchuk, 1965).

\section{HISTORICAL TRENDS IN DIVORCE}

Despite this emphasis on the marriage relationship, divorce has existed throughout American history as an institutionalized mechanism for dealing with problematic unions. Although statistics are quite sketchy, the data 
available indicate that divorce was a solution seldom employed prior to the Revolutionary War. Calhoun (1945), for example, found only 31 recorded divorces in Massachusetts from 1639 to 1760 , yet the northern colonies were considered to be more liberal than the southern colonies in granting marital dissolutions.

Four factors have been identified as viable explanations for the low rate of divorce which existed in colonial America. Strict societal control, economic interdependence, fear of social censure and demographic characteristics acted to reduce opportunities for divorce. Societal control was maintained through the legal system developed to handle requests for marital dissolution. In most states such requests were brought before the legislature or assembly, which was required to act separately on each petition. Such procedures were costly, time-consuming, public and uncertain (Smith, 1981).

If deterrence was the aim of such obstacles, undoubtedly many elected to continue their marriages in the face of such barriers. Social and economic barriers also existed. These barriers arose, in Burgess's (1928) view, as a result of the functional roles played by families in colonial times. A man or woman alone was less able to carry out successfully necessary societal functions, hence society discouraged the presence of single persons through taxation, restrictions on personal freedom and cloistering. 
Despite these efforts, dissolution did occur. Men in particular found freedom by "going west." Women were more likely to seek relief through the existing legal system (Leslie, 1982). Both probably found an unexpected solution in the high mortality rates and the relatively late age at which the first marriage occurred. Men typically did not take wives until they had achieved economic independence. This normative standard, coupled with the preference for mates in the same age range, resulted in later marriages for both men and women. After marriage, the risk of becoming widowed before many years passed was quite high. Thus, the probability of having to endure a long unsatısfactory marriage was reduced considerably.

Yet, for some even a relatively short unsatisfactory marriage was unacceptable. The rate of divorce began to rise in the second quarter of the nineteenth century. 3 In 1860 the crude divorce rate stood at 1.2 per 1,000 population (U.S. Bureau of the Census, 1960). To control what was viewed as an alarming increase in divorce, laws became stricter and religious strictures against divorce increased (Reiss, 197I). In his analysis, O'Neill (1967) shows that by 1890 divorce was viewed as deviant, outside the limits of acceptable social behavior.

For all of this effort, the divorce rate continued to rise. From 1860 to 1900, the refined divorce rate increased threefold from 1.2 to 4.0 per thousand married 
women, then doubled again from 1900 to 1920 (Jacobson, 1959). Since then the divorce rate has continued to rise, but with major fluctuations. As indicated by the dotted line in Figure 1 , the crude divorce rate has been well above projected levels since 1920.

Fluctuations in the divorce rate have been tied to changes in social conditions, business cycles, age structure, and familial roles. Analysis of divorce statistics over the past 100 years indicates rates rise during periods of war and decline during periods of economic depression (Bell, 1967; Carter \& Plateris, 1968; Leslie, 1982; Nye \& Berardo, 1973).

It has been suggested that being at war generates opportunities for marriage to occur under unusual circumstances. Normal procedures for mate selection, courtship and post-marital adjustment may all be disturbed in war time, resulting in more vulnerable marriages. Such marriages are not good candidates to withstand additional strain of separation induced by war (Hill, 1949).

If being at war strains marital relations, economic hard times have acted in the past to bind couples together. During such times, the drain on financial resources has made divorce a less attractive alternative than it might have been otherwise. While in some cases bonds created by financial consideration might have been temporary, in other cases delaying divorce until the financial situation 


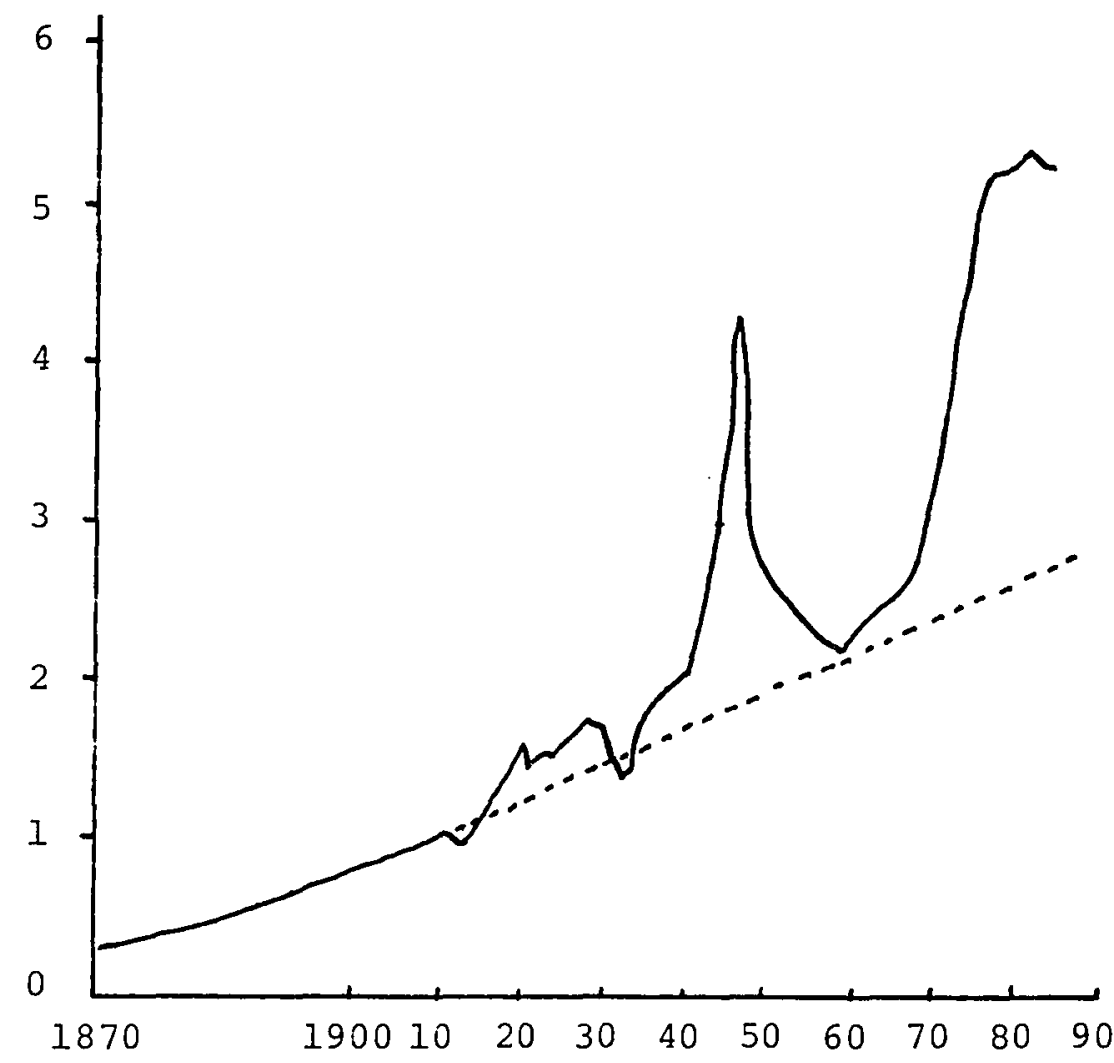

Figure 1. Divorces per 1000 U.S. population, 1870-1981.

Source: Carlson, E., "Divorce Rate Fluctuation as a Cohort Phenomenon." Population Studies, 33, 3, 1979, p. 524; and National Center for Health Statistics, Monthly Vital Statistics Reports, Vol. 30, Nos. 2 \& 3, May 29, 1981 and June 11, 1981. 
improved undoubtedly allowed the marital pair to overcome the problems which led them to consider divorce.

With the most recent upswing of the divorce rate in the 1960's another explanation was put forth. This explanation involved changes in the age structure which is the result of an unusually high fertility rate during the $1940^{\prime} \mathrm{s}$ and 1950's. The "baby-boom" resulted in an unusually large number of females being married in the 1960's and 1970's. This high bulge in the population of newly married, who are at the highest risk of divorce, is believed to be at least partially responsible for the latest increase in divorce rates (England \& Kunz, 1975; Michael, 1978).

But perhaps the most often cited explanation is the changing American family. Some view this change as negative. Hobart (1963), Linton (1936), Nimkoff (1965), Ogburn (1968), and zimmerman (1947) have argued that the dilemma of the modern conjugal family was the loss of function, with instability and disintegration following as consequences. The loss of function typically has been associated with increasing urbanization and industrialization.

Others claim that the attractiveness of family formation actually has increased despite the loss of traditional functions. Support for this claim is found in the extraordinary desire Americans appear to have for 
marriage. In 1970, 93.4 percent of all females and 91 percent of all males age 35 or older had been married at least once (Moles \& Levinger, 1976). Further, 75 percent of all females and 85 percent of all males who are divorced remarry (Norton \& Glick, 1976). This perspective presents the family as undergoing and creating change, during which some upheaval might be expected (Edwards, 1967; Moore, 1960; Reiss, 1971). Divorce, while unfortunate for individuals who experience it, is one of society's ways of coping with these changes in the family.

\section{DIVORCE RATES AMONG THE ELDERLY}

The increase ia divorce rates in recent years has not been distributed evenly across all age categories. As can be seen in Figure 2, the increase in divorce rates over the past 20 years has been greatest for those individuals under age 35. Indeed, 75 percent of the upturn in age specific divorce rates is attributable to the under 35 age group (Michael, 1978). Yet the proportion of those 65 years or older who are divorced relative to those who are married increased 84 percent between 1960 and 1978 (Table I).4

The reasons for the increase in the number of divorced elderly are unclear. Some of the increase undoubtedly is due to the movement into old age of those who do not remarry after a mid-life divorce. Indeed, the probability of remarriage when a marriage is dissolved after age 55 is much lower than for younger cohorts, 


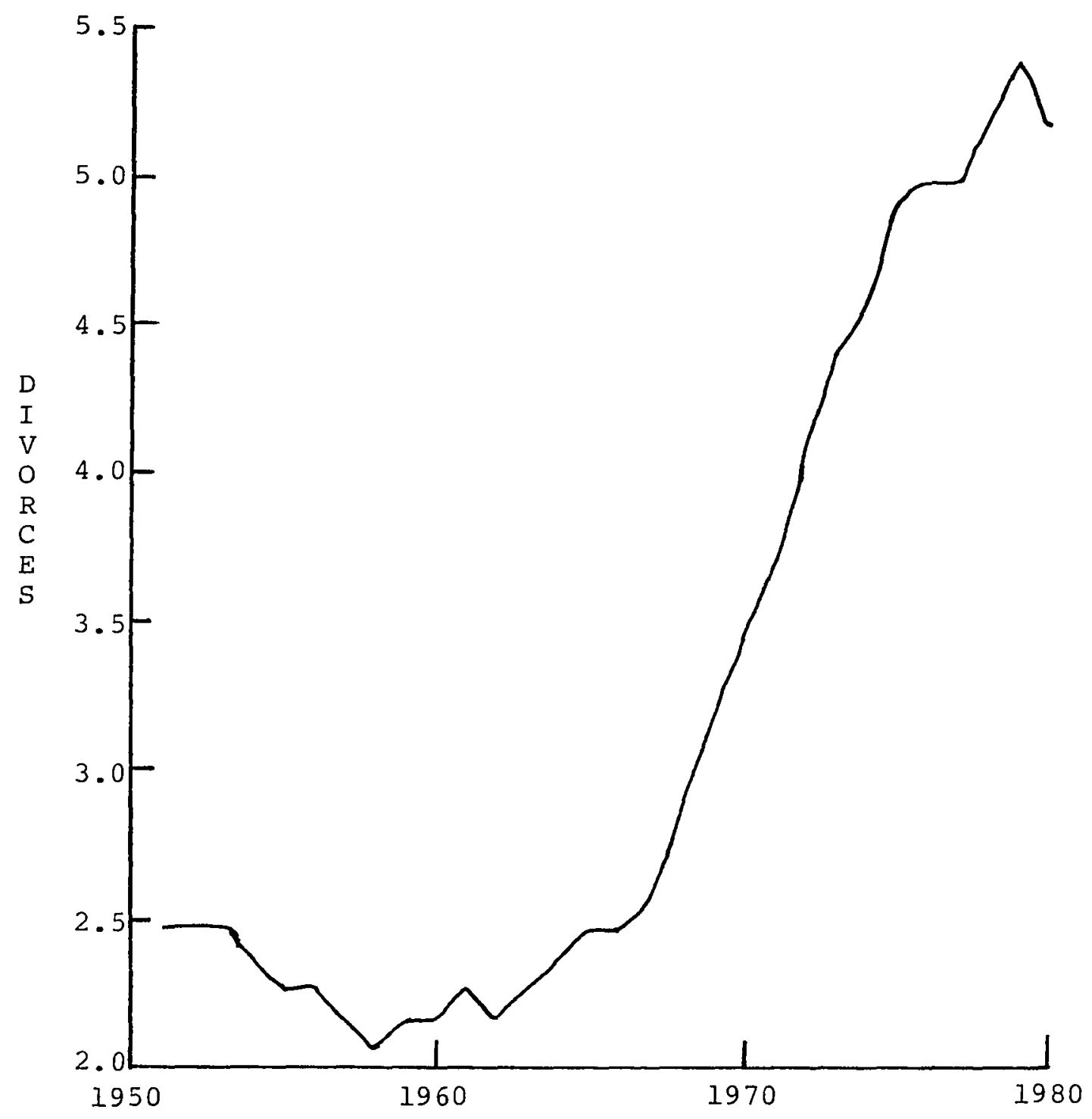

Figure 2. Divorces/annulments per 1000 U.S. population, 1950-1981.

Source: National Center for Health Statistics, Monthly Vital Statistics Reports, Vol. 30, No. 2 Supplement, May 29, 1981 and Vol. 30, No. 3, June 11, 1981. 
TABLE I

NUMBER OF DIVORCED PERSONS PER 1000 MARRIED COUPLES BY AGE FOR SELECTED YEARS

\begin{tabular}{|c|c|c|c|c|c|}
\hline Year & $\begin{array}{l}\text { Under } 30 \\
\text { Years }\end{array}$ & $\begin{array}{l}30-44 \\
\text { Years }\end{array}$ & $\begin{array}{l}45-64 \\
\text { Years }\end{array}$ & $\begin{array}{l}\text { Over } 65 \\
\text { Years }\end{array}$ & Total \\
\hline 1978 & 91 & 108 & 84 & 59 & 90 \\
\hline 1970 & 38 & 47 & 53 & 47 & 47 \\
\hline 1965 & 28 & 41 & 48 & 45 & 41 \\
\hline 1960 & 23 & 33 & 46 & 32 & 35 \\
\hline
\end{tabular}

Source: U.S. Bureau of the Census, Current Population Reports, Series P-20, No. 33, "Marital Status and Living Arrangements: March, 1978." 
particularly among women (Cleveland \& Gianturco, 1976; Treas \& Van Hilst, 1976). In one piece of research, wilson and Deshane (1980) found that divorced individuals in a sample of persons over age 65 had occupied that marital status for an average of 19.2 years.

Another explanation for the increase in the number of persons occupying the divorce status in late life is changes in the mortality rate (Deshane \& Wilson,1981a; Preston \& MacDonald, 1980; Schoen \& Nelson, 1974; Uhlenberg \& Meyers, 1981). Marriages can be dissolved only through divorce or death, although desertion always has served as an informal mechanism for ending marital relationships. Over the past 100 years the total dissolution rate has remained steady (Weeks, 1978). Thus, a decline in the proportion of marital dissolutions due to death would necessarily increase the proportion of marital dissolutions due to divorce. As life expectancy increases and the probability of dissolution due to death declines couples are exposed to the risk of divorce for a longer period of time.

Part of the increase also may be related to increasing numbers of persons who seek divorce in late life. Greater numbers of older persons are moving into the later stages of the life cycle with marriages that are surprisingly fragile. It has been argued that marital satisfaction declines steadily with duration of the marriage (Blood and 
Wolfe, 1960) and that many elderly couples who stay together do so in a state of armed neutrality or mutual hostility (Finkelhor, 1980).

A perception among the elderly that divorce is not an option to end their unhappy marriages apparently has prevented them in the past from seeking divorce more often (Sweeney, 1982). Yet data show that the divorce rate has risen for every birth cohort since 1905. Those born after World war I (1917-1926) and who are just entering late life are nearly twice as likely to have ended their first marriage in divorce than are those older persons born in cohorts prior to 1917 (Glick \& Norton, 1973).

Those now entering late life are a part of the marriage cohort that experienced the post-World War II peak in divorce rates, a level not reached again until 1973. Thus, the 1917-1926 cohort is entering late life with a much higher likelihood of already having experienced divorce at an earlier point in their lives. Divorce, in essence, may be a more acceptable solution to marital problems for the young old than it was to those born prior to the advent of World War I.

Further, high remarriage rates for younger persons have created a large number of married elderly who currently are in second or higher order marriages. These marriages statistically are less stable and are more likely to result in divorce than are first marriages. In con- 
junction with the increased frequency of higher order marriages vill be marriages of shorter duration, which also are statistically less stable. In sum, cohort and demographic characteristics of those currently moving into old age are such that increases in their divorce rate are not unexpected (Glick \& Norton, 1973; Kephart, 1954; Jacobson, 1959; Monahan, 1958).

Aside from demographic explanations which focus upon structural changes in the population as a whole, other types of explanations have been identified as contributing to the rising divorce rates among the elderly. A number of trends have been presented as possible sociological explanations including liberalization of divorce laws by most states, changes in labor force participation rates for women and situational ambiguity of old age (Deshane \& Wilson, 1981b; Uhlenberg \& Myers, 1981).

Some have argued, for example, that "no-fault" divorce laws have eroded the position of the individual seeking to avoid termination of marriage through divorce (Kauffman \& Bycel, 1980; Leonard, 1980). The liberallzation of divorce law has been associated with a decline in the view that divorce is intrinsically evil (Nye \& Berardo, 1973; Udry, 1971). Such a decline would reduce the stigma associated with divorce and make it a more viable solution to an unsatisfactory marriage, particularly for women who have traditionally suffered greater censure in American society 
upon divorce than men (Brandwein et al., 1974; Brown et al., 1976; Cleveland, 1979).

Others have used the movement of women into the labor force as a predictor of higher rates of dissolution (Becker et al., 1977; Hannon et al., 1977; Moore et al., 1977; Ross \& Sawhill, 1975). The working wife has increased the level of affluence in the family and gained new power and independence in the marital relationship. Such changes have acted as threats to marital cohesiveness (Blood, 1972; Norton \& Glick, 1976).

Finally, as the study of older persons has gained prominence, the impact of multiple late life transitions on marriage has been examined. Deshane \& Wilson (1981a) have suggested that experiencing multiple life transitions such as changes in the parental role, retirement, declines in health status, and loss of income in a short period of time may strain marital relations to the breaking point. The lowering of marital quality in later years reported above may be indicative of the stress placed on the marriage during such a crowded period. Further, the clustering of life events has been offered as the reason why some individuals are more vulnerable to stressor events such as divorce (McCubbin et al., 1980).

A somewhat different set of explanations for divorce rates arises from the psychological perspective. These explanations generally focus on personal inadequacy or 
disorganizaton (LeMasters, 1959; Mudd, 1952; Udry, 1971). They suggest that personality defects in individuals make them more susceptible to divorce. While such deficits typically are perceived to be the result of biological chance and experiences in early childhood, the impact of a changing environment on the adult personality also has been used to explain the manifestation of personal disorganization in later life.

In general, personality has been found to be unaffected by advancing age. However, health has been found to provide a major exception to this rule. older persons, for example, are much more susceptible to personality changes induced by cerebrovascular problems and various types of dementia than are younger persons. Nutritional deficiencies and drug usage also have been cited as causing personality changes in older persons. These problems, however, are much more likely to occur among the very old.

Although no single explanation appears likely at this time to explain increases in the divorce rates among older persons, preliminary data generated from a variety of sources indicate these rates will continue to increase in the future. A continued decline in mortality rates should insure some increase in divorce rates by increasing still further the "at risk" period of older married couples. Further, as current younger cohorts enter old age in 
the future, they will enter late life with a much higher likelihood of having experienced divorce at some earlier point. The "baby boom" cohort is expected to be especially vulnerable (Carlson, 1979). Finally, while a slowing down of current societal trends tied to increases in divorce rates may occur in the future, a complete reversal to embrace prevailing norms of 100 years ago seems unlikely. Even if such a reversal were to occur, at least one generation would be needed for the reversal to have a substantial impact on the existing trends in the population. Thus, at least for the short term, increases are likely not only in the number of persons who enter old age in the divorce status but in those who experience divorce after age 60 .

\section{CHARACTERISTICS OF DIVORCING INDIVIDUALS}

Despite the likely increase in the number and proportion of older persons who are divorced, this population has remained largely unstudied. A few longitudinal studies of divorce have included age as a variable, although the number of older persons typically has been too small to allow for separate analysis of those individuals (c.f., Chiriboga, 1982; Chiriboga et al., 1979; Chiriboga, 1979). An abundance of information exists, however, on the characteristics of divorcing younger populations which should provide a useful context in which the characteristics of a divorcing older 
population could be examined.

The probability of divorce is not spread evenly throughout the population. Aside from age, a number of characteristics have been found to be associated with the probability of divorce. Census data, for example, show a differential rate of divorce in the various regions of the United States (Statistical Bulletin, 1981). These data indicate the divorce rate is lowest in the Northeast and highest in the Western region. This trend is not new. Reiss (1971) notes that the pattern has existed since the nineteenth century. Several explanations have been offered. Reiss favors the "frontier" theory advanced by Pang and Hanson (1968). This theory holds that the frontier is less socially stable, attracts individuals who are less socially adept and tolerates higher levels of deviance than other regions. Nye and Berardo (1973) and Carter and Plateris (1968) lend more credence to the effect of divergent divorce law on the concentration of individuals with particular characteristics in different parts of the country. Another structural explanation advanced by Feneton (1972), and supported by Leslie (1982), is that high migratory rates reduce the ability of a population to become socially integrated and thereby reduce the effectiveress of sanctions against deviant behavior. Increasing divorce rates in the sunbelt states lend additional support to this hypothesis. 
Both location and duration of residence have been found to be associated with divorce rates. Data have shown a greater concentration of divorced persons in urban areas (Carter \& Plateris, 1968; Glick, 1968; Leslie, 1982; Nye \& Berardo, 1973). The conditions of urban life are presumed not only to provide more freedom for individuals living there to seek divorce, but to act as a magnet drawing the divorced to the city after divorce logburn \& Nimkoff, 1955). Thus, it is not clear whether persons are residentially less stable before their divorce or whether getting a divorce creates a period of residential instability.

The trends are more complicated with respect to socio-economic characteristics, although generally an inverse correlation between socio-economic status and divorce rates has been demonstrated. The evidence directly contradicts a lingering notion widely held prior to the pioneering work done by Kephart (1955), Monahan (1955), Goode (1956), and Hillman (1962) that divorce was more prevalent among the well-to-do (Terman, 1938). Goode (1966) and Udry (1971) have suggested this condition exists where attitudes and laws concerning divorce are more restrictive. As these conditions ease, the cost of divorce decreases and it becomes a more viable option for the poor to exercise. When the cost is too high the lower classes utilize other methods of dissolving their marriages such as 
separation, desertion and bigamous common-law arrangements (Reiss, 1971).

Goode's (1956) work suggests, however, that it is not social class per se which is responsible for the higher incidence of divorce among the lower class. Rather, it is a matter of lifestyle more commonly associated with the lower class. This style of life involves having less education, weaker kinship structures, less occupational stability and being married at a younger age than the middle class. These factors create highly unstable families prone to economic and personal stress.

More recent work, however, has indicated the relationship between socio-economic status and divorce rates to be less straight-forward than previously was thought. Udry (1968) found differences in the divorce rates due partially to differences in remarriage rates by race and by sex, although he concluded the inverse relationship between education and marital disruption generally held true. However, the effect of education was found to be weakened when controls for age at first marriage, race and religion were added (Thornton, 1978). Houseknecht and spanier (1976) found higher dissolution rates among females with higher educational levels. Carter and Glick (1976) found that dissolution rates were greater among those with some college, suggesting a curvilinear relationship. 
More recently, Locksley (1982:438) has suggested that what is taken for working-class culture in so far as it comprises attitudes and values regarding the marital relationship, may actually be 'high-school culture'.

Her position is that individuals with a high school education do not encounter people whose experiences are highly different from their own except in stylized and role-structured settings. This lack of experience limits ability to understand and accept differences in their marital partners.

The relationship between divorce and occupational status is less clouded. Early studies cited above by Hillman, Goode, Monahan and Kephart indicate that divorce is more characteristic of lower occupational levels than the middle and upper levels. Bernard (1966), Norton and Glick (1976), and Udry (1968) generally support these findings in their analyses of census data, although udry notes that the direct relationship between occupational status and marital stabilitiy is true only for men. He dismisses the differences found for females as insufficient to vitiate this relationship, and argues that prior to 1965 occupation was not a primary indicator of socio-economic status for them.

In the fifteen years or so that have passed since the Udry analysis, the relationship between socio-economic status and divorce rates has been explored further. While Price-Bonham and Balswick (1980) found continued support 
for the inverse relationship between income and divorce in their review, they report that rates are more closely related to lack of assets, loss of income and a history of unemployment as opposed to occupying a particular occupational status. Further, in all socio-economic categories, the presence of a working wife increases the probability of divorce (Becker et al., 1977; Ross \& Sawhill, 1975). This may explain partially the increase in divorce rates among white-collar workers, since the bulk of women entering the labor force in the past two decades have come from the middle class.

Race has also been associated with divorce. Divorce among non-whites has been reported as being substantially higher, even when the effect of income was considered (Bernard, 1966; Udry, 1971). Leslie (1982), using data compiled by Jacobson, suggests that divorce rates among Blacks are more sensitive to fluctuations in economic conditions. No satisfactory explanation of the differential divorce rates between whites and non-whites has been offered yet. However, recent work delineates differences in divorce rates among non-white groups. Eberstein and Frisbee (1976) report that a comparative analysis of divorce rates among Mexican-Americans, Caucasians and Blacks found that when other personal characteristics such as age at first marriage, educational level and residence were controlled for, Mexican-Americans 
had the lowest and Blacks the highest rate of divorce.

Despite a movement in the Church to make divorce easier to obtain, Catholics continue to have the lowest divorce rate (Price-Bonham \& Balswick, 1980). This does not vary with earlier findings reported by Landis (1949), Monahan and Kephart (1954) and Goode (1966). Bell (1967) noted that separation and divorce are higher among mixed marriages and couples who report no religious beliefs, but Burchinal and Chancellor (1963) contend that controlling for age and socio-economic status erase most of the religious differentials in divorce rates.

The evidence is spotty with regard to the relationship between health status and divorce rates. Part of the difficulty lies in determining whether poor health is a cause or the result of divorce. Blood (1972) has suggested that illness impairs role performance and is a source of family instability. LeMasters (1959) identified psychological and psychotic illnesses as contributing to marital dissolution. Finally, Deshane and wilson (1981a) speculated about the effects of long term illness on divorce rates among the elderly.

Turning to the marital behaviors of individuals who are divorced, more definite patterns are found. Age at first marriage has been found to be associated with divorce rates. Census data generally confirm that young age at marriage contributes to marital instability (Glick \& 
Norton, 1973). Nye and Berardo (1973) report that larger than usual age differences (10+ years) are correlated with higher rates of divorce. Norton (1980) suggests early marriage and inadequate spacing of children are positively related to divorce. While most data suggest youthful marriages are the least stable, Becker et al. (1977) found that first marriage at a late age $(35+)$ is also less stable than marriage at a median age.

The evidence for the relationship between divorce and fertility rates is not considered to be as clear as it was once. Monahan (1955) was among the first to challenge the supposition that having children was an effective deterent to divorce. Yet the belief that divorce is harmful to children has generated innumerable studies (c.f., Hetherington et al., 1975; Kelly \& Wallerstein, 1977) and left an indelible print on the psyche of many who remained in unsatisfactory marriages "for the sake of the children." Indeed, some claim that the post-parental phase is one of the most dangerous for marital couples and that children may actually regatively impact marital satisfaction (Sweeney, 1982). The growing number of divorces which involve children suggest that their effectiveness as bonding agents at best is limited, yet Bumpass and sweet (1972) report that the divorce rate is still higher among childless couples.

A profile of the personal characteristics of 
individuals who are divorced in younger populations emerges from these data. They are more likely to reside in urban areas, to be of lower socio-economic status, to have weak religious ties, to have married young and to be childless. The median length of marriage (seven years) and the average age at first marriage (20.4 years for females; 22.0 years for males) suggest that in younger populations divorce is likely to occur before the 30th birthday.

Disparity in age and stage in the family life cycle are at least two differences between younger and older divorcing populations. What other types of differences which might exist in their personal characteristics is largely unknown. As Leslie (1982) noted, marital issues related to the post-parental stage in the life cycle have received virtually no attention. This is confirmed by the general absence of information in the literature. That literature which does exist focuses generally upon marital adjustment or satisfaction, not marital dissolution.

Although an issue of some controversy, marital satisfaction generally is held to decline in the later stages of the life cycle (Blood \& Wolfe, 1960; Burgess \& Wollin, 1953; Luckey, 1961). Others argue that marital satisfaction is actually a curvilinear phenomenon (spanier et al., 1975). These authors suggest that older persons come to value their marriage more highly because of their long investment in it. 
Marital dissatisfaction, which may result in the dissolution of a marriage, has been linked to the unanticipated consequences of two normative life events, the launching of the last child and retirement. The former has been viewed as more stressful for females (Leslie, 1982), while retirement has been reported as more traumatic for males (Cavan, 1962; Lipman, 1962). Other evidence indicates the role changes after retirement create greater marital problems for those in the lower socio-economic status (Kerckhoff, 1964). Finally, inharmonious conjugal relations in old age may be part of a continuing pattern and stem from long-standing problems (Fried \& Stern, 1948; Nye \& Berardo, 1973).

Yet none of the studies reviewed above identifies the characteristics of those who divorce in late life. In one piece of work wilson and Deshane (1980) reported the characteristics of a sample of divorced persons age 65 and older. When comparing this group with married and widowed older persons in the same age group they found no significant differences in socio-economic status, educational level, or race of divorced and non-divorced older persons. Roughly one-half of each group fell into the lower socio-status category, nine out of ten had 12 years or less of education, and nearly all were Caucasian. 5 The mean age for the divorced sample was 74 years, 80 percent had incomes below the federally designated poverty 
level, and one-half of the divorced sample had been married only once. It is important to remember, however, that the individuals in this sample had all been divorced before late life and had occupied the divorced status for an average of 19.2 years. Interestingly, the proportion of divorced persons (148) in this sample of low income, non-institutionalized elderly was substantially greater than age specific divorce rates would indicate likely. This suggests that in mid-life divorce at least, the inverse relationship among divorce, education and occupational status is viable.

\section{CAUSES OF DIVORCE}

Most of the theories proposed as the cause of divorce are only variables associated with divorce. They do not explain why individuals seek divorce, only predict who is Iikely to experience it. In the previous sections of this review, a number of these types of explanations for rising divorce rates were identified. These explanations focused on three sets of factors: 1) structural changes in the population (e.g., declining age at first marriage, changes in age composition and increased life expectancy); 2) general societal trends (e.g., changes in family function, increased participation of women in labor force, liberalized divorce laws and decline of social stigma); and 3) psychological make-up of individuals who seek divorce (e.g., inadequate personality or changes in personality 
which make individuals less "fit" for marriage). An underlying theme has been the effect of urbanization on the family. This section will briefly examine divorce in the context provided by several theoeretical frameworks.

One of these theories focuses upon psychological make-up of individuals who seek divorce. Affect theory proposed by Mckenry et al. (1978) implies a sub-normal capacity to give and receive love among those who seek divorce. Given that such an ability is critical in a society in which marital relationships are based on romantic love, such individuals would be divorce prone. This theory, however, focuses on the presence of such character traits and their impact on intimacy, without attempting to identify the origins of individual affect.

A second explanation for divorce is related to role performance. Nye and Berardo (1973:503) propose that marriage is an exchange of services in a normative framework. In marriage individuals are rewarded through role performances based on normative expectations. Nye and Berardo sum up the relationship between divorce and role performance:

Without a minimal level, the marriage may not become a functioning reality. If all roles are performed at a level that leads the spouse to feel that he is receiving what he should (or more) in marriage, he will be satisfied and unlikely to initiate a divorce. However, if a third person intrudes, offering a higher profit in an alternative marriage, he may seek a divorce if its costs do not appear prohibitively high. 
This explanation focuses on the ability of the marital pair to meet the expectations they hold for each other and for the marriage. Thus, for example, if a mutual expectation of marriage is a continuation of romantic love, the absence of such love would in fact be very threatening to the marital relationship.

Two theories based on power also have been advanced. Scanzoni's (1972) "equal partner" and Walster's et al. (1973) "equity" theories take somewhat differing positions with respect to the issue of power in a marital relationship. on the one hand, the equal partner relationship theory holds that marital conflict stems from the growing power of females. Scanzoni, like Blood (1960), holds that sharing decision-making in a marriage increases the potential areas for conflict. On the other hand, equity theory holds that only if a marital relationship is equitable should divorce be avoided.

A final theory is based on the precept that divorce is an unintended outcome of an unsuccessful attempt at marital adjustment. Lenthall (1977), building on earlier work by Udry (1971), contends that marital satisfaction and marital stability represent entirely different dimensions of marital adjustment. Marital satisfaction, according to Lenthall, is the comparison between marital expectations and marital outcomes, while marital stability is the comparison beween the best available marital alternative 
and marital outcome.

Expanding further on this concept, Lewis and spanier (1979) suggest that divorce is a likely outcome in marriage where both marital satisfaction and stability are low, or where one is high and the other is low. They identify three sets of variables as crucial to determining marital outcomes: 1) premarital variables such as homogamy, resources and adequate role modeling; 2) marital variables such as community embeddedness, role fit, amount of interaction, emotional gratification and regard for spouse; and 3) contingency variables such as alternative attraction and external pressures on the marriage.

While the relevance of the theories discussed in previous paragraphs for persons seeking late life divorce has not been explored, affect, power and role performance would seem less relevant for long term marriages. These theories focus on qualities which would appear to result in a rather quick demise to the marital relationship, which is in fact the case with younger populations. The inability to give or receive love (affect theory) and inadequate role performance may, however, be related to the behaviors of individuals with multiple divorces. Further, role performance in late life could be hindered by other stressors such as illness. All of these factors, however, are considered in the social exchange model, which Holman and Burr (1980) suggest as one of the more profitable ones 
in which tenuous relationships can be examined.

The social exchange model also may be especially helpful in explaining dissolution in long term marriages. It focuses on relationships between rewards and costs in a marriage which are subject to recalculation from time to time. The theory takes into account numerous factors which antedate a marriage, as well as changes which must be accommodated in the course of a marriage; events external to the marital unit also are included in the calculation of costs and benefits. Exchange theory provides a plausible explanation for the apparent willingness of older persons to live in unhappiness or unsatisfactory marriages noted by Sweeney (1982). Put simply, in late life the costs of divorce may be higher and the benefits received lower. The probability of remarriage is lower, the dependency factors are greater and the likelihood of widowhood (an approved form of dissolution) also increases.

\section{THE DIVORCE PROCESS AND ADJUSTMENT}

Normally divorce is not a decision quickly reached or implemented. Nearly every published study indicates that typically a substantial period of time elapses between the onset of marital difficulties and the legal dissolution of a marriage (Price-Bonham \& Balswick, 1980). This lapse of time is explained, in part, by the legal process which is required to terminate a marriage.

Society's interest in the marital relationship is a 
sustained one. Krause (1977:26) has suggested the state has a legitimate legal interest in regulating events deemed relevant to familial functioning:

Even in this (sometimes more reckless than) brave new world and measured by modern pragmatism, there are important social functions that marriage and the family can best fulfill, consistently with our culture, our political philosophy and universal human needs.

Society has tried to protect itselt with an elaborate network of laws governing marriage and marital dissolution (Cavan, 1969). Grounds for divorce have changed considerably in the past 100 years. Udry (1971), using data compiled by Jacobson, shows that in the post Civil war period, desertion and adultery were the most common legal grounds for divorce. By 1980 "cruelty" was the most common grounds for divorce and a majority of states had adopted a version of "no-fault" divorce (Leslie, 1982).

originally promoted as a way to end the hypocrisy of collusion, no-fault divorce has also reduced the amount of time needed to get a divorce.6 From date of filing to final decree, a divorce often can be obtainea in three months, and in some cases even less time is required. If the case is contested, considerably more time may be required for the courts to resolve the issues of property and support. Thus, the period of time an individual is involved in the legal process of terminating a marriage can vary considerably.

Much more time is likely to elapse between the onset 
of marital difficulties and the filing for divorce. Price-Bonham \& Balswick (1980) reviewed several frameworks which show the disintegration of a marriage. Marital conflict arises out of latent issues that are not dealt with and which lead, ultimately, to disenchantment. Ressler's (1975) disillusionment and Weiss's (1975) erosion of love models are two examples of this approach to marital conflict.

LeMasters' (1959) classic study of marriages in chronlc conflict indicates the ability of marital couples to endure unsatisfactory marriages for long periods of time. His work has been confirmed in other studies (Deckert \& Langelier, 1978; Sweeney, 1982). For the most part these studies indicate that a great deal of personal disorganization exists in such marriages and that both partners are cognizant of the problems.

Persistence in maintaining a long unsatisfactory marital relationship is not without fairly severe consequences for the individuals who undertake it. Nye and Berardo (1973) indicate that the pre-decision stage is characterized by conflict, unhappiness and personal disorganizaton. This position is supported by Glenn and Weaver (1981) who argue that a poor marriage negatively impacts global happiness. Others go so far as to link unhappy marriages to physical illness (Fullerton, 1972; Holmes \& Masuda, 1974; Le Masters, 1959). 
Once the possibility of divorce has arisen, another period of time may pass prior to the actual separation. Time is needed to make the decision to divorce. It is not a decision reached quickly. Goode (1956) suggests that this reluctance stems, in part, from the difficulty adjusting to the idea of failure. Denial is often cited as the first stage in the process of an individual coming to grips with the knowledge that the marriage is not working (Froiland \& Hozeman, 1977; Herrman, 1974; Krause, 1979; Weisman, 1975).

Another reason the time prior to separation may be lengthy despite marital problems is that commitment to the marriage or attachment to the spouse is so high that divorce remains a somewhat unattractive alternative. Kitson (1982) argues that attachment explains the contradictory feelings of wanting to be rid of a spouse or out of the marital relationship while grieving over the thought of doing so. She suggests this explains the high incidence of reconciliation and continuing sexual relations found among divorcing individuals. An intriguing alternative explanation, particularly in marriage of long duration, is the concept of vested interest. That is, the longer an individual is married, the more difficult it might become to "walk away" or "quit" the relationship because of the time and energy already devoted to it.

Finally, it has been suggested that reaching the 
decision to divorce may actually involve a great deal of negotiation (Bell, 1967; Blood, 1960; Krause, 1979; Leslie, 1982). These negotiations may be heightened if the decision is not one reached simultaneously by the marital pair, as they seek to sort out their feelings about the "failure" of their marriage. This emotional confrontation triggers the process of adjustment (Bohannon, 1970; Kessler, 1975).

For others, for whom this confrontation already has occurred, the pre-separation period may be used to deal with the mechanics of separating or dissolving the marital partnership. Negotiations for these persons center around bargaining or making deals around issues such as the division of marital property (Froiland \& Hozeman, 1977). Prior to the enactment of various types of "no-fault" divorce, such negotiations were much more prevalent as the "guilty" party sought to win the cooperation of the "innocent" party. The loss of these bargaining chips is the focus of the concerns of those who view some version of fault divorce as necessary to protect the contractual rights of the "resistant" marital partner (Leonard, 1980). Regardless of one's position during this phase of the divorce process such events are bound to be stressful.

Many have suggested that the level of stress is actually greatest during the separation stage of the divorce process (Chiriboga, 1979; Chiriboga \& Cutler, 1979; 
Hunt \& Hunt, 1977; Kessler, 1975; Weiss, 1975). The explanations for this high level of stress suggest that it is during this period the individual must actually come to grips with the reality of marital dissolution.

Spanier and Casto (1979) identify two sets of activities which typically are initiated with separation. The first set involves activities related to the dissolution of the marriage and includes dealing with the legal process, working out a settlement and informing and involving the social network. A second set of activities involves the initiation of a new life. A separated individual must find a place to live, reorder financial priorities and deal with other practical problems presented by the separation.

Berman and Turk (1981) concur, but suggest that these problems continue well into the post divorce period. They divide the issues into three categories: pragmatic, interpersonal/social and family-related. Granvold and Welch (1977) identify four steps the divorcing person goes through in adjusting to divorce. These include the physical separation and emotional detachment from the ex-spouse, the altering of relationships with significant others, the reordering of values and, finally, the development of new interpersonal relationships with others. Adjustment to divorce begins then before any final decision has been made to dissolve the marriage and 
continues well past the actual granting of a decree. Adjustment involves emotional acceptance of the outcome of the decision to divorce and restructing of a lifestyle. A host of factors have been identified as affecting adjustment to divorce. Among them are: who wants the divorce (Spanier \& Casto, 1979; Pais \& White, 1979; Weiss, 1975), length of adjustment time (Raschke and Barringer, 1978), economic difficulties (Brandwein, et al., 1974; Goode, 1956; Pais \& White, 1979; Pearlin \& Johnson, 1977; Spanier \& Casto, 1979), feelings of attachment to ex-spouse (Goode, 1956; Kitson, 1982; Weiss, 1975), social support from family and friends (Colletta, 1979; Hunt \& Hunt, 1977; Spanier \& Hanson, 1978), social participation (Raschke, 1977; Spanier \& Casto, 1979), developing a relationship with a member of the opposite sex (Albrecht, 1980; Bernard, 1956; Cleveland, 1979; Hetherington, et al., 1978; Raschke, 1974; Spanier \& Casto, 1975), age, (Goode, 1956; Meyers, 1976; Pais \& White, 1979), and sex (Brandwein, et al., 1974; Brown, et al., 1976; Granvold, et al., 1979).

Concern with successful adjustment to djvorce stems from the consequences generally presumed to be associated with the dissolution of a marriage. These consequences may be positive or negative. In a general sense, the consequences may be thought of as positive when the overall effect of dissolving the marriage results in the resolution of more or greater problems than it creates. Conversely, 
negative consequences are almost certain to devolve from the host of practical and interpersonal problems which arise from the dissolution of a marriage. Thus, while divorce may resolve one set of problems, it invariably creates another set with which individuals must cope successfully.

The process of maximizing the profit (good consequences) of divorce and minimizing the cost (negative consequences) of divorce is the balancing act called adjustment. Raschke (1977) put it similarly when she equated adjustment with having few problems and low levels of stress. Obviously, if divorce generates many more problems and higher levels of stress for an individual, it is not a very efficient way to deal with marital problems. Unfortunately, marriage involves more than one individual and what is good for one many not be good for the other.

Even when the final result is "good" divorce can be a "painful and crisis-producing event" (Price-Bonham \& Balswick, 1980). Individuals who do not adjust well to the event are reported to be depressed and lonely, to have low self-esteem and self-confidence, to feel negative toward others and to regret the divorce (Spanier \& Casto, 1979). Divorce has been consistently associated with lower psychological well-being and psychiatric distress (Berman \& Turk, 1981; Bloom et al., 1978; Bloom \& Caldwell, 1981; Brown \& Harris, 1978). 
Interestingly, although a host of factors have been identified as related to divorce adjustment in the review of the literature, no model which integrates these findings and predicts adjustment has yet been proposed for younger or older divorcing persons. Part of the difficulty has arisen in distinguishing between the cause and effect relationship of divorce. For example, as noted above one major set of theories holds that deficits in the individual which create the susceptibility to divorce also are linked to the manifestation of personal distress and mental disorders. This perspective suggests that psychological and psychiatric problems are a cause, not the result, of divorce. A related problem has been the inadequacy of measurement. The tangled cause-effect relationships have created difficulties in precisely defining the dependent and independent variables. Finally, studies continue to be beset with the problems inherent in non-experimental designs which deal with closed populations.

In spite of these problems, the review of the literature shows clearly that several factors have appeared in studies of divorce and subsequent adjustment. This study attempts to organize those factors into a model which is described in the next chapter. The model draws heavily upon previous work which delineated many risk factors personal characteristics, characteristics of the divorce and resulting consequences - which impact adjustment. 
CHAPTER III

DESIGN AND METHODOLOGY

Although the literature presented in Chapter II reveals that little work has been done specifically in the area of late life divorce, the review does provide a basis for the conceptual framework used in this study. our framework is premised on three implicit assumptions derived from other studies of divorce. These assumptions are:

1) divorce is a non-normative event which differentially impacts the well-being of individuals;

2) the role played by age is unknown, although it has not emerged in earlier studies as a critical variable; and

3) personal and marital characteristics, type of divorce experienced and consequences of the divorce are important adjustment variables.

This study accepts the first assumption; the second and third assumptions are general propositions to be tested.

The second assumption is the focus of Stage I of the study. Stage $I$ is designed to provide a description of individuals who get divorced in late life and a report of the resulting events they experience. Two hypotheses related to the second assumption are identified to determine whether age is a critical variable with respect to who gets divorced, the causes, the divorce process and the consequences of divorce in late life. 
Stage II is designed to test the third assumption. A divorce adjustment model is developed using various individual factors identified in earlier studies of younger populations as influencing adjustment to divorce. The ability of the model to predict adjustment in a sample of divorcing older persons is tested in stage II of the study. This model not only attempts, for predictive purposes, to integrate a number of factors known to significantly impact adjustment for, but also seeks to determine which factors are most significant. Knowing which individuals are most likely to adjust poorly and which factors are most heavily contributing to poor adjustment is vital to appropriate intervention.

STAGE I: DIVORCE IN LATE LIFE

Apart from age and stage in the family life cycle little is known about divorcing older persons. The major source of information for this group is a descriptive study by Deshane and wilson (1981b). Stage I of this study builds on the findings of that work and incorporates relevant information from studies of divorcing younger persons. Using the same data base as DeShane and Wilson's study, Stage I focuses upon discovering the relationship of age to four areas of interest in late life divorce: 1) personal characteristics normally associated with a higher probability of divorce; 2) "cause" of divorce in late life; 3) "type" of divorce experience; and 4) consequences of 
late life divorce.

In the first part of stage I measures of central tendency, variability and correlation are to be used to examine the data. The findings from other studies, including DeShane and Wilson's effort, suggest that many similarities exist between younger and older divorcing persons. None of the studies, however, examines only the characteristics of those who divorce after age 60 .

\section{Personal Characteristics and Late Life Divorce}

Based on previous work which suggests chronological aging alone is not likely to alter fundamentally an individual's basic character, this study will use parameters previously established in work with divorcing younger populations. The assumption that personal characteristics associated with marital instability do not change solely as a result of chronological aging is supported by the work of Deshane and Wilson. Their sample, in which 73 percent of the individuals were over age 60 , had many characteristics similar to those of divorcing younger persons (Deshane \& Wilson, 1981b:58-64). These same personal characteristics- socio-economic status, marital history, religious membership, residential status, fertility and health status - are to be reexamined in the population of interest (60+) for this study. (See pp.73-76 for variable definitions.) 
Explaining the cause of late Life Divorce

In previous work a number of explanatory factors are identified as causing divorce. However, generally, it has been difficult to use explanations other than those which focused on personal deficits. This difficulty has stemmed, in part, from the lack of a suitable framework in which the more sociologically relevant explanations could be adapted for individuals. A framework which may provide the means for adapting these types of explanations to the individual is one provided by Lewis and spanier's (1979) social exchange model. This model includes three sets of factors said to contribute to marital dissatisfaction and dissolution. These sets are: 1) premarital, marital, and alternative attraction factors. (See page 74 for definitions of these factors.)

A fourth factor, life stress, has been identified as potentially relevant for late life divorce. This factor is based on the work of McCubbin, et al. (1980) who found that individuals already experiencing some type of life stress were more vulnerable to experiencing other kinds of stress as well.

The present study examines individual explanations offered as the reason for a late life divorce using these four factors. Preliminary descriptive analysis by Deshane and wilson (1981b) indicates that older persons provide multiple explanations for their divorce. The authors do not, however, generate a description of how these 
explanations combined to create an overarching "cause" of divorce. Also of interest is whether "cause" of divorce is associated with selected variables describing personal characteristics, type of divorce experience, consequences and adjustment subsequent to the divorce.

Understanding why marriages, particularly those of long duration, become susceptible to divorce is important given the increased investment the marriage represents and the overall societal value still attached to being married. Indeed, the "cause" of divorce may be tied intimately to the consequences felt and, subsequently, to adjustment.

The Divorce Process

Once the individual begins to contemplate divorce, a process is initiated during which the decision to divorce is reached and actions are taken that result in the legal dissolution of the marriage. This process requires the individuals to decide how good a solution divorce is to their marital problems. Determining the desirability of divorce requires that individuals balance out the costs and benefits of ending their marriage. If the perceived costs are considerably greater than the perceived benefits, divorce is likely to be viewed as a less desirable option. Estimates of future costs and benefits are derived, largely, from past experiences; hence, this study seeks to use what is known about the divorcing individual and the marriage being dissolved to create an anticipated cost of 
divorce to individuals. Three scales - marital risk, marital quality and life stress were developed to measure anticipated cost. Variables used to construct the scales for anticipated cost are described in a glossary of terms (pp.73-76).

Following this process are the events which characterize the divorce itself. Historically, the divorce process has been viewed as a final opportunity to: 1) increase the cost of divorce enough to keep it from occurring; 2) make the "guilty" party pay a high cost one way or another; and 3) minimize the cost/maximize the benefits to self when ending the marital relationship. By examining the emotional reaction and the processual conflict exhibited during the dissolution, the type of divorce actually experienced can be measured. Type of divorce experience is a composite variable constructed to reflect the degree of resistance evident in the divorce process. (see p. 75 for additional details of the operationalization of the variable divorce experience.) This study will report upon the response of individuals to late life divorce and the attitudes which characterize their behavior.

The last area of interest in stage $I$ of the study is the consequences of divorce for older individuals. Four types of potential consequences have been identified in the literature. The distribution of legal, economic, psychological and social consequences for the study population 
will be examined. Some consequences are thought to be positive; others are viewed as negative. Negative consequences become additional costs. For those that are negative, effective coping strategies are needed. Pearlin and Schooler's (1978) categories of self-reliance, emotional discharge, positive comparisons and selective ignoring offer a reliable framework for identifying the type of strategies used and their relationship with other variables of interest. Ultimately, however, adjustment depends on the ability to avoid stress created by negative consequences and the successful resolution of problems that cannot be avoided. As the major dependent variable in this study, adjustment is equated with well-being. Definitions of consequences, coping strategies and adjustment are found on pages 74 through 76 .

THE ROLE OF AGE

Once a description of the personal characteristics, the causes, the types of divorce experience and the consequences of divorce for individuals has been provided, Stage I of the study will focus on determining what role age plays in divorce. Toward this end, two hypotheses will be tested. Chi-square and independent samples t-tests will be used initially to determine whether age is a significant variable. The hypotheses are:

$\begin{aligned} & H_{I}: \text { The personal characteristics, causes, } \\ & \text { divorce process and consequences for those } \\ & \text { experiencing divorce after age } 60 \text { will } \\ & \text { differ significantly from those who dissolve }\end{aligned}$ 
their marriage before age 60 .

$\mathrm{H}_{2}$ : The personal characteristics, causes, divorce process and consequences for those experiencing divorce in two birth cohorts, 1917-1926 and 1907-1916, will differ significantly.

As noted previously most cross sectional studies of divorce have not indicated that age acts as a major independent or intervening variable. This lack of significance, however, may be due to the design of these studies. Large cross sectional samples taken from secondary sources, such as the census, provide data only on the current marital status. No allowances, for example, can be made for differences in marital histories.

Longitudinal studies, such as Chiriboga et al., (1978), or divorce studies with primary data sources, such as Goode's (1956), have been limited by the small number of older divorced persons in the sample, as well as the range of ages being compared. Hypothesis 1 is directed to a comparison of individuals who divorce in middle life (40-59) and late (60-79) life. This hypothesis is designed, in part, to examine differences in marital dissolution between those in the pre-retirement stage of the life cycle and those in the retirement stage.

The second hypothesis is concerned with cohort effect. Analysis of age-specific divorce rates have shown some differences in marital behavior (c.f., Carlson, 1979; Michael, 1978; Glick \& Norton, 1973). This hypothesis is designed to compare a birth cohort coming to adulthood in 
the midst of the 1930's Depression (the 1907 - 1916 cohort) with another cohort coming to adulthood during world war II (the 1917 - 1926 cohort). Selection of the groups for testing is based upon prior work on cohort differences (Cain, 1967,1971; Glick \& Norton, 1973; Michael, 1978). This work suggests differences in the behaviors of individuals in these two cohorts. Whether or not cohort differences will be evident in divorce characteristics is not known.

\section{STAGE II: A MODEL OF DIVORCE ADJUSTMENT}

The central focus of the second stage of this study is to test a model which predicts adjustment subsequent to divorce. This model is shown in Figure 3 . In this model the relationship of three predictor variables-anticipated cost, the type of divorce experience and consequences for post-divorce adjustment (the criterion variable)-is shown. This model uses characteristics of individuals and of the divorce to explain variance in adjustment. Multiple regression techniques will be used to test the model.

The relationships diagrammed in Figure 3 were derived from findings in studies of younger divorcing populations, as well as from preliminary analysis conducted in conjuction with the descriptive study completed by DeShane and wilson (1981b).7 All variables used in the model are defined in the glossary of terms at the end of this chapter. The first box, anticipated cost, represents 


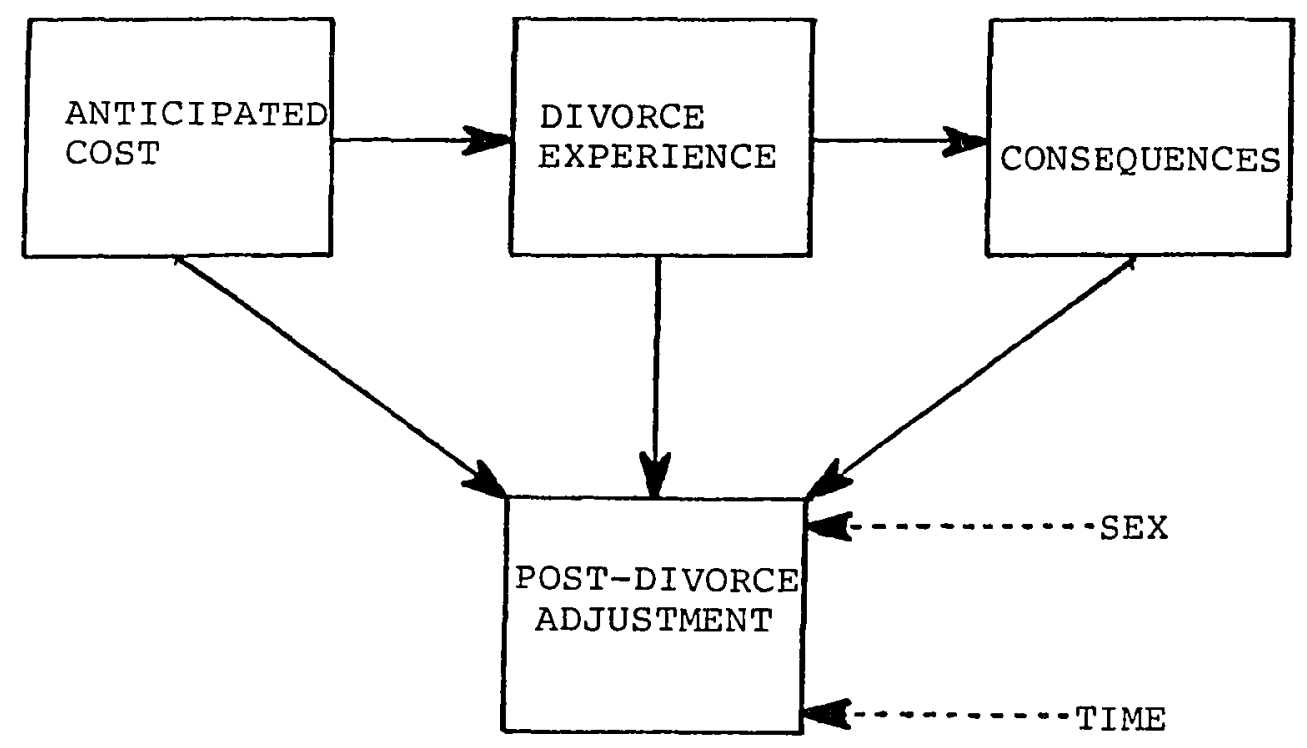

Figure 3. Divorce adjustment model. 
personal and marital factors which are used to calculate the cost of dissolving the marriage. These characteristıcs are shown as predictors of the type of divorce experience. Type of divorce experience refers to the actual response of individuals to the dissolution of their marriage. Consequences are linked directly to the type of divorce experience, suggesting that the absence or presence of problems to be resolved is associated with the response individuals made to the divorce action. All three are shown as related to adjustment, with sex and time acting as intervening variables. Thus, the overall regression equation for the divorce adjustment model would be:

$Y^{l}$ (adjustment) $=a$ (constant) $+x_{1}$ (anticipated cost) $+x_{2}$ (type of divorce experience) $+x_{3}$ (consequences) $+\mathrm{X}_{4}\left(\right.$ sex) $+\mathrm{X}_{5}$ (time)

The approach of stage II of this study is to develop each component individually. A series of hypotheses will be tested for significance in conjunction with the development of the predictor and criterion variables for the regression equation. Once the significance of each component has been established the regression equation will be tested.

\section{Anticipated cost}

In stage I of the study several questions are asked regarding the characteristics of older persons and the causes of late life divorce. These questions help set the stage to identify anticipated cost which subsequently 
impacts upon adjustment to divorce. The model's first component, anticipated cost is derived from scores on the marital risk, marital quality and life stress scales described on page 74. Lewis and Spanier's (1979) social exchange model provides the theoretical framework used to construct scales of marital risk and marital quality. A higher probability of divorce based on personal and marital characteristics is assumed to reduce the anticipated cost of divorce. Life stress, derived from McCubbin et al.'s (1980) work on the effect of closely spaced or ill-timed life events, is presumed to add to the anticipated cost of divorce. In essence, anticipated cost reflects a theoretical base for costs and benefits associated with divorce. Hence, the higher the perceived costs and the lower the anticipated benefits, the less desirable divorce is as an option to marital problems and the more negatively, emotionally and behaviorally, individuals will respond.

$\mathrm{H}_{3}$ : The lower marital risk, the higher marital quality and the higher life stress experienced, the more negative the divorce experience.

To test Hypothesis 3, ANOVA procedures will be used to examine variance in the types of divorce experience. Scores on the marital risk, marital quality and life stress scales will serve as the independent variables. The dependent variable will be the types of divorce experience. As noted previously, divorce experience refers to the level 
of resistance to the divorce. Resistance is measured by conflict and reaction to the divorce (see p. 75). Scores are divided to create three groups - negative, ambivalent and positive divorce experiences - for the ANOVA.

The Types of Divorce Experience

The second component of the model is the type of divorce experience which reflects the amount of processual conflict and the emotional reactions to the divorce. Hypothesis 4 assumes that conflict increases the initial costs of divorce, and that resistance, as indicated in a negative reaction, impairs individual ability to resolve post divorce problems and reduce stress. These assumptions are drawn from earlier work by Pearlin and schooler (1978) who suggest that heightened conflict reduces the ability to develop adequate coping strategies. Others (c.f., Spanier \& Casto, 1979; Weiss, 1975) have noted the impact of resisting the divorce on adjustment.

$\mathrm{H}_{4}$ : The more negative the divorce experience, the greater the negative legal, economic, social and psychological consequences.

To test Hypothesis 4, ANOVA procedures will be used, followed by multiple comparison tests. "Divorce experience," created to act as the dependent variable in Hypothesis 3, will be the independent variable for testing Hypothesis 4. The same three groups-negative, ambivalent and positive divorce experiences-will be used. Scores on 
eight consequence scales will act as the dependent variables. They are: legal, economic, psychological, four social consequence measures (familial, in-law, friend, and/or organizational relations) and overall consequences. More information on the operationalization of consequences scores is found in the glossary of terms at the end of this chapter.

\section{Conseguences of Divorce}

The scores used st the dependent variables to test Hypothesis 4 measure consequences experienced (i.e., number, type and severity of problems) and adjustment. These consequence. scores are shown as the third component of the model in figure 3 (p. 54). Successful adjustment reflects an ability to resolve successfully problems which cannot be avoided and to reduce the amount of stress exhibited subsequent to the divorce (c.f., Raschke, 1977). The divorce adjustment model assumes dealing with fewer consequences will make it easier to adjust. This proposition is the basis of Hypothesis 5:

\section{H5: The fewer consequences experienced as a result of the divorce, the higher post divorce adjustment.}

Individuals typically would find it difficult to avoid many of the more practical problems associated with divorce such as paying for a lawyer, finding a place to live and informing family and friends. Practical problems often generate the least negative consequences because they are 
more easily resolved; moreover, their resolution indicates the initiation of a new pattern of life which is necessary for successful adjustment. Interpersonal problems are more costly than practical problems. They are bound up in feelings of low self esteem and hatred of other individuals viewed as responsible for the divorce. Continued attraction for a former spouse and an inability to establish a satisfying relationship with a member of the opposite sex constitute two of the greatest interpersonal problems. Interpersonal problems are seldom quickly resolved because they are not as amenable to the specific actions individuals can take in response to practical problems.

These differences are accommodated in the adjustment score which acts as the dependent variable in Hypothesis 5. Adjustment, as measured by a standardized test of psychiatric distress and the degree of problem resolution reported, is the dependent variable. The independent variable is an overall consequence score derived from the legal, economic, psychological and social consequences experienced as a result of the divorce. Hypothesis 5 will be tested using a simple regression equation: $Y^{\prime}=X_{I}$, where $Y^{\prime}$ is equal to adjustment and $X_{1}$ is equal to consequences.

Interactive Nature of the Divorce Adjustment Model As noted in the beginning of this section, the divorce 
adjustment model shown in Figure 3 (p. 54) indicates more than a linear relationship between anticipated cost, the type of divorce experience and post divorce consequences. Adjustment, as depicted in the model, also is influenced by anticipated cost, the type of divorce experience, sex and time. Time refers to the period an individual has to adjust to the divorce. Thus, it is necessary to establish whether significant direct relationships between these variables and adjustment also exist.

To test Hypotheses 6,7 and 8 regression techniques will be used. An independent samples t-test will be used to test the hypotheses related to sex. In all of the hypotheses adjustment will serve as the criterion (dependent) variable. The hypotheses are:

$\mathrm{H}_{6}$ : The lower marital risk, the higher marital quality and the higher life stress, the lower post divorce adjustment.

H7: The more negative the divorce experience, the lower post divorce adjustment.

H8: The shorter period of time an individual has to adjust, the lower post divorce adjustment.

Hg: Females will have lower post divorce adjustment than will males.

Once the significance of the components to each other and to adjustment has been established, the multiple regression analysis will be conducted to determine how much of the variance in adjustment is explained by anticipated cost, divorce experience, consequences, sex and time. 
STUDY SAMPLE

Data for this study come from two sources--records of 240 individuals filing for divorce in the state of oregon and in-depth structured interviews with 81 individuals involved in those actions. 8 The 240 individuals involved in these actions represent the sampling universe for the population of interest in this study.9 Three criteria were used to establish this sampling frame:

1) Residence at divorce filing. Two contiguous Oregon counties, Multnomah and Clackamas, were selected for inclusion in the sample.

2) Time of divorce filing. Persons filing divorce actions in Multnomah or Clackamas County, Oregon, between January 1,1980 and June 30, 1980, were selected for the study population.

3) Age at divorce filing. Only those divorce filings in which at least one of the parties to the action was 60 years of age or older were used in the sample.

\section{Rationale for Selection Criteria}

The sampling criteria of residence provided for a diverse population base. Multnomah county is the most urban county in the state of Oregon. Clackamas County, located just south of Multnomah County, represents a partly rural and partly suburban county. Time also was perceived to be a crucial element in adjustment; hence, the sample was drawn from actions which had been filed approximately 12 months prior to the planned interview dates. This time period was selected on the basis of earlier work which had shown the separation phase prior to decree to be the most 
stressful time during divorce and that most dissolutions were completed within one year (Chiriboga et al., 1978).

Age, of course, was the selection criteria of primary interest. To ensure adequate sample size and to accommodate the age differences commonly found in American marriages, the decision was made to include those actions in which only one of the parties involved was over age 60 . One unintended consequence of this was a cross sectional sample of divorcing individuals; of the 240 individuals identified in these actions, one-third were under 60 years of age.

The initial sample of 240 individuals was drawn from county clerk records in the two counties. This process involved a visual review of each divorce action filed in both counties for the designated six month perioa. After the sample was drawn, ten individuals were removed before interviews were attempted. In these cases individuals had moved from oregon or had requested their address be withheld from the record.

Contact was attempted for the remaining 230 individuals and of these 81 agreed to interview. Table II indicates sampling loss. All of the 230 individuals remaining in the sampling frame was mailed a letter indicating they had been selected for the study. The letter explained the study and indicated that the subject would be contacted to determine his or her willingness to participate in the study. 
TABLE II

SAMPLE LOSS FROM SELECTED CAUSES

\begin{tabular}{llc}
\hline & $\mathrm{N}$ & Percent \\
\hline $\begin{array}{l}\text { Sample drawn from court files } \\
\begin{array}{l}\text { Number lost before contact } \\
\text { attempted--out of state or }\end{array}\end{array}$ & 240 & 100.0 \\
address withheld & 10 & 4.2 \\
$\begin{array}{l}\text { Number lost because individual } \\
\text { could not be located or had } \\
\text { moved from state }\end{array}$ & 71 & 29.6 \\
$\begin{array}{l}\text { Number lost because individual } \\
\text { was deceased, ill or incapac- } \\
\text { itated }\end{array}$ & 12 & 5.0 \\
$\begin{array}{l}\text { Number lost because of recon- } \\
\text { ciliation }\end{array}$ & 17 & 7.1 \\
$\begin{array}{l}\text { Number lost because individual } \\
\text { refused interview }\end{array}$ & 49 & 20.4 \\
$\begin{array}{l}\text { Number of completed interviews } \\
\text { Number }\end{array}$
\end{tabular}


The first follow-up to the letter was attempted within two weeks. Locating subjects proved to be exceedingly difficult; roughly one-third of the sampling loss reported in Table II was due to out of state moves or not being able to trace the whereabouts of subjects subsequent to divorce. In 20 per cent of the actions, both individuals listed the same address at the time the divorce action was filed. Attorneys, statewide phone directories and reverse street directories were used in an attempt to locate the current address of these individuals. In those cases when a thorough search did not reveal new addresses for one or both parties, the letter was sent to the female at the filing address.

\section{DATA COLLECTION AND PREPARATION}

Information was collected from publicly available court records on all 240 individuals. Additional information gained during sampling also was recorded for these individuals. Table III identifies the information collected from court records and from subjects prior to interview. These data later were used to determine the representativeness of the inteiview sample to the sampling universe.

After consent was obtained for an in-person interview, an appointment was scheduled at the subject's convenience. Interviews were held during the weekdays, in the evenings and on weekends. The majority of interviews (72.88) took 
TABLE III

INFORMATION COLLECTED FOR EACH MEMBER OF THE DIVORCING COUPLE FROM PRE-INTERVIEW

INFORMATION PROVIDED BY SUBJECT

AND COURT FILES IN MULTNOMAH

AND CLACKAMAS COUNTIES, OREGON

$\mathrm{N}=240$ Individuals

Name, address at filing
Changes in address since filing
Petitioner, respondent, or co-petitioner status
Health status, Age, Sex, Children in the marriage
Assets held in marriage, Previous marriages
Date of marriage, Date of filing
Outcome of filing, Date of outcome
Legal representation
Type of action (contested or not contested)
Degree of conflict, "Cause" of divorce
Separation prior to filing
Issues raised during divorce process
Settlement information
Outcome of pre-interview contact


place at the home of the subject; the balance (27.28) were in other places of the subject's choice. Most (86.4\%) of the interviews occurred within a fifty mile radius of downtown Portland; a few $(13.68)$ were scattered throughout Oregon. Interviews were begun in early February, 1981, and completed in May, 1981.

Subjects were given a choice of a male or female interviewer; two male and two female interviewers were used. In those cases where both parties to the divorce action elected to be interviewed, a different interviewer was used for each subject to ensure confidentiality and to avoid any bias in the interview process. Prior to the interview, subjects were read, or asked to read, a statement of informed consent regarding the nature of the study and emphasizing the voluntary nature of their participation. Completed interviews were secured in a locked filing cabinet and identifying information removed to maintain subject confidentiality.

\section{Reliability of Interview Data}

The interviews varied in length, with the average being one and one-half hours. Six variables--age of subject, filing date, outcome of filing, date of marriage, petitioner-respondent status, and legal representation in the divorce process--were selected to test the reliability of interview data. This was accomplished by cross validation; interview and court record data were compared 
on these six variables for the 81 subjects. The agreement rate between the two sources was nearly 100 percent $(96.48) .10$

During the interview information was gathered in three areas--personal characteristics, the divorce experience and consequences of the divorce for subjects. Operationalization of these variables is discussed in another section of this chapter (p. 71).

All data from the court files and the interviews were coded and computerized. Court file data were coded by two coders, with ten percent of the cases $(n=24)$ selected at random for independent review of accuracy. After the court file data were computerized, verification procedures were undertaken to ensure accuracy of the transmittal of the raw data onto the computer. These procedures involved a random check of another ten percent of the cases.

Data preparation procedures for the interviews were somewhat more involved, given the volume of information to be coded and the number of open-ended questions in the instrument used. Intitial preparation included panel review of open-ended data in the development of the coding format. Coding was completed by three individuals. Approximately 15 cards of data were coded for each of the 81 subjects. To test inter-coder reliability, 25 percent $(n=20)$ of the subjects were coded in a panel session. In this session, three coders independentiy coded the information for all open-ended or qualitative questions. 
The overall agreement/disagreement rate was 92 percent. After routine verification of coded and punched data, a second computer file was established for the 81 interview subjects. Routine editing procedures were used to clean the data in preparation for initial frequency runs.

\section{SAMPLE REPRESENTATIVENESS}

Prior to undertaking extensive analysis of the data, sample representativeness was checked. The high loss rate in the initial sample, the small $\mathrm{N}$ of the interview sample and the non-random assignment of subjects to interview raises questions about representativeness and the generalizability of findings to other divorcing older populations. To determine what, if any, interview sample bias existed, key characteristics of the initial ( $n=240)$ and interview $(n=81)$ samples were compared.

Chi-squares and independent samples $t$-tests were used to compare the interview and the initial samples on ten variables. These variables were selected to represent personal and divorce characteristics in the two samples. Other variables such as health status, children in the marriage and assets to be divided were excluded due to the amount of missing data in the court files. The results of the comparison tests are shown in Table IV.

Table IV indicates the interview sample is significantly different on two of ten characteristics compared. The interview sample had been married longer 
TABLE IV

COMPARISON OF INTERVIEW WITH INITIAL SAMPLE ON SELECTED PERSONAL AND DIVORCE CHARACTERISTICS FROM COURT RECORDS*

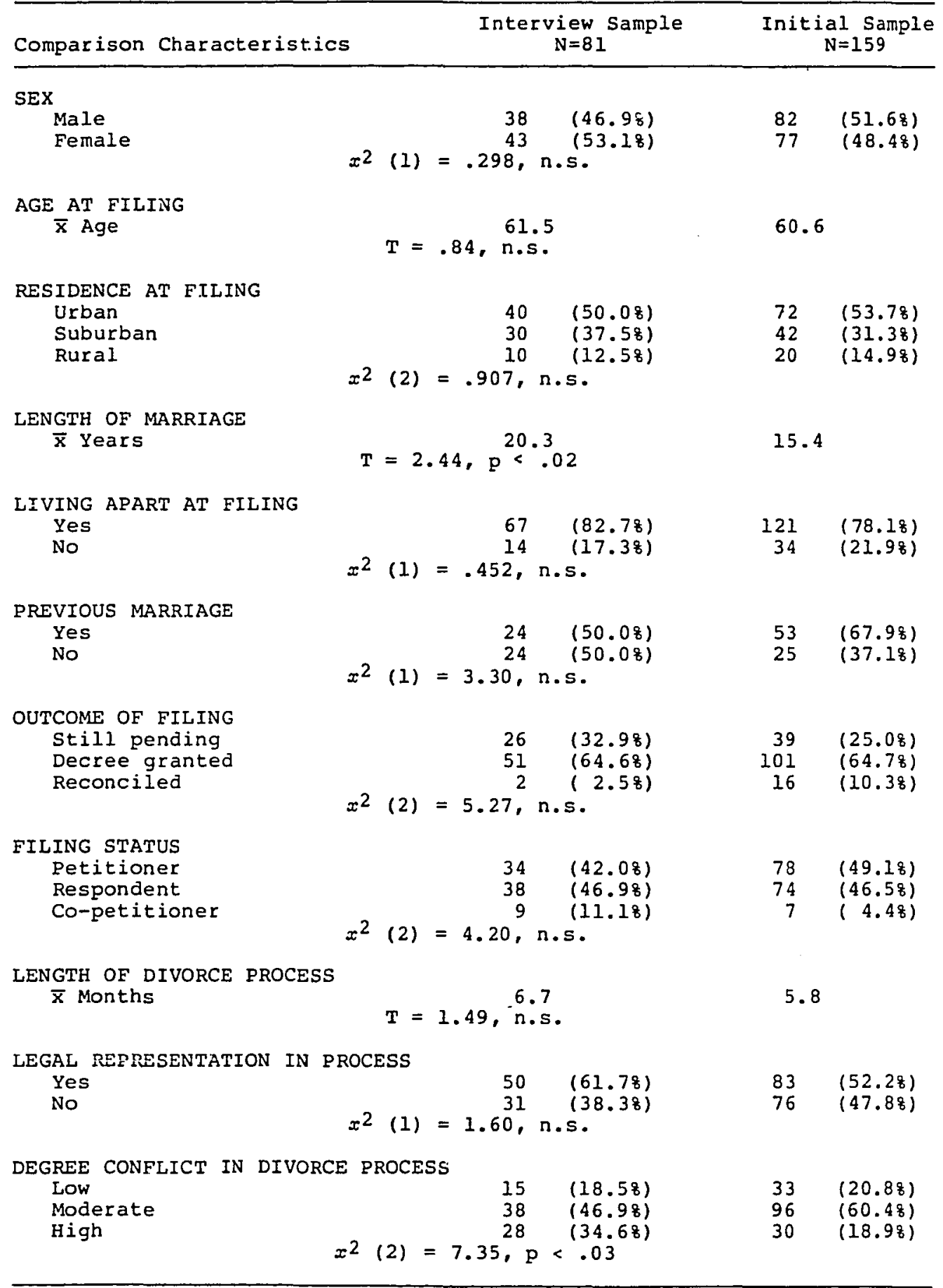

Note. Totals do not always equal 81 and 159 respectively due to missing data. 
( $p<.02)$ and were involved in a more legally conflicted divorce $(p<.03) .11$ That both variables were significant is not surprising given the direct relationship found between length of marriage and conflicted divorce actions $(t=2.75$, $\mathrm{p}<.05)$

In general, then, it would appear that the interview sample may be biased toward individuals who were married longer and who had more legal conflict in their divorce actions. Given that the type of divorce experience includes a legal conflict dimension and is a major variable in the divorce impact model to be tested, the generalizability of the model may be affected. It is important to note, however, that no other significant differences were found between the interview and the initial sample. Thus, a tentative conclusion can be reached that the interview sample is representative of the study population at least with respect to characteristics such as sex, age, residence, outcome of divorce action, filing status, and the amount of time it takes to get a divorce in late life.

OPERATIONALIZATION OF THE VARIABLES

Operationalization of the variables for this study consisted primarily of identification of the appropriate variables from the data set used by Deshane and wilson (1981b) in their study of late life divorce. However, new variables also were created. Creation of new variables 
involved using multiple count, computation and scale construction procedures. The glossary of measures provided at the end of this chapter contains a list of the created variables, their definitions and tables with summary data for the scales.

To answer the questions related to the personal characteristics of a divorcing older population, both existing and new variables were used. Sex, age, ethnicity, educational level and occupational status were existing variables. Employment stability, health status, religious affiliation, fertility, residential stability and marital history are scales constructed to measure personal characteristics (see Table V, p. 77).

The creation of the "cause" variables for late life divorce described on pages $47 \& 48$ involved the coding of explanations provided by subjects into one of four categories--premarital, marital, alternative attractions and life stress. A scoring system which assigned a different value to each of the four explanations was used to determine the relative contribution of each explanation to the decision to divorce. The resulting scores then were used to compute an overarching "cause" of divorce.

Determining the type of divorce experience involved creating three scales to measure the anticipated cost. The marital risk scale was derived from 12 personal and premarital characteristics which influence marital quality and, subsequently, marital satisfaction. six items were 
used in constructing a scale of marital quality to measure the amount of prefiling stress exhibited in the marriage. The life stress scale was made up of ten items designed to measure the occurrence of other stressful events in the ten years prior to the divorce action (see Table VI, p.78). These three scales collectively represent the anticipated cost of divorce.

Determining the type of divorce experience involved measuring the level of conflict in and reaction to the divorce. Conflict and reaction to the divorce were assumed to represent two different concepts. Conflict provided a measure of disagreement around the outcomes of the decision to dissolve the contractual obligations incurred in marriage and was computed using a seven item scale shown in Table VII (p. 79). A single question related to emotional response was used to measure feelings about the divorce.

Individual consequence scales were constructed to measure the impact of divorce legally, economically, socially and psychologically. Items used to construct the scales are found in Table VIII (p 80). These were then combined to create an overall consequence scale. Coping strategies involved the coding of methods used by subjects to resolve problems into one of four categories self-reliance, emotional discharge, positive comparisons and selective ignoring. A scoring system was used to determine the predominant strategy used by subjects to resolve the problems created by divorce. To measure 
adjustment, a problem resolution score was computed. The score was computed on the degree of resolution reported with a range of 5 (low) to 15 (high) points possible. Degree of stress exhibited was measured with the 22 item Langner Psychiatric symptoms Checklist. The cut off points used for this standardized scale 10-3 no impairment; 4-6 mild impairment; and $7+$ severe impairment) are those recommended to minimize false positive diagnoses of significant psychiatric impairment (Langner, 1962). Checklist items are listed in Table IX, page 81 .

The general procedure followed for creating scales was to select individual items that appeared to have face validity, had been found to be associated previously in correlational procedures or were identified in the literature as related to one another. All of the scales used were tested for internal consistency using item-total correlational procedures. Only those scales having a standardized alpha of at least .60 were accepted. Generally, item correlations were moderate ones, ranging from .40 to .60 . Where applicable, alpha levels are listed with the scale items in the tables.

\section{GLOSSARY OF TERMS}

The terms in this section are presented in order of their appearance in Chapter III. The definitions are meant as a guide to use of terms which appear throughout Chapters III, IV and $\mathrm{V}$. 
Socio-economic status is based upon primary occupation, years of education and a five item scale which measures employment stability (Table V).

Marital History scale is based upon the stability shown in the marital relationship (Table V).

Religious Affiliation scale is based upon the overall role religion plays in an individual's life (Table V).

Residential status scale is based upon the stability shown in living arrangments (Table V).

Eertility scale is based upon the reproductive behavior of an individual (Table V).

Health status scale is based upon the reported health of an individual (Table V).

Premarital Factors are based upon the concept that individuals come into a marriage with certain expectations and resources. The degree to which marital partners are similar in both and the extent to which others view them as similar contribute to the success of the marriage.

Marital Factors are based upon events wiich occur after marriage. Socio-economic conditions, involvements outside of the marriage, regard for spouse, emotional gratification in marriage and role fit are marital factors.

Alternative Attraction Factors are based upon events external to the marriage. They involve attraction to other individuals or life styles.

Life Stress Factors are based upon experiencing events perceived to result in increased stress. They include changes in personal relationships, environment, finances and health.

Marital Risk scale is based upon personal characteristics associated with a higher probability of divorce (Table VI) .

Marital Quality scale is based upon marital characteristics associated with strain in marriage (Table VI).

Life stress scale is based upon the occurrence of other stressful events in the lives of divorcing older persons (Table VI).

Anticipated cost is based upon scores computed for the 
marital risk, marital quality and life stress scales. It provides a projected cost of divorce to individuals.

Emotional Reaction is based upon a single question about how subjects felt about getting a divorce.

Conflict scale is based upon the level of dissension surrounding the dissolution of the marriage (Table VII).

Divorce Experience is based upon scores computed for the emotional reaction and conflict scales. It measures the degree of resistance to the divorce.

Legal Consequences scale is based upon the contact individuals have with the judicial system (Table VIII).

Economic Loss score is based upon the actual division of marital financial assets (Table VIII).

Psychological Consequences scale is based upon the interpersonal problems reported by individuals (Table VIII).

Social Consequences scale is based upon changes in familial and in-law relations, friendships and organizational affiliations (Table VIII).

everall consequences scale is based upon a score computed from legal, economic, psychological and social consequences.

Coping strategies are based upon Pearlin and schooler's categorizations: a) self-reliance - individual is responsible for fining appropriate solution to problem, b) emotional discharge - individual seeks to focus responsibility for problem and solution on others, c) positive comparisons - individual views consequences as good, and d) selective ignoring - individual denies or supresses problems.

Problem Resolution is based upon a computation of the degree of problem solving reported by subjects.

Stress is based upon the score received on Langner's Psychiatric symptoms Checklist (Table IX).

Adjustment is based upon a score computed from problem resolution and stress.

Adjustment Time is based upon the length of time from an individual's first contemplation of divorce until date of interview. 
Divorce Adjustment Model predicts post divorce adjustment using five predictor variables - anticipated cost, type of divorce experience, consequences, adjustment time and sex (Table $X$ ). 


\section{TABLE V}

\section{ITEMS USED TO CONSTRUCT SCALES DESCRIBING \\ PERSONAL CHARACTERISTICS OF THE STUDY POPULATION}

\begin{tabular}{|c|c|}
\hline $\begin{array}{l}\text { EMPLOYMENT STABILITY } \\
\text { Lengthy unemployment } \\
\text { Employment stability } \\
\text { Occupational stability } \\
\text { Years work history provided } \\
\text { Number jobs held } 10 \text { years }\end{array}$ & $\begin{array}{l}\mathrm{n}=73 \\
\alpha=.81 \\
\text { Range }=3-15\end{array}$ \\
\hline $\begin{array}{l}\text { HEALTH STATUS } \\
\text { Number health problems } \\
\text { Self reported status } \\
\text { Days confined } \\
\text { Severity problems }\end{array}$ & $\begin{array}{l}n=77 \\
\alpha=.84 \\
\text { Range }=4-12\end{array}$ \\
\hline $\begin{array}{l}\text { RELIGIOUS MEMBERSHIP } \\
\text { Religious membership } \\
\text { Religious strength } \\
\text { Religious activity }\end{array}$ & $\begin{array}{l}\mathrm{n}=76 \\
\alpha=.66 \\
\text { Range }=3-9\end{array}$ \\
\hline $\begin{array}{l}\text { RESIDENTIAL STABILITY } \\
\text { Number residences past } 10 \text { years } \\
\text { Years of residential history provided } \\
\text { Perceived stability }\end{array}$ & $\begin{array}{l}n=78 \\
\alpha=.84 \\
\text { Range }=3-9\end{array}$ \\
\hline $\begin{array}{l}\text { FERTILITY } \\
\text { Number of all children born to subject } \\
\text { Subject age at birth of lst child } \\
\text { Number of children born in divorcing } \\
\text { marriage }\end{array}$ & $\begin{array}{l}\mathrm{n}=79 \\
\alpha=.63 \\
\text { Range }=3-9\end{array}$ \\
\hline $\begin{array}{l}\text { MARITAL HISTORY } \\
\text { Number of marriages } \\
\text { Length of divorcing marriage } \\
\text { Outcome previous marriages } \\
\text { Date of divorcing marriage }\end{array}$ & $\begin{array}{l}\mathrm{n}=80 \\
\alpha=.86 \\
\text { Range }=3-12\end{array}$ \\
\hline
\end{tabular}


TABLE VI

ITEMS USED TO CONSTRUCT SCALES OF MARITAL RISK, MARITAL QUALITY AND LIFE STRESS

MARITAL RISK

Educational level Primary occupation Age birth lst child Number children in marriage Number of marriages Length divorcing marriage

$\mathrm{n}=67$

$\alpha=.64$

MARITAL QUALITY

History marital separation Perceived instability Prior threat to divorce

$\mathrm{n}=79$

$\alpha=.59$

LIFE STRESS

Retirement within 10 years

Last child gone within 10 years

Divorce/widowhood within 10 years

Multiple jobs within 10 years

Lengthy unemployment within 10 years

$n=64$

$\alpha=.63$
Outcome prior marriage

Religious strength

Religious membership

Employment stability

Self reported health status

Premarital characteristics perceived as major marital problem

12 item, 3 point scale Range of scores: 12-36

Commitment to divorce Commitment to marriage

Marital characteristics perceived as major marital problem

6 item, 3 point scale Range of scores: 6-18

Lengthy confinement within 10 years

Severe health problems within 10 years

Multiple residences within 10 years

Multiple changes in living arrangements within 10 years

Life stress perceived as major marital problem

10 item, 3 point scale Range of scores: $10-30$ 
TABLE VII

ITEMS USED TO CONSTRUCT MEASURES OF CONFLICT IN THE DIVORCE PROCESS

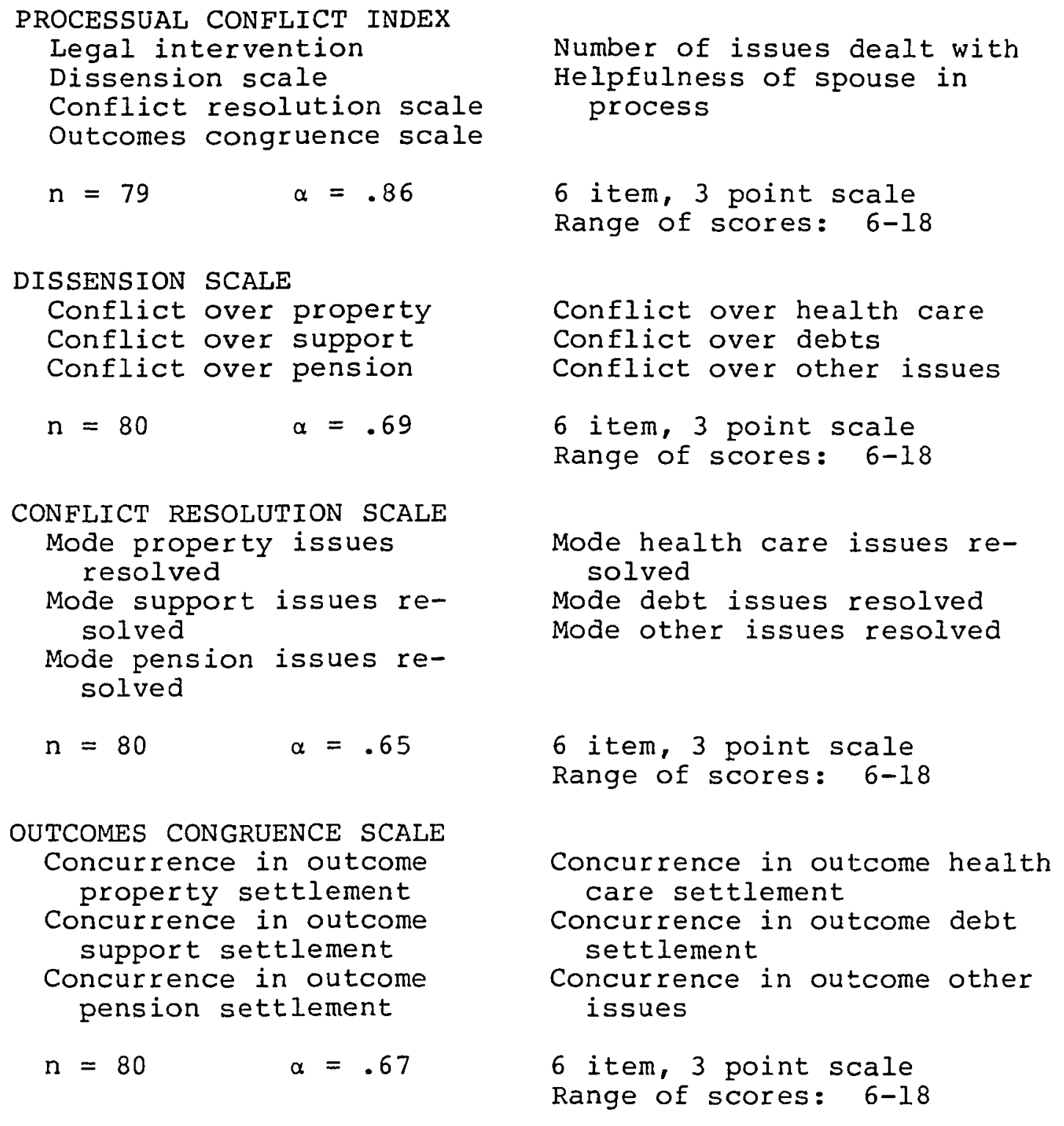


TABLE VIII

ITEMS USED TO CONSTRUCT SCALES OF PSYCHOLOGICAL, SOCIAL, LEGAL CONSEQUENCES AND MEASURE OF ECONOMIC LOSS CAUSED BY DIVORCE

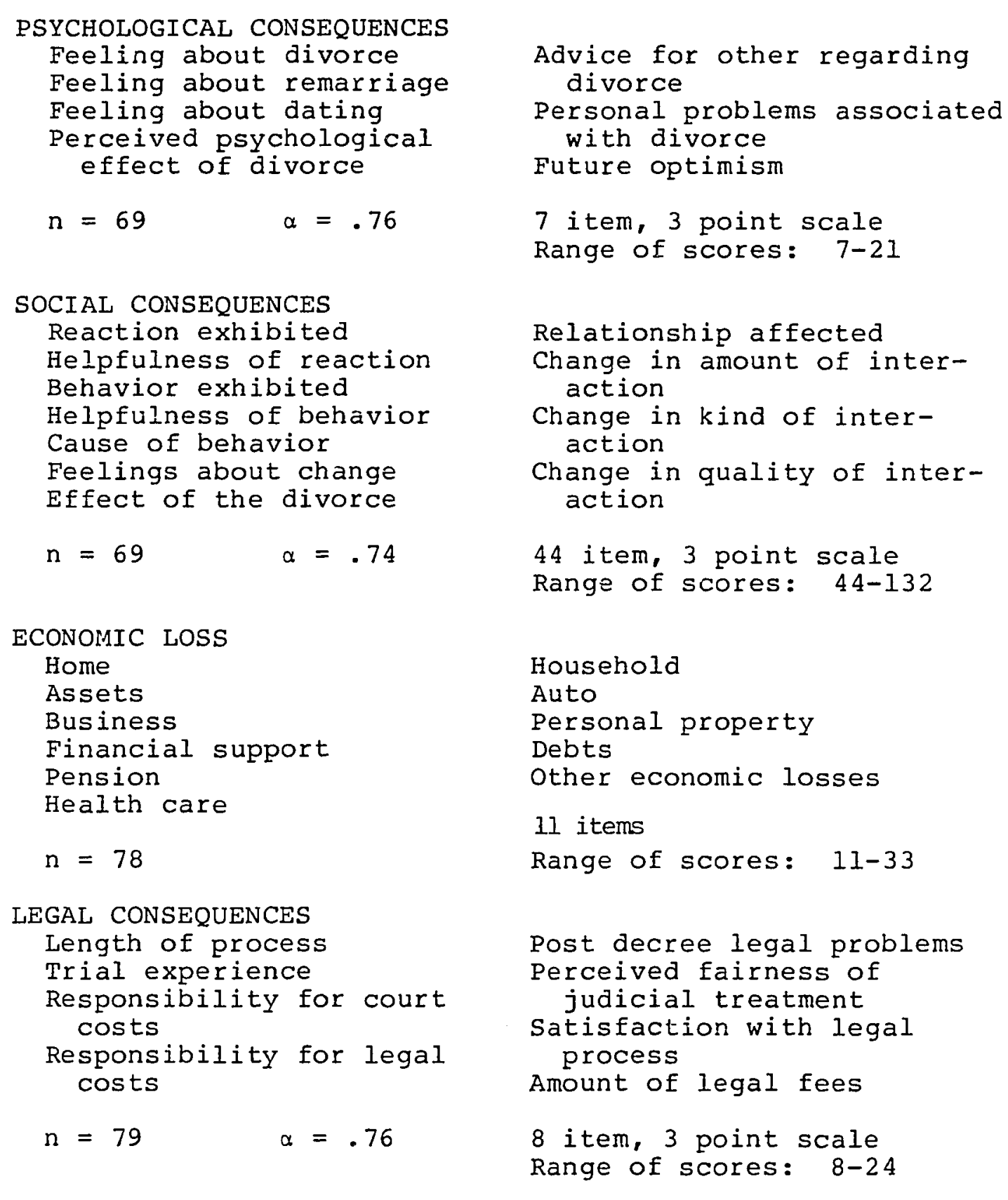


1. I feel weak all over much of the time.

2. I have had periods of days, weeks, or months when I couldn't take care of things because I couldn't "get going."

3. In general, would you say that most of the time you are in high (very good) spirits, good spirits, low spirits, or very low spirits?

4. Every so often $I$ suddenly feel hot all over.

5. Have you ever been bothered by your heart beating hard? Would you say: often, sometimes, or never?

6. Would you say your appetite is poor, fair, good or too good?

7. I have periods of such great restlessness that I cannot sit long in a chair (cannot sit still very long).

8. Are you the worrying type (a worrier)?

9. Have you ever been bothered by shortness of breath when you were not exercising or working hard? Would you say: often, sometimes, or never?

10. Are you ever bothered by nervousness (irritable, fidgety, tense)? Would you say: often, sometimes, or never?

11. Have you ever had any fainting spells (lost consciousness)? Would you say: never, a few times, or more than a few times?

12. Do you ever have any trouble in getting to sleep or staying asleep? Would you say: often, sometimes, or never?

13. I am bothered by acid (sour) stomach several times a week.

14. My memory seems to be all right (good).

15. Have you ever been bothered by "cold sweats"? Would you say: often, sometimes, or never?

16. Do your hands ever tremble enough to bother you? Would you say: often, sometimes, or never?

17. There seems to be a fullness (clogging) in my head or nose much of the time.

18. I have personal worries that get me down physically (make me physically ill).

19. Do you feel somewhat apart even among friends (apart, isolated, alone)?

20. Nothing ever turns out for me the way I want it to (turns out, happens, comes about, i.e., my wishes aren't fulfilled).

21. Are you ever troubled with headaches or pains in the head? Would you say: often, sometimes, or never?

22. You sometimes can't help wondering if anything is worthwhile anymore.

$\mathrm{n}=81$

$\alpha=.84$

Range: $0-22$ 
TABLE X

ITEMS USED TO CREATE PREDICTOR AND CRITERION VARIABLES IN DIVORCE ADJUSTMENT MODEL

\begin{tabular}{|c|c|}
\hline $\begin{array}{l}\text { ANTICIPATED COST } \\
\text { Marital risk scale } \\
\text { Marital quality scale } \\
\text { Life stress scale }\end{array}$ & $\begin{array}{l}\mathrm{n}=57 \\
\text { Range }=28-84\end{array}$ \\
\hline $\begin{array}{l}\text { DIVORCE EXPERIENCE } \\
\text { Processual conflict index } \\
\text { Emotional reaction to divorce }\end{array}$ & $\begin{array}{l}n=78 \\
\alpha=.86 \\
\text { Range }=2-6\end{array}$ \\
\hline $\begin{array}{l}\text { CONSEQUENCES } \\
\text { Legal consequences } \\
\text { Social consequences } \\
\text { Economic consequences } \\
\text { Psychological consequences }\end{array}$ & $\begin{array}{l}n=62 \\
\alpha=.74 \\
\text { Range }=60-180\end{array}$ \\
\hline $\begin{array}{l}\text { ADJUSTMENT } \\
\text { Langner psychiatric checklist } \\
\text { Problem resolution score }\end{array}$ & $\begin{array}{l}\mathrm{n}=79 \\
\alpha=.85 \\
\text { Range }=5-37\end{array}$ \\
\hline $\begin{array}{l}\text { TIME } \\
\text { Computed length time (months) } \\
\text { from first thought of filing } \\
\text { to interview }\end{array}$ & $\begin{array}{l}\mathrm{n}=81 \\
\text { Range }=1-76\end{array}$ \\
\hline SEX & $n=8 I$ \\
\hline
\end{tabular}


CHAPTER IV

FINDINGS AND INTERPRETATIONS

PROFILES OF DIVORCING OLDER PERSONS

A basic question to be addressed by this study was who gets divorced in late life. To answer this question, eleven personal characteristics were selected to examine in this study. These characteristics represent those most often associated with studies of divorcing populations. Given that the personal characteristics of the interview sample were not found to differ significantly from the study population, some observations about the personal characteristics of individuals involved in late life divorce can be made from the data presented (Table XI).

Turning first to age distribution, in our sample we found that late life divorce was a phenomenon experienced much more often by the young-old than the old-old. A comparison of the ages of the indiviauals involved in the divorce actions indicated a difference of six years in the mean age of females (58.1 years) and males (64.7 years). This difference supports earlier findings of a cultural preference in America for brides to be somewhat younger than their mates. Thus, it is not surprising that all but one of the individuals in the sample under age 60 are females in their mid to late fifties. 
TABLE XI

PERSONAL CHARACTERISTICS IN A SAMPLE OF DIVORCING OLDER PERSONS

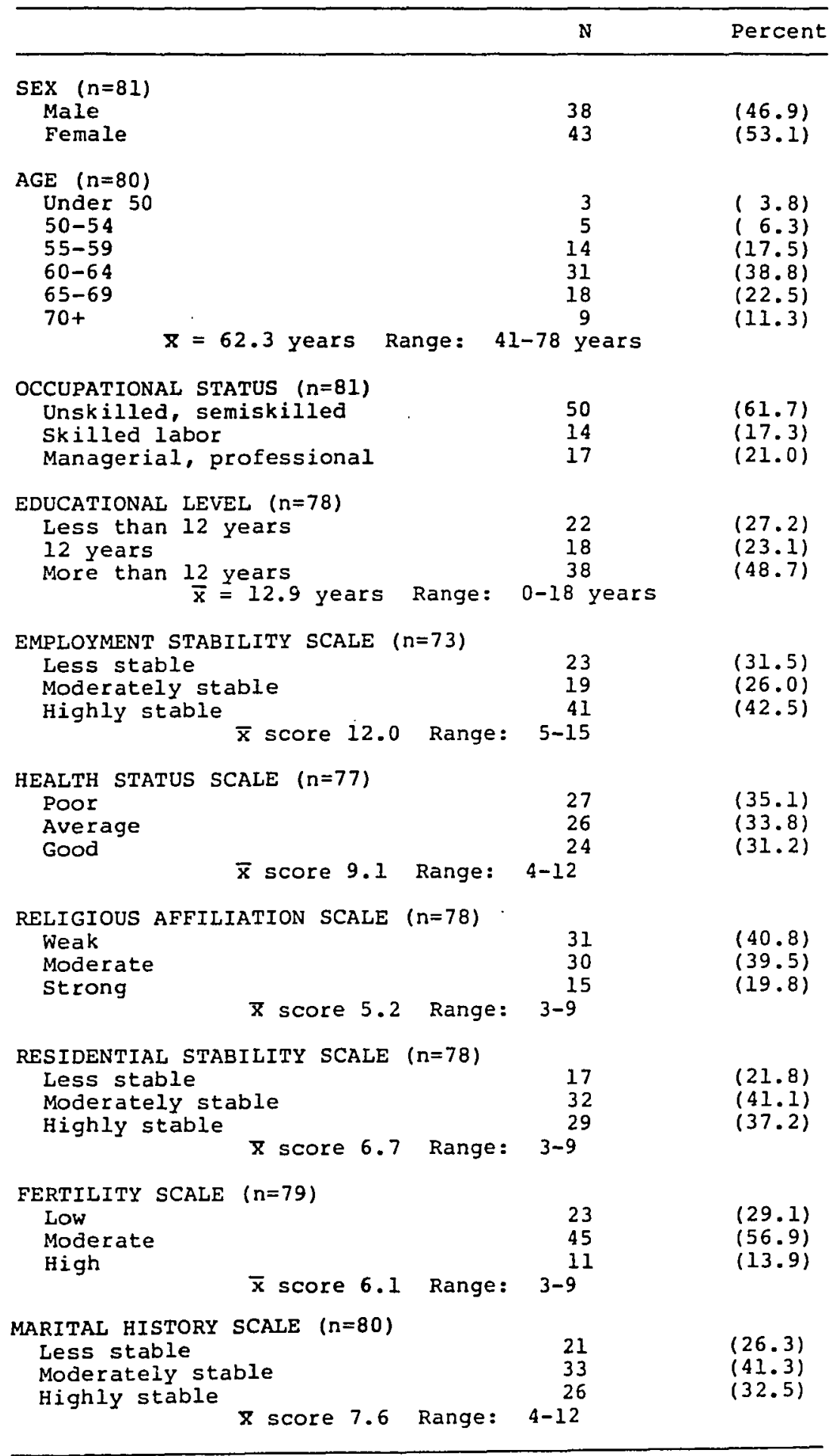


An examination of other personal characteristics yielded some interesting patterns. The sample was overwhelmingly white. This finding may be explained by the low percentage of minority elderly living in the geographic area from which the sample was drawn. It also may be explained, in part, by differential marriage and remarriage rates for whites and nonwhites. Higher divorce rates and lower remarriage rates for nonwhites in younger populations may result in fewer marital unions which would be susceptible to legal dissolution after age 60 .

\section{Differences Between Younger and older Divorcing Persons}

Socio-economic indicators also yielded some unexpected results. Most findings have reported divorcing individuals as having less education; our sample had a relatively high level of educational attainment $(\bar{x}=12.9$ years). The pattern for employment stability was not the same as for younger populations either. While their employment histories indicated very stable occupational careers the majority (61.7\%) of the sample subjects scored low on occupational status. In younger divorcing populations, both employment stability and occupational status are likely to be low. However, Price-Bonham \& Balswick (1980) have suggested that stability is a better predictor of divorce than occupational status for younger divorcing persons.

Cohort effect may account for some of the difference. 
The occupational status of the sample may be skewed by the large number of females who worked sporadically at part time jobs or not at all. Females in the sample cohort may represent a generational phenomenon which held that wives should not work. Thus, somewhat ironically, those females who had the lowest occupational status in their own right were likely to have been married to males of the highest status. This may account, in part, for the higher educational levels and employment stability reported by the subjects in the sample.

The high level of employment stability was not unexpected given what is known about the working habits of older people. High educational attainment, however, was somewhat more surprising. This finding may provide some support for Udry's (1971) contention that when attitudes are more restrictive, a direct relationship between socio-economic status and the probability of divorce will exist. Sweeney (1982) has argued that despite a movement toward more liberal attitudes, older persons generally do not perceive divorce to be an option to marital problems. Hence it may be that our sample was actually more representative of middle or upper class older persons.

Divorcing older persons are different from younger divorcing persons in at least one other area, residential stability. Unlike younger persons, who are reported to be less residentially stable, older persons getting divorced appeared to be residentially stable before and after their 
divorce. An examination of residential histories indicates a record of home ownership, infrequent changes in type or conditions of living arrangements and almost no rural-to-urban movement. While the majority of individuals in the sample were urban residing (50.0\%), the distribution of residences was comparable to the distribution of the elderly within the geographical area sampled. Interestingly, most of the migration which did occur was urban to rural, representing, primarily, individuals moving to a place in the country after retirement. Such findings would be typical for a general population of older persons.

\section{Similarities Between Younger and older Divorcing Persons}

In other areas--religion, health, fertility and marital history--divorcing older persons appeared to have personal characteristics somewhat more similar to younger divorcing persons. A majority reported weak religious ties (59.38); only 13 percent were actively involved in organized religious activities. In comparing the religious status of 17 couples in the sample, we found that two-thirds (64.7\%) reported differences in their affiliations and/or the strength of their religious beliefs. These findings are consistent with those reported for younger divorcing persons, but are in contrast to those for the general older population.

Just as for younger divorcing persons, health status indicated no clear patterns. The proportion of older 
persons scoring poorly $(35.18)$ was comparable to another group of older persons who experienced a stressful life event (Wilson \& Schulz, 1982). In both groups approximately one-fourth of the members reported no health problems of any type. However, it is worth noting that the average age of the older divorcing population was nearly ten years younger than the comparison population. Further, the general population of noninstitutionalized elderly have a much lower incidence of reported poor health. The problem remains as to whether the poor health is a cause of, or the result of, divorce.

Turning next to the fertility patterns in the study popuiation, the data show that the majority (88.98) had children in the divorcing marriage. This is comparable to rates found in studies of divorce involving long term marriages ( 20 or more years). Only one-third (33.38) of the study population, however, reported the birth of their first child during the expected time frame, 21 to 26 years of age. This conforms to findings for younger divorcing populations which positively associates younger than average age at the birth of the first child with a higher probability of divorce (Norton, 1980). Fertility rates themselves were slightly less than what might be expected in the general population of older persons.

The marital history of the study population showed some interesting trends. Nearly two-thirds (61.78) of the sample had ended a prior marriage in divorce; yet just as 
many (60.58) had been married 20 years or more. These data, combined with the dates of the divorcing marriages, suggest a special vulnerability for marriages conceived during the war years. Prior research has indicated that war marriages are more vulnerable; these data appear to suggest that they remain vulnerable, even after the point (six to seven years) at which most marital dissolutions in younger populations occur. The findings, however, are confounded by the prior marital experiences of the sample; thus, part of the vulnerability may stem from the individual's willingness to use divorce as a solution to marital problems. In general, late life divorce appears to involve individuals who have been married a long time (20 to 40 years).

In summary, the length of marriage, higher socio-economic status and residential stability, set the divorcing older population apart from divorcing younger persons. On the whole, however, divorcing older and younger persons share many characteristics associated with higher probability of divorce: weak religious ties, poor health, children at a younger age than usual and a prior experience with divorce. Thus, it appears that older divorcing persons do not conform completely with either the profile of younger divorcing persons or that of the elderly population. 


\section{CAUSES OF LATE LIFE DIVORCE}

In their study, Deshane and Wilson (1981b) reported that lack of emotional intimacy was given most frequently by subjects as the "cause" of their late life divorce. Using a framework derived from the work of Lewis and Spanier (1979) and McCubbin et al. (1980) to take another look at these data, we found some interesting results.

It is clear from an examination of cause scores computed for subjects, using the four general categories suggested by our framework, that a variety of explanations for late life divorce can be generated. Thirteen distinct combinations of causes emerge when the data are collapsed, of these only one-fourth involved a single type of explanation, suggesting that, at least in late life, the decision to divorce was a complex one involving multiple factors (Table XII).

Marital factors, such as lack of emotional gratification and regard for spouse, were identified as the predominant causes of late life divorce. This corresponds with Deshane and Wilson's (1981b) findings and is consistent with findings for younger populations. Marital factors frequently were found in combination with alternative attraction factors as expressed through desertion, adultery and behavior described by subjects as "wanting out." Neither life stress factors, such as 
TABLE XII

CAUSES OF DIVORCE IN A SAMPLE OF 81 DIVORCING OLDER PERSONS

\begin{tabular}{|c|c|c|c|c|c|c|}
\hline & \multirow{2}{*}{$\frac{\text { Only }}{\mathrm{N}}$} & \multirow{2}{*}{ "Cause" } & \multicolumn{2}{|c|}{ Precipitating "Cause" } & \multicolumn{2}{|c|}{ Influencing "Cause" } \\
\hline & & & $\mathrm{N}$ & Percent & $\mathrm{N}$ & Percent \\
\hline Premarital & 2 & $(2.5)$ & 8 & $(9.9)$ & 33 & $(40.7)$ \\
\hline Marital & 12 & $(14.8)$ & 39 & $(48.1)$ & 70 & $(86.4)$ \\
\hline Alternative Attraction & 5 & $(6.2)$ & 24 & $(29.6)$ & 40 & $(59.4)$ \\
\hline Life Stress & 1 & $(1.2)$ & 10 & $(12.3)$ & 27 & $(33.3)$ \\
\hline
\end{tabular}


retirement and illness, nor premarital factors, which included factors such as homogamy, familial support, or personal resources, appeared to be important causes of late Iife divorce.

In this sample, late life divorce typically involved a loss of love, coupled with an event which heightens the attractiveness of ending the marriage. Alternative attraction factors occasionally involved attachment to a new person, but more often was expressed as a vague desire to live the balance of life differently. Premarital and life stress factors generally appeared unimportant as precipitating events, but emerged as influencing factors. Thus, a subject might identify, by way of example, the "cause" of the divorce as being a loss of love, fueled by long-standing conflicts and a desire to make changes after obligations to family, community and work are met.

\section{Cause of Divorce and Personal Characteristics}

Turning next to a comparison of the causes of late life divorce by selected characteristics, we found almost no differences. Cause of divorce was not associated with sex, filing status, educational level, marital history, health status, employment stability, religious affiliation, fertility or residential stability. only occupational status was significantly different $\left(x^{2}=13.7,6\right.$ df, $p<$ .03). Individuals with higher occupational status were less likely to name premarital and life stress factors as 
the sole, or even the primary, cause of their divorce. This finding is consistent with that reported in other studies. These studies suggest that a more restricted selection process occurs in the upper class which results in a more homogeneous, evenly matched marital pair; other studies indicate that life stress is less of a problem for those in the upper socio-economic levels.

\section{Cause of Divorce and the Divorce Process}

Interestingly, only one of six scales designed to measure probability of and reaction to divorce, marital guality, was associated significantly with cause of divorce $\left(x^{2}=14.4,6 \mathrm{df}, \mathrm{p}<.03\right)$. Most noteworthy in this finding is that 75 percent of those reporting life stress factors as causing their divorce scored high on the marital quality indicator. One conclusion which might be drawn from this finding is that stressful life events, in fact, may impact negatively upon marriages previously perceived as satisfying relationships. Almost as noteworthy is the absence of an association between the cause of and reaction to the divorce. subjects identifying alternative attraction factors as the cause of their divorce were not more likely to have negative feelings or to experience more conflict in the divorce process, than subjects who identified other factors as causing their divorce. This suggests that individuals were not attempting to penalize others, nor were they absorbing additional costs 
traditionally associated with a decision of that type.

A somewhat different picture emerged when we looked at cause in conjunction with other aspects of the divorce process. While cause was not associated significantly with filing status, length of marriage, satisfaction with the process, consequences, or the way in which subjects dealt with the divorce, it was associated strongly with time variables. Subjects reported less time prior to filing in which divorce is contemplated when alternative attraction factors were given as the cause of their divorce and more time when marital factors are given $\left(\mathrm{x}^{2}=16.5,6 \mathrm{df}, \mathrm{p}<\right.$ .01). The shorter anticipatory period for subjects who identified an alternative attraction cause suggests that they may have been caught unaware, or reached a decision to divorce quickly, once conditions seem right to make a change in their lives. Subjects reporting marital factors as the cause of their divorce reported longer anticipatory, process and adjustment time across the board. This general lengthening of time is suggestive of ongoing conflict in a long marriage. Additional support for this interpretation was provided by the lower marital quality and higher levels of conflict reported by subjects who identified marital factors as the cause of their divorce.

Length of process between filing and decree was shorter for subjects who identified premarital factors as the cause of their divorce and longer for subjects with life stress factors $\left(x^{2}=13.4,6\right.$ df, $\left.p<.04\right)$. Those 
subjects identifying premarital factors also had much shorter marriages, suggesting perhaps a lower level of emotional investment and fewer marital assets which reduced the time needed for negotiation. The longer time, for subjects with life stress, may be indicative of an attempt to cushion the "cost" of divorce through a process of voluntary or involuntary bargaining.

In summary, then, we find the "cause" of divorce generally not to be associated with other variables of interest. Of 36 tests of significance performed, only five were statistically significant. Individuals with selected personal characteristics were not any more likely to identify one set of factors more than another set as causing their divorce. Neither their response to, nor the consequences they experienced as a result of divorce, appeared to be affected by the cause they identify. only the time during which they were contemplating, negotiating or adjusting to their divorce was associated with cause.

\section{EXPECTATIONS AND REACTIONS TO DIVORCE}

The divorce process involved the period of time during which the decision to divorce was reached, a petition for dissolution was filed and proceedings occurred which resulted in the termination of the marital union. This process was described, for individuals divorcing in late life, by DeShane and Wilson (1981b, p. 81), who noted:

The respondents were typically dissolving a long marriage in which a moderate to high amount of 
marital instability had been present for a long time. Although they reported multiple problems, most blamed the loss of emotional intimacy as the major problem in the marriage. Decisions to file for divorce tended to be made without help or advice from others.

They also noted that divorce was not an easily arrived at decision for individuals divorcing in late life.

In this study the divorce process was analyzed further by examining how individuals responded to this stressful event. We suggested previously that an anticipated cost could be derived from an estimate of the costs and benefits associated with terminating the marriage. Further, we suggested, drawing upon the work of Lewis and Spanier (1979) and McCubbin et al. (1980), that an estimate could be based upon scores for three scales called marital risk, marital quality and life stress.

Our first task, thus, was to determine a marital risk factor based on personal characteristics associated with a higher probability of divorce, a marital quality factor based on strain reported in the marriage and a life stress factor based on other pivotal events which may leave individuals more vulnerable to additional stressful events (see p.73 for items used to construct scales). The results, shown in Table XIII, indicate the majority of subjects scored in the moderate range for each of the factors.

Perhaps the most interesting finding evident in these data was the uniformly low percentage of subjects who 


\section{TABLE XIII}

DISTRIBUTION OF SUBJECT SCORES ON MARITAL RISK, MARITAL QUALITY, LIFE STRESS AND ANTICIPATED COST SCORE

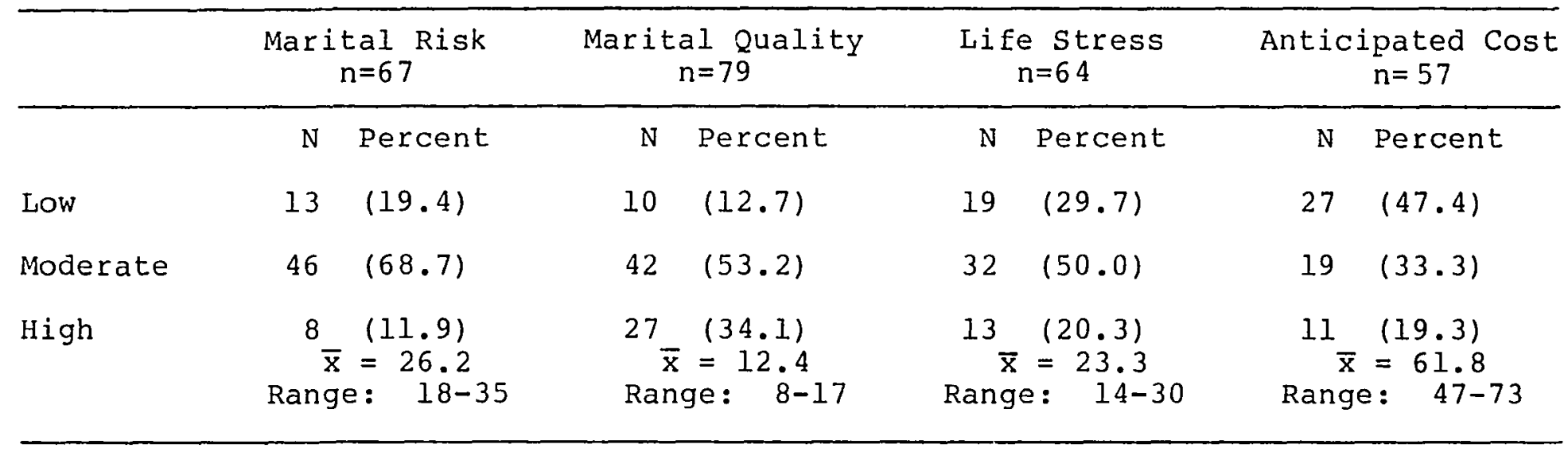


scored as being high risk, having low quality marriages or experiencing multiple stressful life events. With no group against which comparisons can be made, it is difficult to know whether these uniformly low percentages are higher than would be those for a general population or a non-divorcing group.

In the relationship between marital risk, marital quality, life stress and other variables of interest, two findings were worth noting. First, the life stress scale showed a significant association with only one of the 25 variables tested. Shorter marriages were associated with higher Iife stress $\left(x^{2}=15.2,4 d f, p<.004\right)$. Such a finding was not surprising given the association between length of marriage and outcome of prior marriage, a factor included in the development of the life stress scale. Other findings suggested that subjects with low risk, high quality marriages were likely to experience mixed consequences and to require more time to dissolve their marital union, but subsequently to be more satisfied with outcomes of the divorce process and to experience lower levels of stress. Low risk, high quality marriages also were likely to involve marriages of 20 or more years duration.

In general this inverse relationship between marital risk and marital quality was not surprising given the moderately negative correlation which existed for the two scales $(x=-.41, p<.0005)$. However, marital risk and 
life stress also were correlated ( $r=.37, p<.003$ ) and no such pattern emerged in those data.12 Further, life stress was not correlated with marital quality $(r=.09)$. One explanation may be that, as has been suggested in studies with other populations, stressful life events are experienced and their impact felt more keenly by individuals who already are at greater risk of divorce. Thus, a positive correlation between life stress and marital risk would be the expected one. The negligible correlation of life stress with marital quality suggests that experiencing multiple stressful life events may have an impact only if the risk of divorce is there initially or the quality of the marriage is not high. Yet, as noted above the majority of those reporting life stress factors as the cause of their divorce also scored high on marital quality.

The use of retrospective data and a non-random sample limit the conclusions which can be drawn from these findings. However, it would appear that the best estimate of anticipated cost of divorce to individuals would be based on marital risk and marital quality. The relationships discussed above suggest that dissolving low risk, high quality marriages may have high costs initially, but result in high benefits to subjects. These findings may be interpreted as providing support for the argument that divorce is linked to deficits in an individual; that is, personal disorganization is not corrected by divorce. 
Alternatively, it may be that individuals find it more difficult to report marriages of long duration as being of low quality; to do so would devalue the investment they had made in the marriage. It also may be that the findings are influenced by the significantly higher ratings of quality given by men to their marriages ( $T=2.98, p<.004)$ for they also report fewer consequences and higher adjustment.

\section{Divorcing Behaviors}

Turning now to the actual behaviors reported for the divorce process, we found that, as was suggested in the comparison of the interview and initial samples (p. 68), a fair amount of conflict was experienced. Table XIV shows the distribution of scores on six variables used to measure the level of conflict in the divorce process. These variables were used to construct a scale for conflict in the divorce (p.75). As can be seen, the subjects did not deal with a large number of issues in their divorce. This may be a result of the relatively modest socio-economic status of the sample. Children aside, the sample had relatively little about which to argue. Yet argue they apparently did. The majority relied upon a lawyer in a no-fault divorce state, found their spouse not to be helpful in settling the divorce and were not wholly satisfied with the outcomes of the divorce process. All things considered, then, it is not surprising that the level of processual conflict was moderate to high for 
TABLE XIV

LEVEL OF CONFLICT IN THE DIVORCE PROCESS

\begin{tabular}{|c|c|c|}
\hline $\begin{array}{l}\text { Yes, own attorney } \\
\text { Yes, shared attorney } \\
\text { No, no legal representative }\end{array}$ & $\begin{array}{r}60 \\
6 \\
15\end{array}$ & $\begin{array}{l}(74.1) \\
(7.4) \\
(18.5)\end{array}$ \\
\hline $\begin{array}{l}\text { DISAGREEMENT OVER SETTLEMENT } \\
\text { Far apart } \\
\text { Somewhat apart } \\
\text { Not far apart }\end{array}$ & $\begin{array}{l}25 \\
19 \\
36\end{array}$ & $\begin{array}{l}(31.3) \\
(23.8) \\
(45.0)\end{array}$ \\
\hline $\begin{array}{l}\text { METHOD OF RESOLVING DISAGREEMENTS } \\
\text { Legal intervention } \\
\text { Negotiation } \\
\text { Mutual agreement }\end{array}$ & $\begin{array}{l}27 \\
22 \\
31\end{array}$ & $\begin{array}{l}(33.3) \\
(27.2) \\
(38.3)\end{array}$ \\
\hline $\begin{array}{l}\text { NUMBER OF ISSUES DEALT WITH IN DIVORCE } \\
\begin{array}{l}7-12 \\
2-6 \\
0-1\end{array}\end{array}$ & $\begin{array}{l}21 \\
19 \\
40\end{array}$ & $\begin{array}{l}(26.3) \\
(23.5) \\
(50.0)\end{array}$ \\
\hline $\begin{array}{l}\text { HELPFULNESS OF SPOUSE DURING PROCESS } \\
\text { Not helpful } \\
\text { Somewhat helpful } \\
\text { Very helpful }\end{array}$ & $\begin{array}{r}59 \\
17 \\
5\end{array}$ & $\begin{array}{l}(72.8) \\
(21.0) \\
(6.2)\end{array}$ \\
\hline $\begin{array}{l}\text { AGREEMENT WITH OUTCOME OF NEGOTIATION } \\
\text { Neither satisfied } \\
\text { One satisfied } \\
\text { Both satisfied }\end{array}$ & $\begin{array}{l}34 \\
14 \\
32\end{array}$ & $\begin{array}{l}(42.5) \\
(17.5) \\
(40.0)\end{array}$ \\
\hline
\end{tabular}


nearly two-thirds $(62.08)$ of the sample.

Being willing to "fight" during the divorce process, however, does not necessarily indicate an individual opposes the divorce and wishes to prevent it from occurring. High conflict may indicate the subject's desire to punish a spouse or an attempt to minimize the financial cost of the divorce. Thus, we sought also to measure the emotional reaction of subjects to the divorce, independently and in combination with conflict. The results are shown in Table XV. Distribution for the reaction variable was very similar to that for processual conflict and the two exhibited a moderately high correlation $(\mathrm{r}=.38, \mathrm{p}<.0005)$.

When the two were added together to compute a divorce experience score we saw some shifting in the categories. Those reacting negatively and reporting high conflict with the divorce process (17.78) might be said to be resisting the divorce. The ambivalent/moderate group included those whose feelings and behaviors did not match completely $(49.48)$. For this group benefits did not clearly outweigh costs. It included those who wanted the divorce, but felt the costs were higher than they needed be and those who were willing to dissolve the marriage but only after extracting additional benefits for themsalves. The third group was made up of individuals who viewed the divorce positively and were able or willing to avoid conflict over their marital dissolution (3l.68). This avoidance was 
TABLE XV

SUBJECT DIVORCE EXPERIENCE BASED ON REACTION TO DIVORCE AND CONFLICT EXHIBITED DURING THE DIVORCE PROCESS

$\begin{array}{lll}\text { REACTION TO DIVORCE } & & \\ \text { Negative } & 26 & (32.5) \\ \text { Ambivalent (mixed) } & 27 & (33.8) \\ \text { Positive } & 27 & (33.8) \\ \text { PROCESSUAL CONFLICT } & & \\ \text { LOW } & 30 & (38.0) \\ \text { MOderate } & 26 & (32.9) \\ \text { High } & 23 & (29.1) \\ \text { DIVORCE EXPERIENCE } & & \\ \text { Negative/high } & 14 & (17.7) \\ \text { Ambivalent/moderate } & 39 & (49.4) \\ \text { Positive/low } & 25 & (31.6)\end{array}$


based on either spousal concurrence in the decision to divorce or upon a willingness to pay any cost to get out of the marriage.

In looking at the relationships between divorce experience and the personal characteristics of subjects we found mixed results. Individuals who scored highly on the marital history, fertility and residential stability scales were significantly more likely, at the .02 level, to report a negative divorce experience, while those who scored lower were more likely to report a positive experience. This is in line with findings for younger populations which associate these personal characteristics with probability of divorce. Females also were more likely to report a negative divorce experience $\left(x^{2}=9.8,4\right.$ df, $p(.008)$. Somewhat surprisingly, no significant relationship was found between employment stability, occupational status, educational level, religious affiliation and health status, although individuals in poor health tended to be less positive about the divorce.

The mixed results are evident in the correlations which exist between divorce experience and the three scales - life stress $(r=.01)$, marital quality $(r=.38)$, and marital risk $(r=-.38)$ - developed to explain variance in response to divorce. Virtually no differences were found in the distribution of responses for the life stress scale $\left(x^{2}=0.86,4\right.$ df, n.s.). This finding provides additional support for the argument we made previously that stressful 
life events would not appear to help identify individuals for whom divorce would be a negative experience.

Those individuals with low quality marriages clearly were more ambivalent about their divorce experience than those with high or moderate quality marriages. Since the data indicated that low quality marriages also were longer in duration and that more time had been spent contemplating divorce, we might argue that the ambivalence grew more out of a desire to reduce the costs associated with divorce than a desire to avoid it. Overall, however, the data suggested a general lack of enthusiasm for divorce among the subjects, particularly among those with the fewest resources with which to offset its cost.

The high cost of divorce was particularly evident among those who reported it a negative experience. With the exception of legal consequences, individuals who had a negative divorce experience reported higher consequences. The inverse pattern reported for legal consequences may be reflecting a willingness on the part of some subjects to "pay something to get something." such subjects endured a lengthy process, took responsibility for the legal fees and accepted the settlement received with nary a murmur. This passivity may have been generated by the desertion of a spouse or through fear of even greater negative consequences if a battle was waged.

No significant differences were found between the "cause" of divorce or the way in which individuals coped 
with the problems generated by the divorce and the type of divorce experience. However, nearly all of the individuals who reported using emotional discharge as the method by which they resolved their problems also reported a negative divorce experience. Further, those with negative divorce experiences also reported less successful resolution of their problems $\left(x^{2}=10.0,4 \mathrm{df}, \mathrm{p}<.04\right)$ and higher levels of stress $\left(x^{2}=16.3,4 \mathrm{df}, \mathrm{p}<.003\right)$. Thus, the strong association between adjustment and divorce experience is not surprising $\left(x^{2}=19.9,4 d f, p<.0005\right)$.

We were left with the conclusion that, at best, the relationship between the personal and marital characteristics and divorce experience was clouded. However, one's attitude about the divorce and the approach taken to dissolve the marriage (i.e., the amount of conflict in the divorce process) were strongly associated with the consequences experienced and adjustment subsequent to the divorce action.

\section{CONSEQUENCES OF LATE LIFE DIVORCE}

Divorce generally is recognized as a solution to marital problems, yet it can create as many or more problems as are resolved. The impact of these problens can be so great as to negate whatever positive consequences devolve from divorce, particularly when individuals approach the termination of their marriage with negative or ambivalent feelings. Even individuals who initially 
perceive the divorce as having a positive impact can suffer sufficiently negative consequences to alter positive feelings. In Table XVI, the distribution of scores on seven scales measuring the impact of divorce on our sample is shown. With the exception of economic consequences, for which the majority of subjects reported moderate "real costs," scores are distributed evenly across all three categories.13 when the scores were added to create an overall real cost we found a slight shift which resulted in fewer subjects scoring in the high consequence range. Nevertheless, approximately two-thirds (67.88) of the subjects scored in the range indicating consequences which were at least moderately severe.

\section{Correlations Between Types of Consequences Experienced}

In analyzing the relationships between the consequence scales we found several interesting results. First, we found that social, economic and psychological consequences were positively correlated with one another (see p.75 for items used to construct scales). The legal consequences scale, however, was correlated negatively with the other three consequences scales. This suggests that incurring high legal costs reduces the consequences experienced in other areas. Such a relationship appears to fly in the face of conventional wisdom. To score high on the legal consequence scale the subject likely would have had a lengthy trial, borne high legal costs, have had 
CONSEQUENCES OF DIVORCE IN A SAMPLE OF 81 DIVORCING OLDER PERSONS

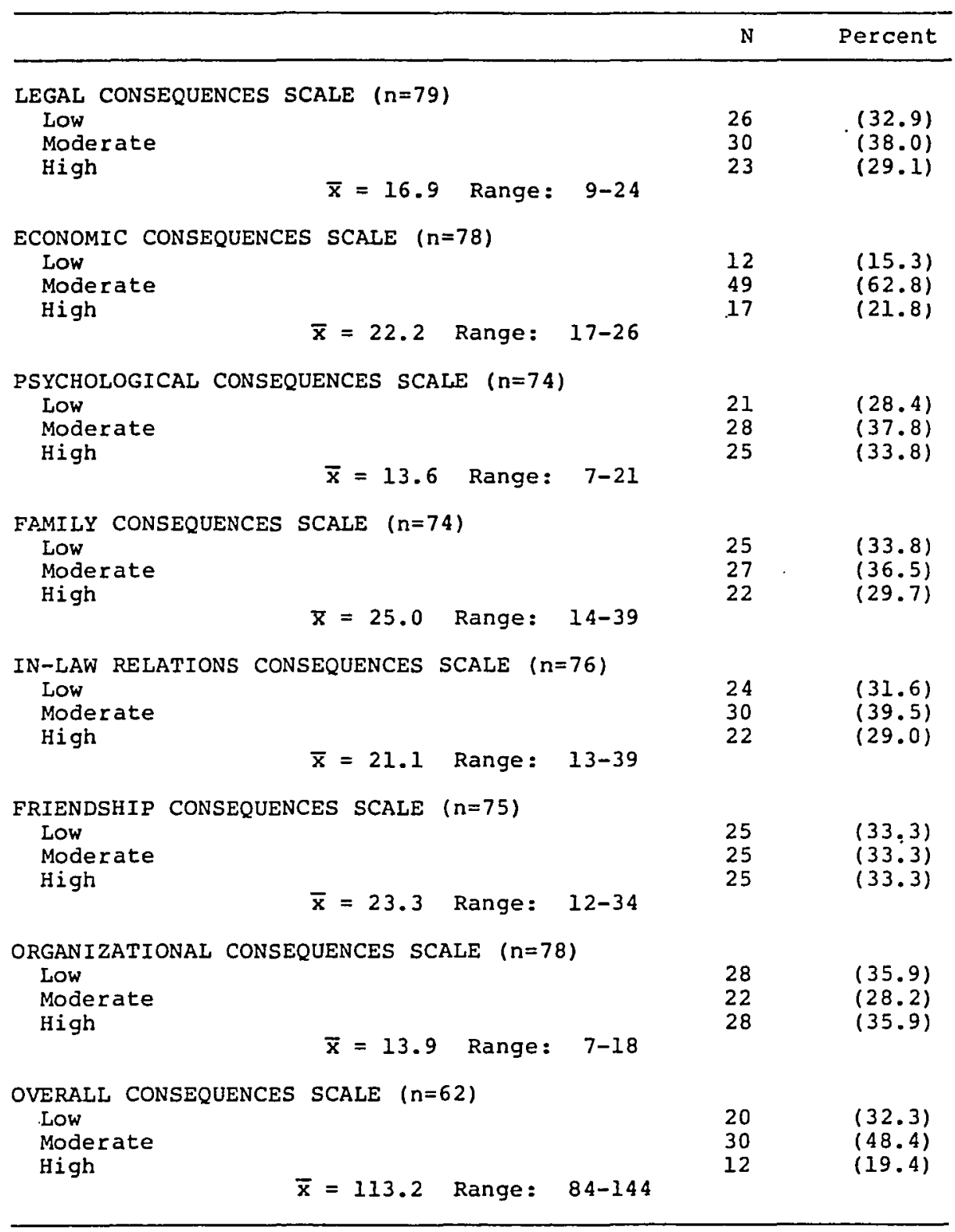


post-decree problems requiring legal assistance and perceived the judicial process to have been unfair.

Our assumption initially was that a divorce with high legal consequences would generate additional intergenerational and intra-familial conflict, increase the financial costs and heighten psychological consequences for subjects. Instead, we found that legal consequences were greatest in marriages of shorter duration $\left(x^{2}=16.1,4 \mathrm{df}\right.$, $p<.003)$ and when preparatory time had been shorter $\left(x^{2}=\right.$ 9.9, $4 \mathrm{df}, \mathrm{p}<.04)$. Subjects with high legal consequences are significantly more likely to report high levels of processual conflict $\left(x^{2}=52.2,4 \mathrm{df}, \mathrm{p}<.0001\right)$ and have somewhat more negative feelings about the divorce, but they typically had shorter periods of time between filing and decree $\left(x^{2}=22.7,4 \mathrm{df}, \mathrm{p}<.0001\right)$ and a shorter adjustment period overall $\left(\mathrm{x}^{2}=10.8,4 \mathrm{df}, \mathrm{p}<.03\right)$. Further, legal consequences were not associated with problem resolution or psychiatric distress. These trends appear as contravening those found for psychological and social consequences in particular.

Psyhological and social consequences showed a definite pattern. Both were associated significantly with problem resolution and psychiatric symptoms at the .001 level or higher. The findings indicated that low consequences in these areas were associated with higher levels of post-decree adjustment. High psychological consequences also were associated with higher levels of 
processual conflict $\left(x^{2}=26.9,4 \mathrm{df}, \mathrm{p}<.0001\right)$ and more negative feelings about the divorce $\left(\mathrm{x}^{2}=48.8,4 \mathrm{df}, \mathrm{p}<\right.$ $.0001)$. Although not significantly associated with these variables, the same trends were found for economic consequences. Thus it would appear in this sample that legal consequences represented a dimension of real cost which ran counter to that of social, psychological and economic costs. Again, we are left with the impression that enduring high legal consequences may in some sense enable subjects to externalize some of the costs, hence make them feel better about the divorce in general.

\section{coping Strategies Used for Problem Resolution}

How subjects coped with the consequences or the problems generated by the divorce also was an issue of central concern. Pearlin and schooler (1978) have argued, along with many others, that some coping strategies are more effective in resolving problems than others. In looking at Table XVII, we can see that, for the most part, subjects preferred to ignore selectively their problems. This may be translated to mean either that only time could solve their problems or that no solution at all was possible. subjects also relied heavily upon themselves, not only to resolve practical problems such as getting a job, but to deflect the emotional and social consequences of the divorce. Self-reliant subjects typically perceived very specific activities as being the means by which 
TABLE XVII

COPING STRATEGIES IN A SAMPLE OF 81 DIVORCING OLDER PERSONS

\begin{tabular}{|c|c|c|c|c|c|c|}
\hline & Only & Strategy Used & Primary & Strategy Used & \multicolumn{2}{|c|}{ Strategies Used } \\
\hline & $\mathrm{N}$ & Percent & $\mathrm{N}$ & Percent & $\mathrm{N}$ & Percent \\
\hline Emotional Discharge & 2 & $(2.5)$ & 8 & $(9.9)$ & 10 & $(12.4)$ \\
\hline Selective Ignoring & 32 & $(39.5)$ & 39 & $(48.2)$ & 57 & $(70.4)$ \\
\hline Positive Comparisons & 3 & $(3.7)$ & 6 & $(7.4)$ & 7 & $(8.6)$ \\
\hline Self Reliance & 16 & $(19.8)$ & 28 & $(34.6)$ & 36 & $(44.4)$ \\
\hline
\end{tabular}


problems could be mediated.

Interestingly, few subjects used emotionalism or rationalism to deal with their problems. This may be, in part, explained by the ambivalence many subjects felt about getting a divorce. Clearly, it would be difficult to wax enthusiastically about a wonderful life after divorce if one's circumstances did not support such a view. Conversely, to vent would be inappropriate if one did not feel strongly about the marriage, nor did not suffer many consequences as a result of its dissolution.

The type of coping strategy used was not found to be associated significantly with 30 other characteristics tested. It was not related to sex, filing status, health, marital history, nor indicators of socio-economic status. Additionally, length of marriage, cause of divorce, time factors and amount of conflict were not associated with the type of coping strategy used. The lack of an association with time factors indicated that those who selectively ignore their problems did not equate the passage of time alone as a measure of resolution.

Analysis of the relationships between how subjects coped with consequences and how successful they were in resolving their problems indicates that, in general, those subjects who ignored them fare better $\left(\mathrm{x}^{2}=11.9,6 \mathrm{df}, \mathrm{p}<\right.$ .04). It is not particularly surprising that ignoring a problem resulted in higher resolution; denial was a very effective means in many instances of dealing with stress. 
Those selectively ignoring their problems also had higher adjustment scores. However, some portion of this phenomenon may be explained by the more positive divorce experience reported by subjects who used selective ignoring strategies to resolve problems. That is, for example, if their divorce was less conflicted emotionally and legally, subjects potentially would have fewer problems of less consequence to resolve.

\section{FACTORS INFLUENCING ADJUSTMENT SUBSEQUENT TO DIVORCE}

The ability to resolve problems and avoid stress generated by the divorce act as the measure of adjustment in this study. Thus, the type of consequences experienced and the means by which problems are addressed constituted another area of interest. Beyond that, however, we wanted some notion of how well subjects appeared to have adjusted subsequent to their divorce. Table XVIII shows that 50 to 60 percent of the subjects displayed few symptoms indicative of psychiatric distress and reported a high degree of problem resolution; thus, the overall post divorce adjustment of the majority of subjects also was high.

There were some differences of interest. While problem resolution skills and the level of stress displayed by subjects were positively correlated ( $\mathrm{r}=.27, \mathrm{p}<.009)$, significant associations found for one did not always hold true for the other. For example, reduced stress was 
TABLE XVIII

ADJUSTMENT IN A SAMPLE OF 81 DIVORCING OLDER PERSONS

\begin{tabular}{lcccccc}
\hline & Stress & Displayed & Degree Problem Resolution & Overall Adjustment \\
\hline & $\mathrm{N}$ & Percent & $\mathrm{N}$ & Percent & $\mathrm{N}$ & Percent \\
Low & 50 & $(61.7)$ & 9 & $(11.4)$ & 10 & $(12.7)$ \\
Moderate & 16 & $(19.8)$ & 22 & $(27.8)$ & 30 & $(38.0)$ \\
High & 15 & $(18.5)$ & 48 & $(60.8)$ & 39 & $(49.4)$ \\
\hline
\end{tabular}


associated at the .01 level with both high marital quality and low marital risk; problem resolution had no such relationship. Both were, however, strongly correlated with the type of divorce experience and resulting consequences $(p<.01)$. Subjects who had negative divorce experiences and suffered high consequences were less likely to resolve their problems and were more likely to exhibit symptoms of stress.

Looking at personal characteristics in conjunction with adjustment, we found that sex, health, and fertility were associated significantly with post divorce adjustment. Marital history, religious affiliation, residential and economic stability were not associated with adjustment. These findings suggest that being male $(T=4.7, p<$ $.0001)$, having good health $(r=.31, p<.003)$ and children $(\mathrm{r}=.34, \mathrm{p}<.003)$ were characteristic of subjects exhibiting higher levels of post divorce adjustment. subjects with these characteristics appeared better equipped to resolve problems and avoid stress. The importance of a support system inherent in children, of health as an intervening variable and of a socialization process which apparently better prepares men to cope with a stressful personal event was evident in these characteristics.

We already have indicated that those who experienced a negative divorce experience and higher consequences would exhibit lower post divorce adjustment. This was, in fact, 
the case. Both negative feelings $\left(x^{2}=16.9,4 d f, p<\right.$ $.002)$ and a conflictive divorce process $\left(x^{2}=18.1,4 \mathrm{df}, \mathrm{p}\right.$ <.001) resulted in lower adjustment. The level of dissent, method of conflict and agreement on the outcome of the process also were significantly associated at the .05 level with adjustment.

The relationship between adjustment and consequences was more mixed. Predictably, those who experienced low psychological consequences were far more likely to score higher on adjustment $\left(x^{2}=30.3,4 \mathrm{df}, \mathrm{p}<.0001\right)$. These subjects were more optimistic about the future, more positive about marriage and more likely to have established a satisfying heterosexual relationship. Perceived economic consequences also were lower for individuals with higher adjustment. Subjects with higher adjustment generally felt they had lost less in the divorce.

Social relations, however, did not show a clear pattern. Those reporting high negative consequences in friendship networks $\left(x^{2}=11.0,4 \mathrm{df}, \mathrm{p}<.03\right)$ and in organizational involvement $\left(x^{2}=11.9,4 \mathrm{df}, \mathrm{p}<.01\right)$ also reported lower adjustment. No significant relationship emerged from relations with blood anc in-law relatives, although the trend was similar. But perhaps the larger surprise was that high legal consequences are associated with high post divorce adjustment $\left(\mathrm{x}^{2}=9.6,4 \mathrm{df}, \mathrm{p}<\right.$ .05). While we had seen evidence previously in our analysis which suggested this relationship, this finding 
again tends to suggest that high legal consequences generated a means by which blame for the divorce and its outcomes can be shifted. This allocation may allow the individual to feel better about the divorce and hence have higher post divorce adjustment.

\section{DIVORCE IN TWO STAGES OF THE LIFE CYCLE}

A primary thrust of this study was to determine the role age plays in divorce. We have noted from our review of the literature that age had not emerged as a critical variable in prior studies. This lack of emergence, we argued, might have been the result of sampling and study designs. Thus, we formulated two hypotheses to test with a sample of individuals who were party to a divorce action in mid and late life.

Hypothesis 1 was directed to a comparison of marital dissolution between individuals of pre-retirement and post-retirement stages of the life cycle. The hypothesis was :

$$
\begin{aligned}
\mathrm{H}_{I}: & \text { The personal characteristics, causes, } \\
& \text { divorce process and consequences for those } \\
& \text { experiencing divorce after age } 60 \text { will } \\
& \text { differ significantly from those who dissolve } \\
& \text { their marriages before age } 60 .
\end{aligned}
$$

To test Hypothesis 1 , the sample was divided into two groups. Approximately 27 percent of the sample was under age 60, ranging in age from 41 to 59; those over age 60 (72.88) ranged in age from 61 to 78 . Chi square and independent samples $t$-tests were conducted first to 
determine whether there were any significant differences between the two age groups. These tests were conducted on variables related to personal characteristics, cause of divorce, type of divorce experience and consequences of divorce.

\section{Personal Characteristics of Divorcing Individuals of Pre and post Retirement Age}

Looking first at personal characteristics shown in Table XIX, we found significant differences for three of the nine variables. Individuals less than 60 years of age were significantly more likely to be female, to have managerial or professional occupations and to have a higher score on the fertility scale. These results were not totally unexpected. The preponderance of females under age 60 was expected given the method of sampling which dictated selection of a divorce action in which either party was over age 60 and a cultural preference for brides to be somewhat younger than their mates. Occupational status distributions which show increased numbers of white collar workers is a trend noted in younger divorcing populations over the past 10 years or so. We would expect this trend to be more evident in the under 60 population, particularly given the influence of the working female in this group. Differences in fertility rates are reflective of the role the under age 60 group played in the production of a "baby boom." Conversely, those over age 60 were more likely to experience parenthood during a period when fertility rates 
TABLE XIX

COMPARISONS OF PERSONAL CHARACTERISTICS OF SAMPLE SUBJECTS IN TWO STAGES OF THE LIFE CYCLE

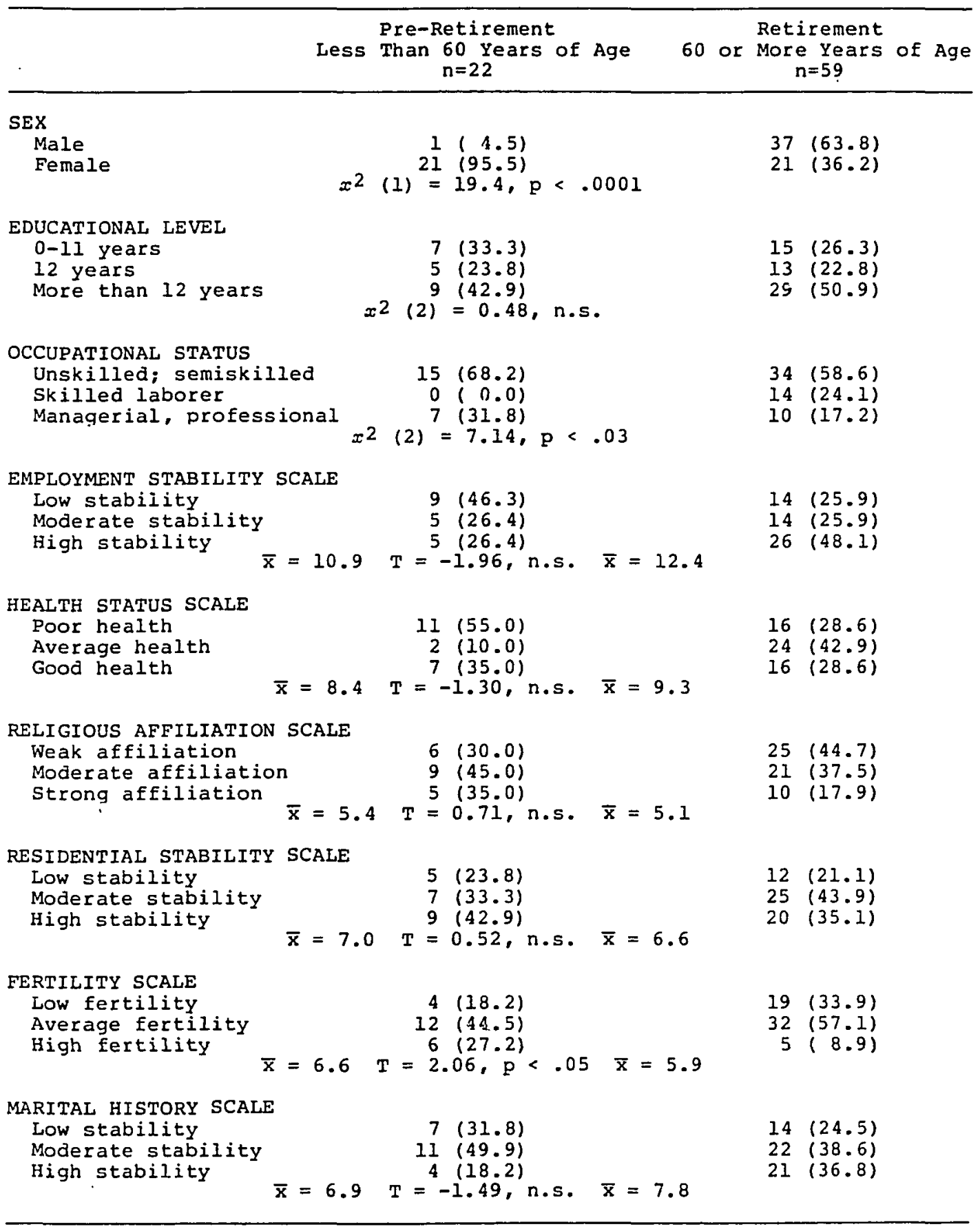


were lower for the general population.

The Divorce Process for Individuals of Pre and Post Retirement Age

No differences emerge when we look at characteristics of the divorce itself. We found that none of the eight variables tested show any significant differences between the two age groups (Table $\mathrm{Xx}$ ). Those over age 60 were, however, somewhat more likely to identify life stress and premarital factors as causing their divorce. The role premarital factors played may be the result of a second marriage which subjects felt was entered into too quickly after a previous divorce or widowhood. We had expected life stress to play an even more significant role in late Iife divorce than it appeared to have for our subjects.

Although not shown in the table, t-tests computed for the marital risk, marital quality and life stress scales also indicated no significant differences between those over age 60 and those under age 60. Thus, according to our proposed method of anticipating the cost of divorce to individuals, the reaction of both groups to the divorce should have been similar. This was, in fact, the case, although those under age 60 were somewhat more likely to have had a negative divorce experience. This is accounted for largely by the dominance of females in the under 60 age group who were significantly more likely to report a highly conflicted divorce process than were males $(T=2.07, P<$ $.04)$. 
TABLE $X X$

COMPARISONS OF DIVORCE CHARACTERISTICS OF SAMPLE SUBJECTS IN TWO STAGES OF THE LIFE CYCLE

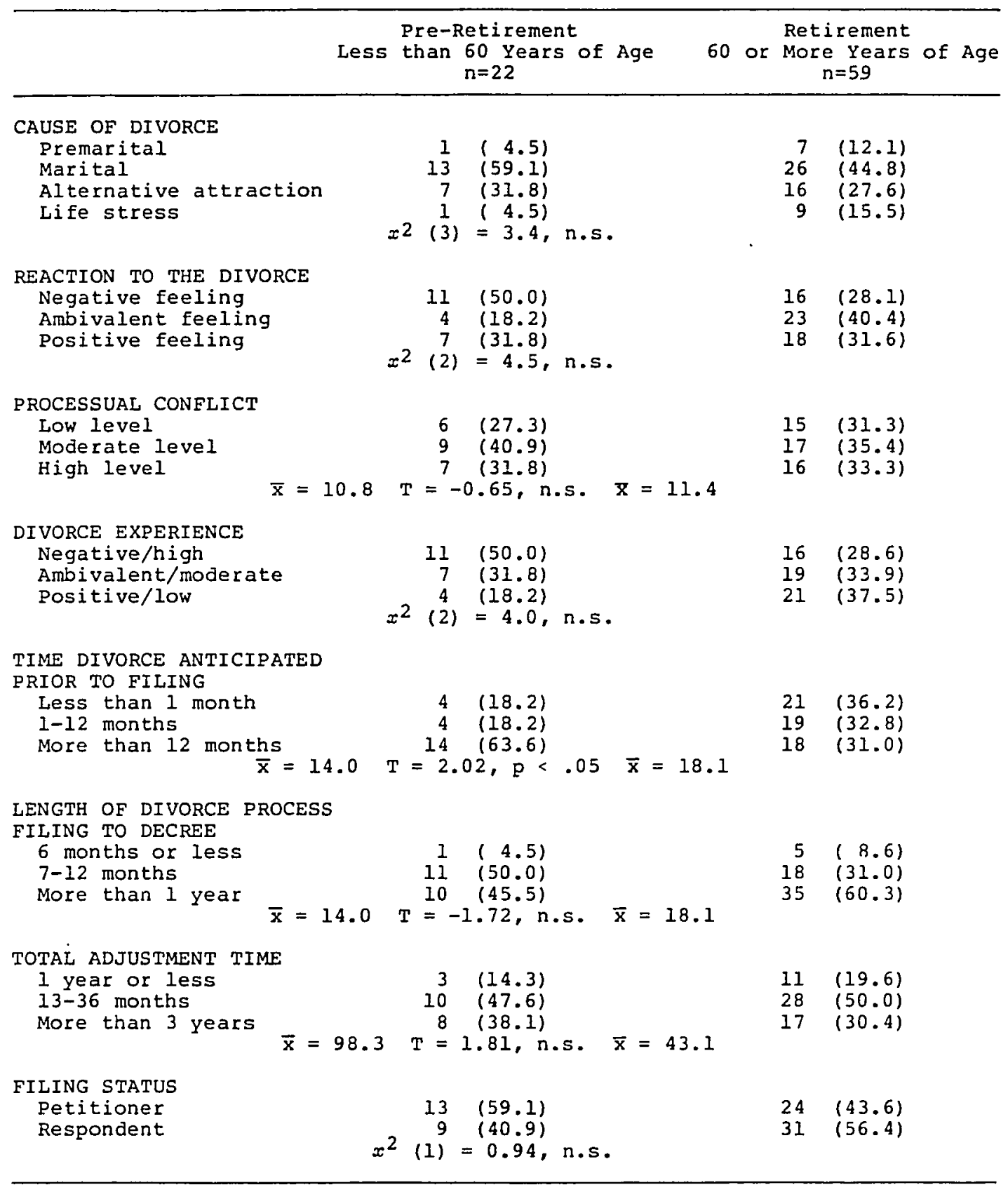


The longer anticipatory time for individuals under age 60 was somewhat surprising, given that the two age groups showed no significant differences in the degree of marital instability or in length of marriage. Again we found that sex was a factor; females reportedly thought about divorce twice as long as did men (55 months v. 26 monins). Interestingly, this sex difference did not show up in the filing status, where males were just as likely to file for divorce as were females. This is in contrast to findings for younger divorcing populations where females are still more likely to file. Further, it may lend some support to arguments made by Leonard (1980) and others that no-fault divorce works against older women.

\section{Conseguences of Divorce for Individuals of Pre and Post} Retirement Age

of the eight tests performed to determine whether age and consequences were associated, none was significant. Indeed, the mean scores for both groups of subjects were relatively close (Table XXI). We did find, however, that the under 60 group typically had higher consequence scores. Again, this is due, partially, to the gender of the pre-retirement group. Females reported higher psychological $(T=3.01, p<.004)$ and organizational activity $(\mathrm{T}=2.15, \mathrm{p}<.04)$ consequences. Overall, females scored an average of ten points higher on consequences they reportedly experienced as a result of the divorce $(T=3.21, \mathrm{p}<.002)$. 
TABLE XXI

COMPARISONS OF CONSEQUENCES EXPERIENCED BY SAMPLE SUBJECTS IN TWO STAGES OF THE L.IFE CYCLE

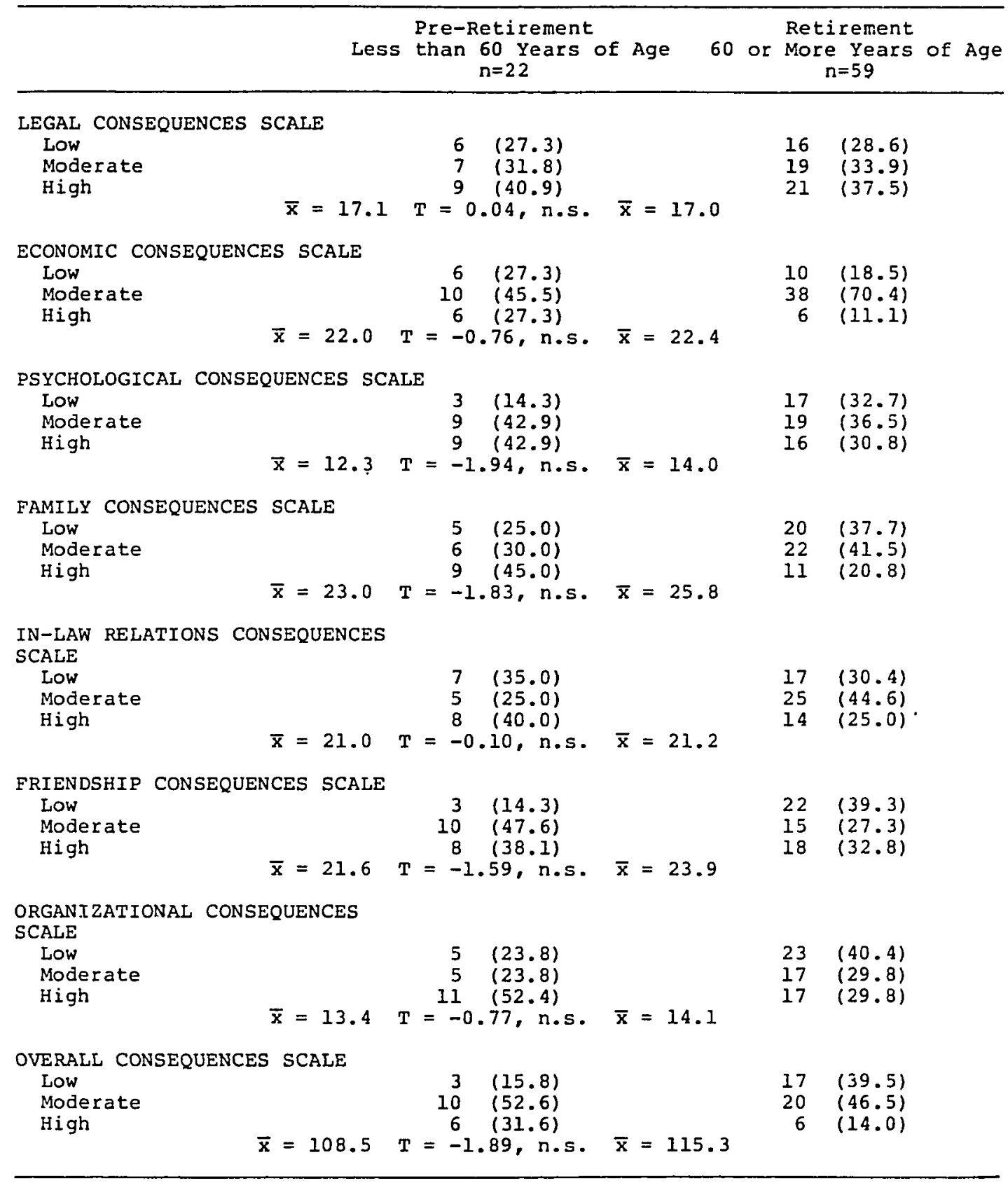


We did find differences between the pre-retirement and the retirement groups on adjustment variables. Those under 60 years of age were more likely to use emotional discharge as their primary means of coping with the consequences of their divorce and were more likely not to be successful in resolving their problems (Table XXII). Further, they were significantly more likely to exhibit psychiatric symptoms associated with stress subsequent to the divorce and to have lower levels of post divorce adjustment. Again, this is at least partially a function of gender. Females were half as successful in resolving their problems $(T=4.00, \mathrm{p}<.001)$, twice as likely to display symptoms of psychiatric distress $(T=3.13, p<$ .005), and thus scored much lower on post divorce adjustment $(T=-4.68, p<.001)$. Given that the under 60 group included only one male, we must conclude that the differences we saw may be a matter of gender differences. In sum, we failed to reject Hypothesis 1 : sex would appear to explain most of the differences found in the personal characteristics, causes, divorce process and consequences of divorcing individuals in the pre and post retirement stages of the life cycle.

\section{DIVORCE IN TWO BIRTH COHORTS}

Our second hypothesis was designed to compare marital dissolution in two birth cohorts. The cohorts, as described in Chapter III, were selected to determine 
TABLE XXII

COMPARISONS OF ADJUSTMENT OF SAMPLE SUBJECTS

IN TWO STAGES OF THE LIFE CYCLE

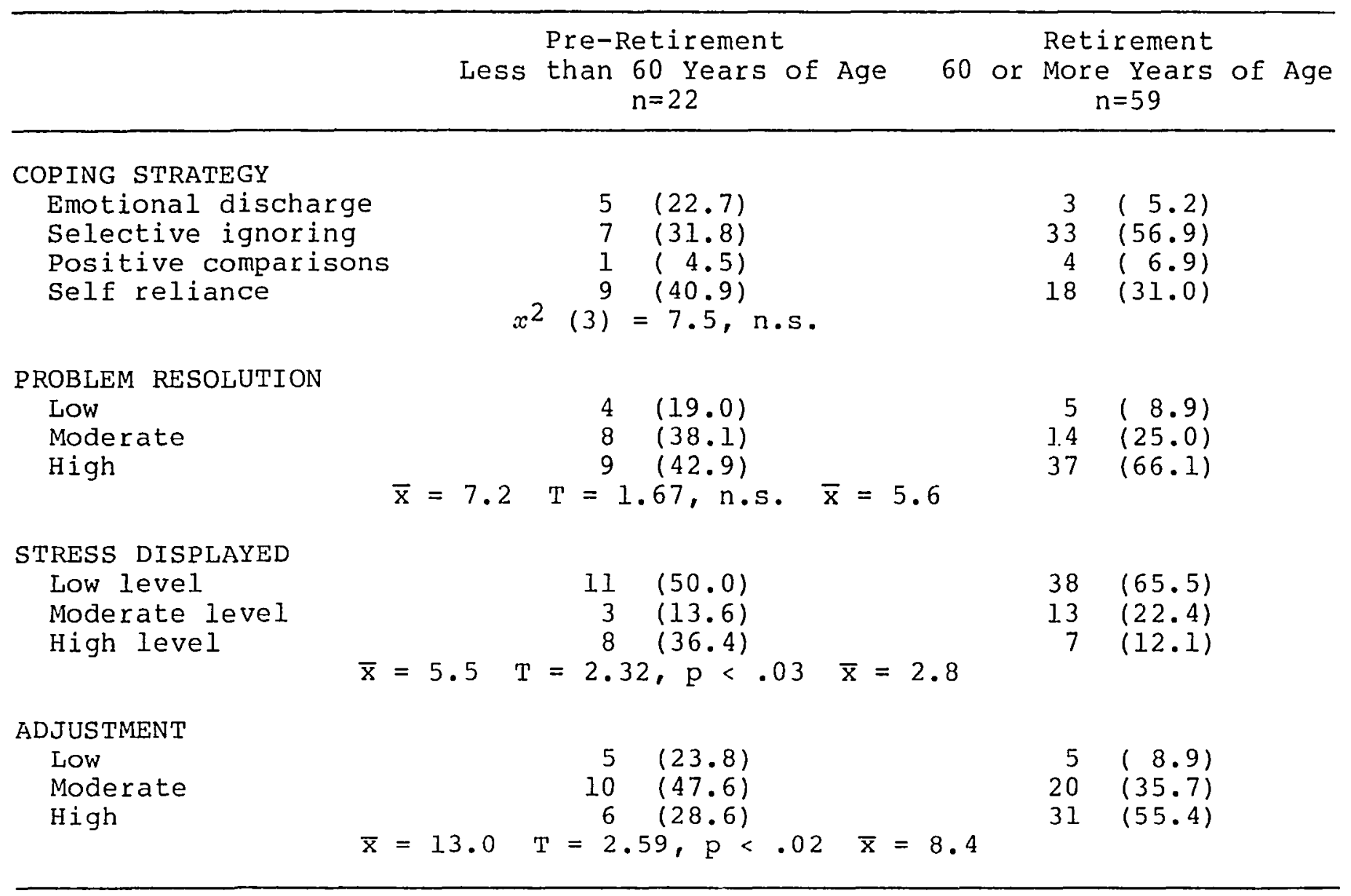


whether coming to adulthood in the "Great Depression" versus the "War Years" would be associated with the characteristics of individuals experiencing a late life divorce. Hypothesis 2 was:

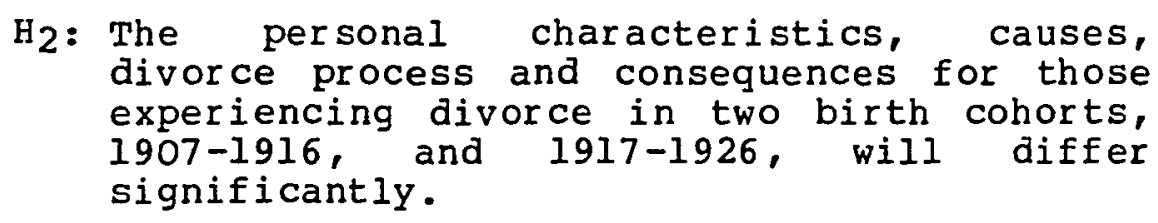

To test Hypothesis 2, the sample was divided into two groups representing the two birth cohorts. Slightly more than one-third $(37.58)$ of the group were in the "Great Depression" cohort, born between 1907 and 1916; the balance (62.5\%) represented the "War Years" cohort, born between 1917 and 1926. Chi square and independent samples t-tests were conducted to test for dirferences between the two cohorts. The same variables, personal characteristics, cause of divorce, type of divorce experienced and consequerces, used to test Hypothesis 1 were used to test Hypothesis 2 .

\section{Characteristics of Divorcing Individuals in Twe Birth Cohorts}

As can be seen in Table XXIII, there was no significant difference in the distribution of males and females in the two birth cohorts. Given the importance sex was found to play in explaining differences found for the pre-retirement (under 60) and retirement (60 and over) groups, this lack of significance is important. We still 
TABLE XXIII

COMPARISONS OF PERSONAL CHARACTERISTICS OF SAMPLE SUBJECTS IN TWO BIRTH COHORTS

\begin{tabular}{|c|c|c|}
\hline $\begin{array}{c}1907-1916 \\
n=27\end{array}$ & & $\begin{array}{l}17-1926 \\
n=45\end{array}$ \\
\hline \multicolumn{3}{|l|}{ SEX } \\
\hline $\begin{array}{r}17(63.0) \\
10(37.0)\end{array}$ & $\begin{array}{l}21 \\
24\end{array}$ & $\begin{array}{l}(46.7) \\
(53.3)\end{array}$ \\
\hline $\begin{array}{l}\text { EDUCATIONAL LEVEL } \\
\begin{array}{l}0-11 \text { years } \\
12 \text { years }\end{array} \\
\begin{array}{l}\text { More than } 12 \text { years } \\
x^{2}(2)=3.97, \text { n.s. }\end{array}\end{array}$ & $\begin{array}{r}8 \\
10 \\
26\end{array}$ & $\begin{array}{l}(17.8) \\
(22.2) \\
(57.8)\end{array}$ \\
\hline $\begin{array}{l}\text { OCCUPATIONAL STATUS } \\
\text { Unskilled, semiskilled } \\
\text { Skilled labor } \\
\begin{array}{r}12(44.4) \\
9(33.3) \\
\text { Managerial, professional } \\
x^{2}(2)=7.0, \mathrm{p}<.03\end{array}\end{array}$ & $\begin{array}{r}33 \\
5 \\
7\end{array}$ & $\begin{array}{l}(73.3) \\
(11.1) \\
(15.6)\end{array}$ \\
\hline $\begin{array}{lr}\begin{array}{l}\text { EMPLOYMENT STABILITY SCALE } \\
\text { LOW }\end{array} & 7(30.4) \\
\text { Moderate } & 8(34.8) \\
\text { High } & 8(34.8) \\
& \mathrm{x}=12.2 \quad \mathrm{~T}=0.51, \mathrm{n} . \mathrm{s} \cdot \mathrm{x}=12.5\end{array}$ & $\begin{array}{r}9 \\
10 \\
23\end{array}$ & $\begin{array}{l}(21.4) \\
(23.8) \\
(54.8)\end{array}$ \\
\hline 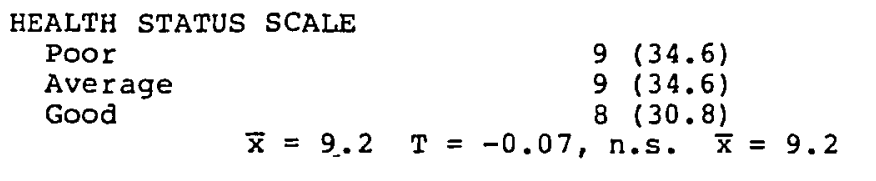 & $\begin{array}{l}12 \\
17 \\
13\end{array}$ & $\begin{array}{l}(28.6) \\
(40.5) \\
(31.0)\end{array}$ \\
\hline 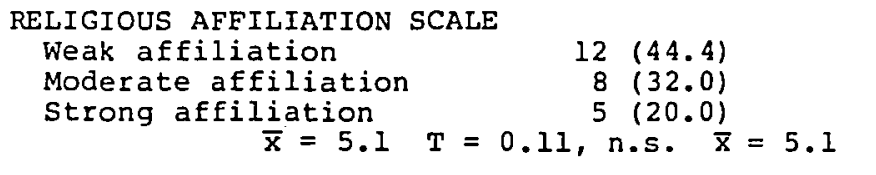 & $\begin{array}{r}18 \\
18 \\
8\end{array}$ & $\begin{array}{l}(40.9) \\
(40.9) \\
(18.2)\end{array}$ \\
\hline 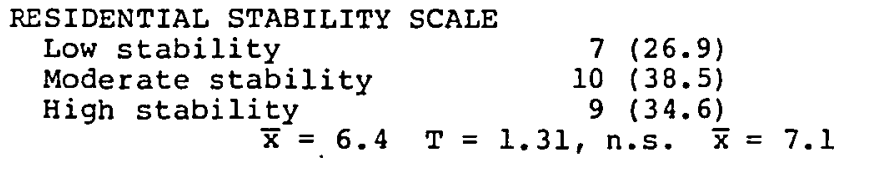 & $\begin{array}{r}6 \\
19 \\
17\end{array}$ & $\begin{array}{l}(14.3) \\
(45.2) \\
(40.2)\end{array}$ \\
\hline 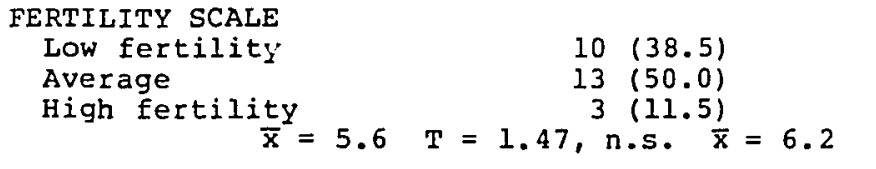 & $\begin{array}{r}13 \\
25 \\
6\end{array}$ & $\begin{array}{l}(29.5) \\
(56.8) \\
(13.6)\end{array}$ \\
\hline $\begin{array}{l}\text { MARITAL HISTORY SCALE } \\
\text { LOW stability } \\
\text { Moderate stability } \\
\text { High stability } \\
\qquad \bar{x}=7.7\end{array}$ & $\begin{array}{l}12 \\
15 \\
17\end{array}$ & $\begin{array}{l}(27.3) \\
(34.1) \\
(38.6)\end{array}$ \\
\hline
\end{tabular}


found, however, a significant difference in occupational status for the two groups. Indeed, the percentage of subjects occupying the lower occupational status category actually increased for the younger of the two groups. Despite the lack of a significant difference in the distribution of males and females, sex may account for some of the difference. There were proportionately more females in the younger cohort (55-64 years) than in the older cohort $(65+)$. As females, they were part of a birth cohort which emphasized a role of wife and mother not employed outside of the home. While not significant, another trend consistent with other findings was evident; the older cohort was somewhat more likely to have less than a high school education. None of the other characteristics related to cause, the divorce process or consequences which were tested showed differences. Those over 65 were slightly more likely to identify life stress as the cause of their divorce and to report a more rapid divorce (Table XXIV). Further, in general, they reported slightly lower consequences (Table XXV). Finally, those over age 65 were not quite as succesful in resolving their problems and were less likely to have a high level of adjustment (Table XXVI). In spite of these suggestive findings, Hypothesis 2 was not supported.

ANTICIPATED COST AND THE TYPE OF DIVORCE EXPERIENCE

Next we turn our attention to testing the 
TABLE XXIV

COMPARISONS OF DIVORCE CHARACTERISTICS OF SAMPLE SUBJECTS IN TWO BIRTH COHORTS

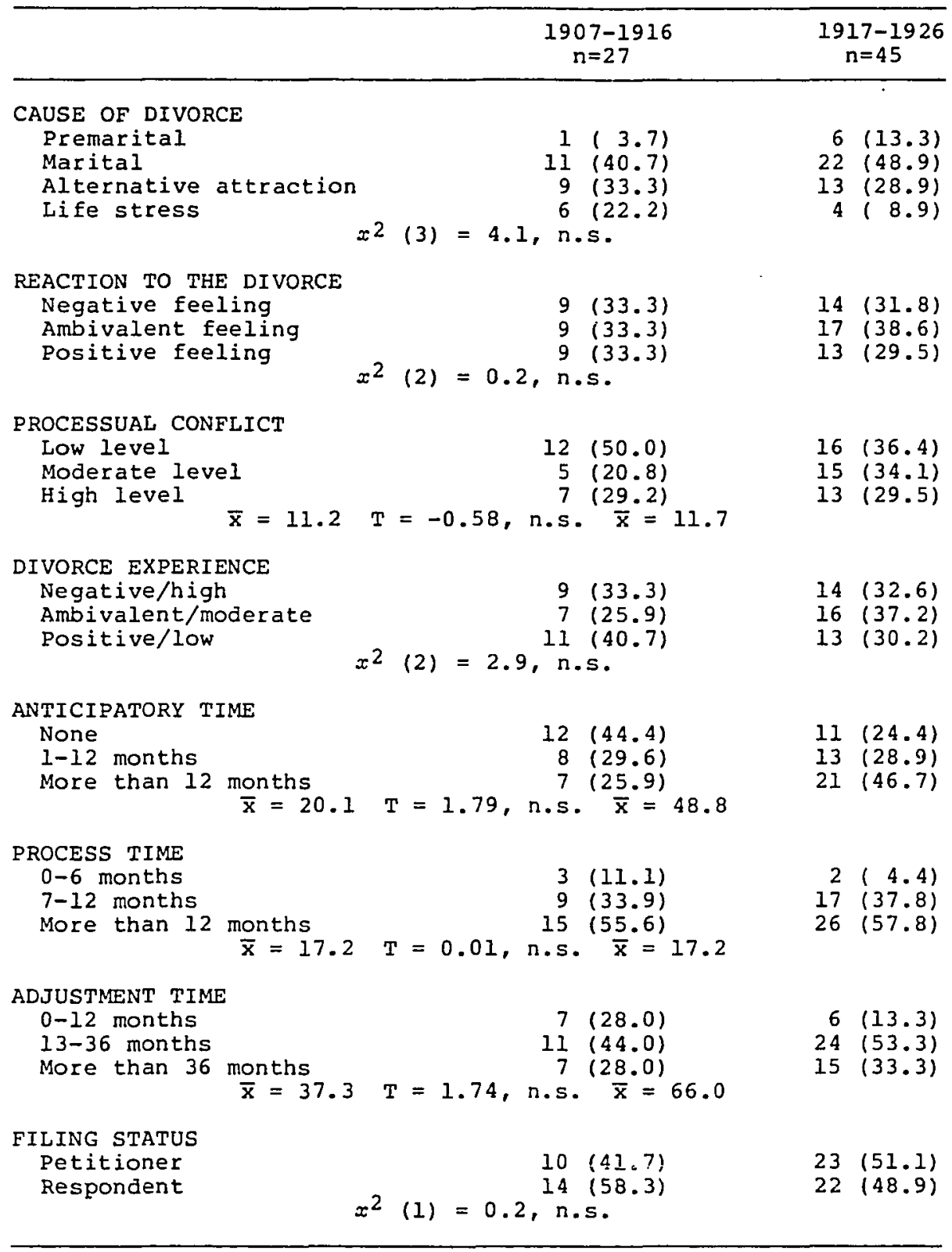


TABLE XXV

COMPARISONS OF CONSEQUENCES EXPERIENCED BY SAMPLE SUBJECTS IN TWO BIRTH COHORTS

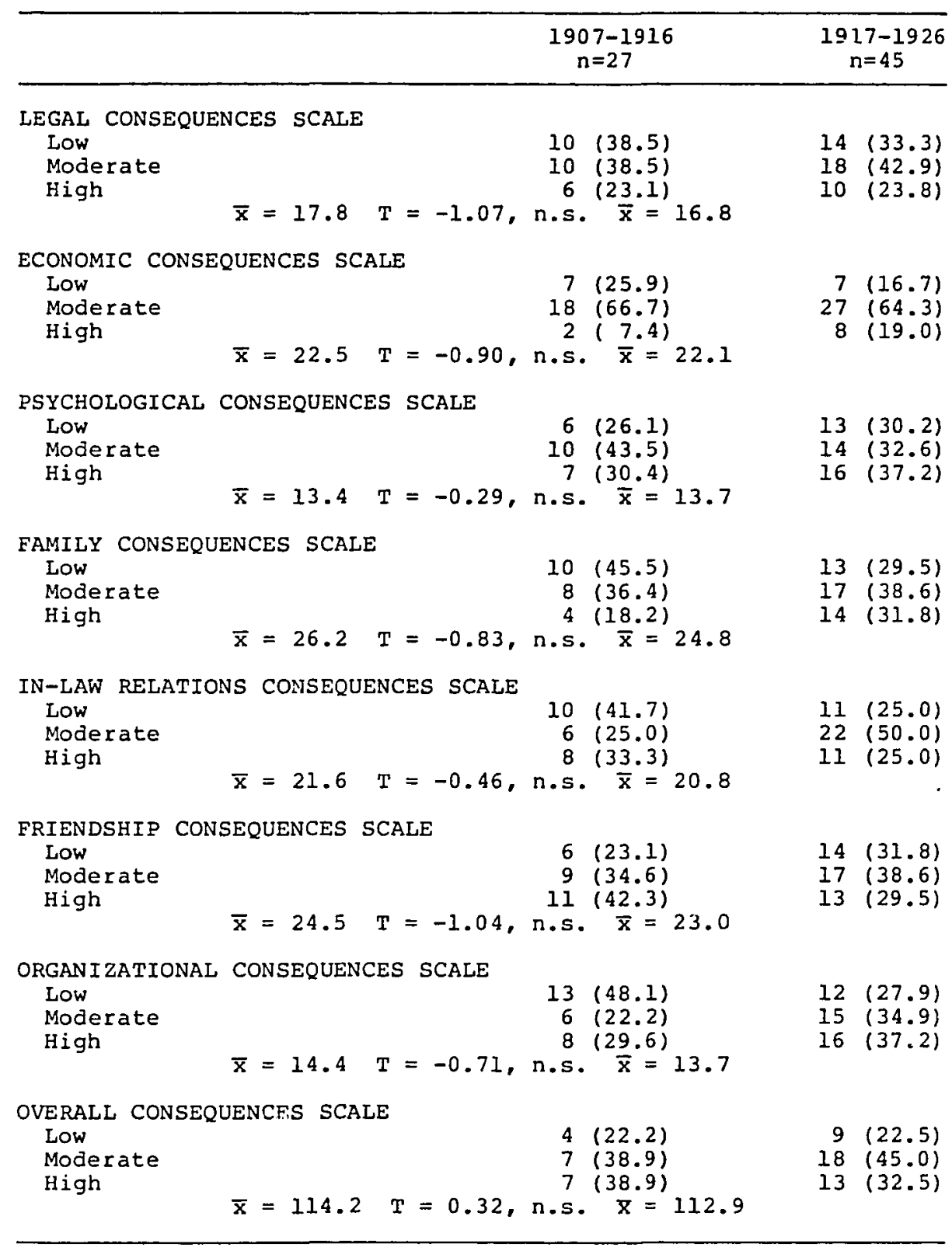


TABLE XXVI

COMPARISONS OF ADJUSTMENT OF SAMPLE SUBJECTS

IN TWO BIRTH COHORTS

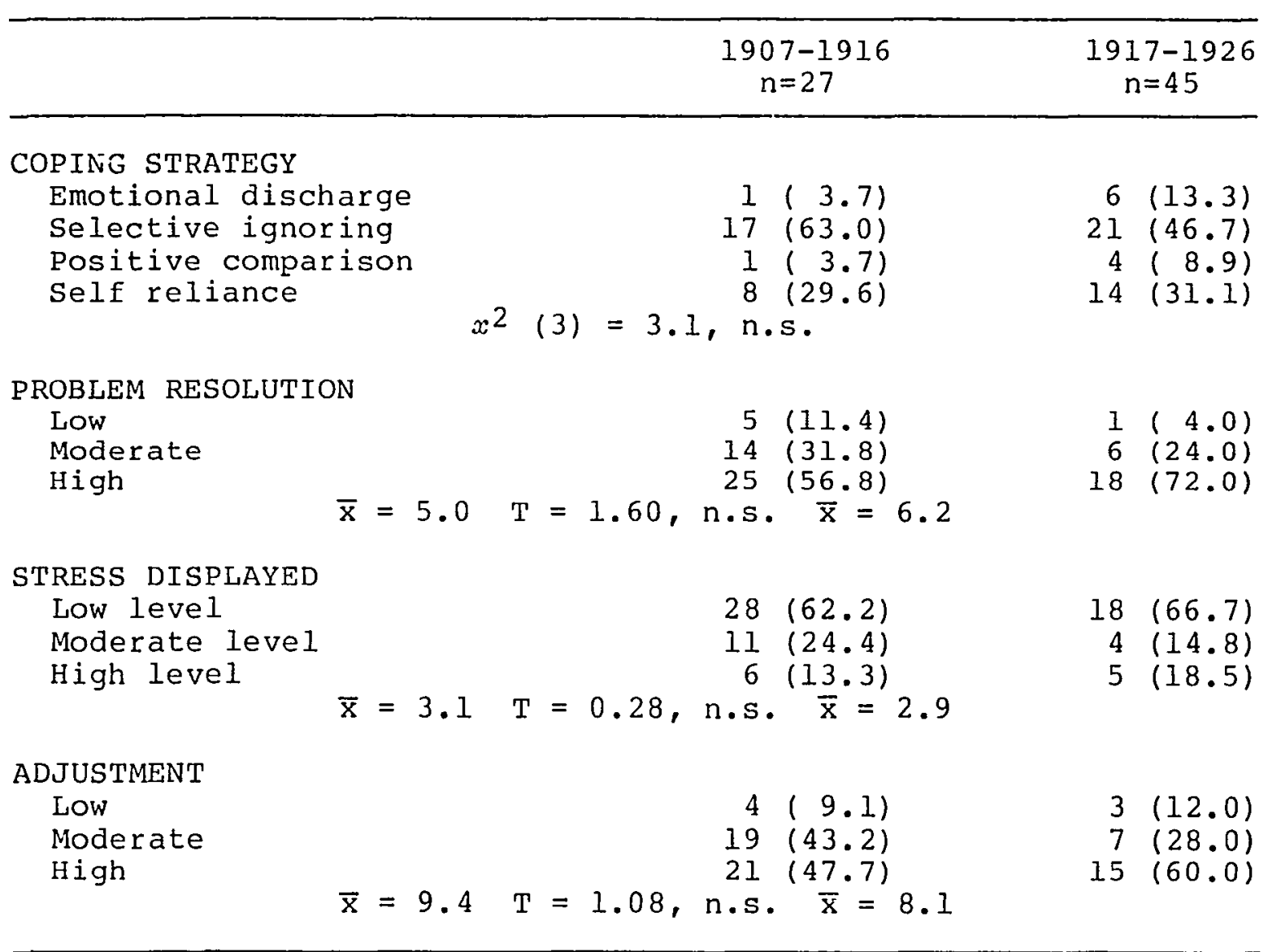


relationships among components of our model shown in Figure $3($ p.54). We had suggested, from our review of the literature, that certain personal and marital characteristics would yield an anticipated cost of late life divorce for subjects in our study. This anticipated cost would, in turn, enable us to explain variance in the type of divorce an individual experienced. Our assumption was that higher anticipated costs would result in a more negative experience as measured by the emotional reaction to and the amount of conflict exhibited in the divorce process. We hypothesized that the cost of divorce would be greatest, and therefore a more negative experience for those who: 1) had personal characteristics associated with a low probability of divorce; 2) perceived their marriage as a stable, high quality union; and 3) were suffering from the effects of other stressful life events. The hypothesis thus formulated was:

\section{$\mathrm{H}_{3}$ : The lower marital risk, the higher marital quality and the higher life stress exper- ienced, the more negative the divorce exper- ience.}

The lack of strong positive correlations among the variables of interest (p.94) led us to test independently the relationship between each of the three scales and the type of divorce experience. Oneway ANOVA procedures were used. Initial inspection of the data indicated unequal group size; hence, tests were performed for homogeneity of variance. A Cochrans $C$ test indicated the assumption of 
equal variances was supported for marital risk ( $p=0.681)$, marital quality $(p=0.452)$ and life stress $(p=0.36)$.

In Table XXVII we see that the between group variance was significant for marital risk and marital quality, but not for life stress. To determine where the significant differences lay, multiple comparisons using scheffe's tests were performed. It was found that those with ambivalent divorce experiences had significantly lower marital risk and marital quality scores. Based on these findings, Hypothesis 3 was rejected.

The message which emerges from these data is that marital risk, marital quality and life stress, at least as they are measured in this study, would not be good predictors of type of divorce experience. This was confirmed further by the results of a discriminate function analysis in which only 57 percent of the cases were classified correctly using anticipated cost as the discriminate variable. Further, individuals in long marriages of poor quality were most likely to have mixed feelings about the divorce; for them, the cost of divorce does not clearly outweigh the benefits to be derived.

\section{TYPE OF DIVORCE EXPERIENCE AND RESULTING CONSEQUENCES}

The type of divorce experience reflected the emotional and behavioral response of individuals to the termination of their marriage. Emotional response was measured by the reported reaction to the dissolution; the 
TABLE XXVII

ANALYSIS OF VARIANCE OF MARITAL RISK, MARITAL QUALITY

AND LIFE STRESS SCORES FOR NEGATIVE, AMBIVALENT

AND POSITIVE DIVORCE EXPERIENCE GROUPS

\begin{tabular}{|c|c|c|c|c|}
\hline & SS & $d f$ & MS & $\mathbf{F}$ \\
\hline MARITAL RISK SCALE & & & & \\
\hline $\begin{array}{l}\text { Between Ss } \\
\text { Within Ss }\end{array}$ & $\begin{array}{l}107.41 \\
9.38 .04\end{array}$ & $\begin{array}{r}2 \\
62\end{array}$ & $\begin{array}{l}53.70 \\
14.65\end{array}$ & $3.667 *$ \\
\hline $\begin{array}{l}\text { MARITAL QUALITY SCALE } \\
\text { Between Ss } \\
\text { Within Ss }\end{array}$ & $\begin{array}{r}67.77 \\
407.08\end{array}$ & $\begin{array}{r}2 \\
74\end{array}$ & $\begin{array}{r}33.89 \\
5.50\end{array}$ & $6.160 * *$ \\
\hline $\begin{array}{l}\text { LIFE STRESS SCALE } \\
\text { Between SS } \\
\text { Within Ss }\end{array}$ & $\begin{array}{r}7.16 \\
713.62\end{array}$ & $\begin{array}{r}2 \\
59\end{array}$ & $\begin{array}{r}3.58 \\
12.10\end{array}$ & 0.296 \\
\hline
\end{tabular}


behavioral component was measured by the amount of conflict generated during the divorce process. Just as we had speculated that selected personal and marital characteristis would explain variance in the type of divorce experience, we hypothesized that:

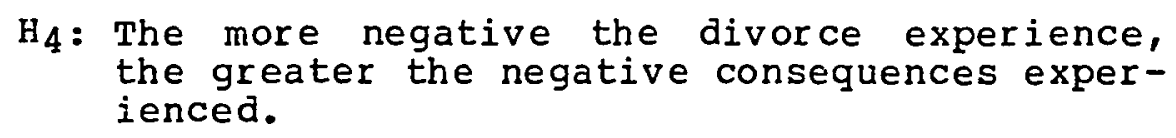

Prior to testing the hypothesis, correlational procedures were used to determine the relationship between reaction to and conflict during the divorce process. The moderate positive correlation $(\mathrm{r}=.44, \mathrm{p}<.001)$ indicated that the scale divorce'experience did reflect two separate dimensions. The divorce experience scale acted as the independent variable and five consequence scale scores were the dependent variables tested. Analysis of variance, followed by multiple comparison tests, was used for testing Hypothesis 4. Tests for homogeneity of variance conducted using Cochrans $C$, indicated all variables met the equal assumptions criteria for unequal group size.

From a summary of the ANOVA results shown in Table XXVIII we can see that between group variance was significant for all but one of the four scales designed to measure legal, economic, psychological and social consequences. The lack of significance in the economic consequence scale, however, appears to be masked in the total consequence scale; the total consequence score also 
TABLE XXVIII

ANALYSIS OF VARIANCE OF CONSEQUENCES FOR NEGATIVE, AMBIVALENT AND POSITIVE DIVORCE EXPERIENCE GROUPS

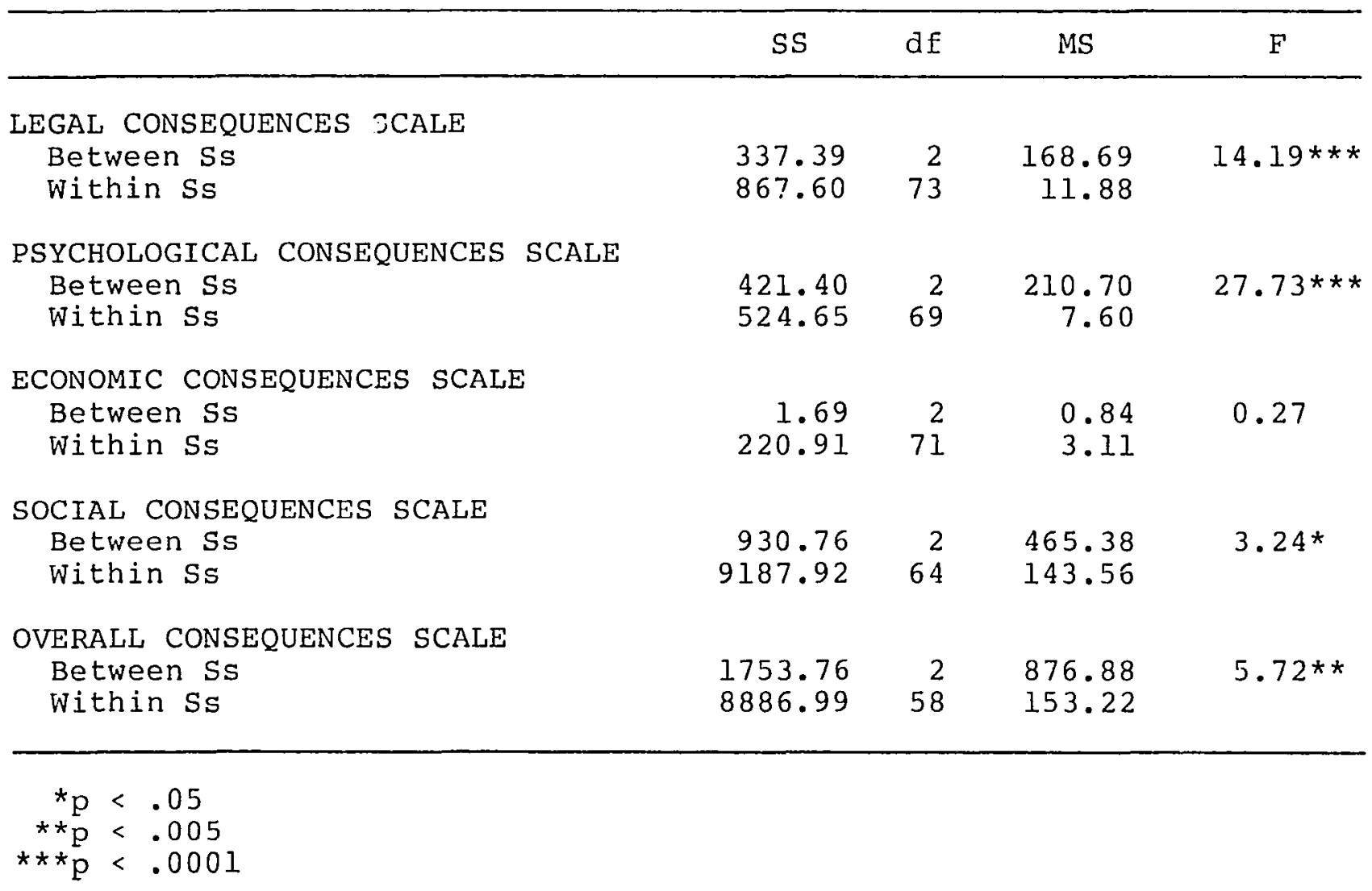


indicates greater between group variance. Thus, we know that significant differences existed in the consequences divorce had for subjects with positive, ambivalent and negative divorce experiences.

Using Scheffe's test with a <.05 cut off, we found significant differences in the group means of legal, social, psychological and total consequence scales. Group variance for the legal consequences scale indicates that those with positive divorce experiences had significantly higher consequences than did those with negative or ambivalent divorce experiences. Just the opposite trend was found for all of the other consequence scales, including those for which the group means did not differ significantly. The scores on the total consequences scale confirm, despite the contravening trend presented by legal consequences, that those with negative divorce experiences also had significantly more negative consequences. Hypothesis 4 was confirmed.

\section{CONSEQUENCES OF AND ADJUSTMENT TO DIVORCE}

The next component of the divorce impact model to be tested was the relationship between the consequences experienced and adjustment subsequent to divorce. we hypothesized that individuals with high consequences would be less able to resolve their problems and avoid stress successfully. Work with younger divorcing populations suggests that both problem resolution and the avoidance of 
stress are important indicators of post divorce adjustment. Thus, one scale measuring stress and another scale measuring the degree of problem resolution were combined to create a measure of post divorce adjustment to be tested in Hypothesis 5 .

$\mathrm{H}_{5}$ : The fewer consequences experienced as a result of the divorce, the higher the post divorce adjustment.

A simple regression equation was used to test Hypothesis 5 with an adjustment score serving as the criterion variable and the total consequences score acting as the predictor variable. The equation was:

$$
\text { Adjustment }=34.30-0.21 \text { (Total Consequences) }
$$

This equation yielded a multiple $R$ of -0.46 , indicating that 21.2 percent of the variance in post divorce adjustment scores was explained by differences in the consequences experienced $(F=15.59,44$ df, $P<.001)$. The negative regression coefficient and multiple $R$ support the direction of Hypothesis 5 .

\section{INTERVEN ING VARIABLES AND ADJUSTMENT}

To a certain extent the linearity of the divorce impact model has been supported by the results of tests conducted on Hypotheses 4 and 5. In this section, the significance of other variables to post divorce adjustment is reported. These hypotheses tested the relationships between the criterion variable adjustment and four predictor variables - anticipated cost, type of divorce 
experience, total adjustment time (from first recognition of the probability of divorce to interview date) and sex. The hypotheses were:

$\mathrm{H}_{6}$ : The lower marital risk, the higher marital quality and the higher life stress the lower post divorce adjustment.

H7: The more negative the divorce experience the lower post divorce adjustment.

$\mathrm{H}_{8}$ : The shorter period of time an individual has to adjust, the lower post divorce adjustment.

Hg: Females will have lower post divorce adjustment than will males.

The first three hypotheses were tested using regression equations. Table XXIX provides summary statistics for the regression equations listed below.

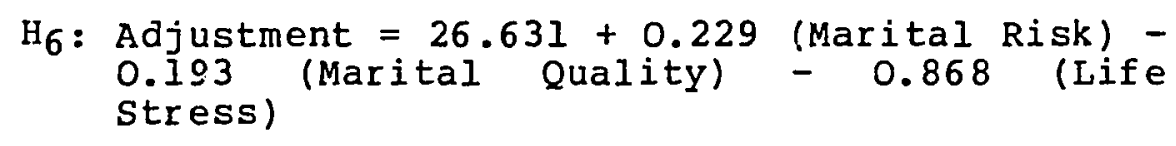

H7: Adjustment $=15.343-2.865$ (Divorce Experience).

$\mathrm{H}_{8}:$ Adjustment $=8.410+0.228$ (Time for Adjustment)

As can be seen in Table XxIX only Hypothesis 7 had a significant $F$ ratio and thus was confirmed. In looking closer at the components of Hypothesis 6 we found that neither marital risk $(F=0.664)$ nor marital quality $(F=$ 0.214) contributed much to the overall $F$; life stress exhibited a strong negative association with adjustment (F =7.57). This was reconfirmed with a simple regression of adjustment and life stress $\left(\mathrm{r}^{2}=.152 ; \mathrm{F}=7.3\right)$. Thus, 
TABLE XXIX

SUMMARY RESULTS FROM THREE REGRESSION EQUATIONS FOR THE CRITERION VARIABLE ADJUSTMENT

\begin{tabular}{lccc}
\hline & \multicolumn{3}{c}{ Predictor Variables } \\
\cline { 2 - 4 } Statistic & $\begin{array}{c}\text { Marital Risk/Marital } \\
\text { Quality/Life Stress }\end{array}$ & $\begin{array}{c}\text { Divorce } \\
\text { Experience }\end{array}$ & $\begin{array}{c}\text { Time for } \\
\text { Adjustment }\end{array}$ \\
\hline $\begin{array}{l}\text { Multiple Correlation } \\
\text { R Squared }\end{array}$ & .422 & .404 & .267 \\
F Ratio & .179 & .163 & .072 \\
\hline
\end{tabular}

$*_{\mathrm{p}}<.01$ 
only that portion of Hypothesis 6 which asserted that high life stress was associated with lower post divorce adjustment was supported. Hypothesis 8 also was rejecteả.

Turning now to Hypothesis 9, we find, using an independent samples $t$-test, that females score significantly lower on post divorce adjustment with an average score of 12.1 as compared to 6.7 for males $(T=-4.68$, $\mathrm{p}(.0001)$. Thus, Hypothesis 9 is supported.

\section{TESTING THE DIVORCE ADJUSTMENT MODEL}

Our analysis independently confirmed the importance of sex, divorce experience and consequences in predicting post divorce adjustment. Total adjustment time was related to adjustment, but not significantly so. Two predictor variables used to derive anticipated cost, marital quality and marital risk, showed almost no correlation with adjustment. The third scale used to measure anticipated cost, life stress, showed a moderately strong inverse correlation with adjustment. On the basis of these findings our multiple regression equation was modified to read:

$$
\begin{gathered}
\text { Adjustment }=35.78-0.35 \text { (Life Stress) }-0.54 \\
\text { (Divorce Experience) }-0.13 \text { (Consequences) }+0.01 \\
\text { (Adjustment Time) }+4.01 \text { (Sex) }
\end{gathered}
$$

Summary statistics for the equation are presented in Table $x x x$. The equation worked moderately well with a multiple $\mathrm{R}$ of .73 and an $\mathrm{r}^{2}$ of $.54(\mathrm{~F}=8.34,5 / 36 \mathrm{df}, \mathrm{p}<$ .01). Roughly one half of the variance in post divorce 
TABLE XXX

SUMMARY STATISTICS FOR DIVORCE ADJUSTMENT MODEL MULTIPLE REGRESSION EQUATION WITH FIVE PREDICTOR VARIABLES

\begin{tabular}{lccccc}
\hline & \multicolumn{4}{c}{ Predictor Variable } \\
\cline { 2 - 5 } Statistic & Sex & $\begin{array}{c}\text { Divorce } \\
\text { Experience }\end{array}$ & Consequences & Life Stress & $\begin{array}{c}\text { Adjustment } \\
\text { Time }\end{array}$ \\
\hline Multiple R & .545 & .654 & .702 & .724 & .733 \\
R Squared & .297 & .428 &. .327 & .523 & .537 \\
Beta Weight & .343 & -.3271 & -.191 & .125 \\
F Ratio & $7.394 *$ & $6.733^{*}$ & $5.186 *$ & 2.633 & .031 \\
\hline
\end{tabular}

$$
\begin{aligned}
{ }^{*} p<.05 \\
{ }^{*} p<.01
\end{aligned}
$$


adjustment was accounted for by our five predictor variables. Additionally, four of the variables contributed in the predicted direction. The negative betas of life stress, divorce experience and consequences indicated they were, in fact, working in the predicted direction. They are associated negatively with post divorce adjustment. The higher adjustment of males also was expected.

Total adjustment time, however, was not related to adjustment as expected. The regression results indicate that individuals with a shorter period of time scored higher on post divorce adjustment. The literature had indicated that time was an important element in accepting the divorce and in working out problems associated with the dissolution of the marriage. We also can see from the summary statistics that sex, divorce experience and consequences contributed most to the variance explained. Taken together these three predictor variables accounted for 49 percent of the variance in post divorce adjustment scores. 


\section{CHAPTER $V$}

\section{DISCUSSION AND CONCLUSIONS}

This study was designed in two stages to address three issues relevant to late life divorce. Stage I focused on describing the phenomenon of late life divorce and the role played by age; Stage II was directed toward the testing of factors influencing post divorce adjustment. In this chapter findings for stages I and II are discussed and some conclusions are presented.

\section{STAGE I: THE PHENOMENON OF LATE LIFE DIVORCE}

As the descriptive portion of the study, stage I provided answers to four fundamental questions about late life divorce. The most basic of these questions was who gets divorced in late life. Perhaps the most notable finding about the personal characteristics of our sample of older divorcing persons was how similar they appeared to descriptions of younger divorcing persons. The majority had low occupational status, few assets and weak religious ties. They were urban residing, had weak ties with kin and reported marrying and having children at an earlier than average age. A comparison of 17 couples in the sample indicated higher educational attainments for females and disagreement over religious convictions in a majority of 
cases. They had a higher than expected incidence of poor health and their marital history indicated one half had been divorced previously.

We did not find, however, that divorcing older persons were less residentially or occupationally stable. Nor did we find any evidence of a rural to urban migration before or after the divorce action was filed. The majority of the marriages had endured for longer than the median seven years reported for the general divorcing population and had resulted in the birth of one or more children.

our sample yielded no definitive description of who divorces in late life. The data support, in large part, earlier findings of selected personal characteristics associated with a higher probability of divorce in younger populations. Whether these similarities reflect the rippling effect of change across different groups in society or an inherent susceptibility of certain groups to experience divorce cannot be ascertained from these data.

\section{Rrofiling Causes of Late Life Divorce}

Certain profiles, which tend to confirm existing stereotypes, can be identified from the data presented; these include: 1) the multiple marriage, characterized by three or more divorces, 2) the mistaken second marriage, typically cntered into after being widowed and 3 ) the collapsed marriage. Of these, the collapsed marriage was, by far, the most common in our sample. While the multiple 
marriage and the mistaken second marriage did occur, the majority of individuals seeking divorce in our sample were ending a long marriage that had collapsed.

One obvious question was why individuals would terminate a marriage in which they had invested so many years. We had speculated previously that the social exchange model proposed by Lewis and spanier (1979) might provide a viable means of explaining the "cause" of late life divorce. Our speculation was based on the assumption that personality deficits or inadequate role performance of such great magnitude would be intolerable for the length of time represented by marriages which collapsed after surviving twenty years and longer.

Our data provide some support for this view. The "cause" of divorce most often identified was lack of emotional gratification. One could argue that this explanation indicated an inadequately developed personality (inability to give/receive love) or an inadequate performance of the role most important in a conjugal marriage (fulfilling the affectional obligation of the significant other). Indeed, it may be that individuals who experience multiple marriages are exhibiting symptoms of an inadequately developed personality or that those who cannot adjust to life with a new marital partner perceive the role performance of the second mate to be inadequate. But few of our sample had failed repeatedly in marriage or were trying to accommodate the role expectations of a relative 
stranger .

In examining the collapsed marriages the importance of "love" and "affection" in long marriages was confirmed. Our subjects expected marriage to entail more than continued accommodation at any cost. Yet the absence of love alone was not enough to induce individuals to seek divorce. Typically, in long marriages the decision to divorce involved a lengthy period of thinking about divorce prior to the actual filing. Thoughts of divorce were precipitated by a general unhappiness in the marriage punctuated by occasional periods of acute strain. Things bumped along, however, because it was "too costly" to get a divorce at the moment. The marriage had not represented that poor an investment. At some point, however, the balance tipped in favor of divorce.

This tipping often appeared to take the form of a particular event such as an adulterous affair, retirement, illness, conflict over a major purchase, or the launching of the last child. Interestingly, the precipitating event often served as a means to focus a sense of general dissatisfaction with the marriage. Whether the event was of an on-going nature (e.g. adultry) or represented a new experience (e.g. retirement) at least one of the marital partners viewed it as overwhelming evidence that what had been tolerable in the past would get worse in the future if things did not change. Individuals responded to these precipitating events in different ways. Some perceived 
these events as opportunities to live differently, others saw an opportunity to do things differently in their marriage. Each one, however, went through a period of reassessing the marriage.

This reassessment of the marriage and the formulation of an alternative attraction (Lenthall, 1977) to a deficient relationship occurred at a vulnerable point in many marriages. The data show most of the individuals in long marriages of moderate to low quality had experienced a fair amount of life stress in the ten years prior to filing for divorce. They also indicated no strong relationship beween low marital quality and high life stress suggesting that stressful events do not generally, in and of themselves, impact marital quality. It may be, in fact, this independence that acted to make the marriage so vulnerable.

A high investment goes into long marriages. A marginal rate of return represented by marriages of low to moderate quality may be acceptable when there are other sources of gratification or if the support provided in the marriage is adequate to deal with the external threats to marital cohesiveness. Removal of other sources of gratification, such as that represented by work, or an increase in external stressors, such as those caused by illness, may require a reformulation of the costs and benefits in a marginal quality marriage of long duration. 
Reaction and the Type of Divorce Experience

We noted previously that personal and marital characteristics showed almost no relationship with the type of divorce experience. The notable exception to this was the role of sex. In our sample significantly different responses were found for older men and women to the termination of their marriage. Women were significantly more likely to rate their divorcing marriage as low quality, but more likely to react negatively to the idea of a divorce. This may reflect an assessment of a higher cost of divorce for them. Conversely, men rated their divorcing marriages more positively; they also reacted more positively to getting a divorce.

Qualitative data presented in the interviews provided some explanation of these differences. Older women foresaw few opportunities to establish a new life or for "retooling" to live a different life. They were much more likely to promote a confrontation in hopes of forcing change within the marriage. In contrast, older men envisioned the opening up of opportunities to do things they had always wanted to do, yet were concerned that the cost of their "freedom" not be too great. Males were more likely to force a confrontation hoping to be able to call the bluff inherent in "either/or" situations.

These attitudes help explain the ambivalence the majority of subjects exhibited during the dissolution of their marriage. They may also help explain the amount of 
conflict surrounding the divorce, as well as why, unlike in younger populations, males were just as likely to file as females. Women appeared to be seeking to increase their benefits and men to reduce their costs associated with divorce. Few individuals portrayed themselves either as hapless victims or as joyful participants in the divorce process.

Consequences and Post Divorce Adjustment

The data clearly show the severe consequences of having negative feelings about the termination of the marriage and being involved in a highly conflicted divorce process. Subjects who generally had a negative divorce experience typically suffered greater real costs. They reported higher legal, economic, social and psychological consequences as a result of the divorce. Not only were the negative consequences greater for these subjects, but the successful resolution of problems typically was lower and levels of stress subsequent to divorce were higher for them. Again, these findings are consistent with those for younger divorcing populations.

Sex also was strongly associated with consequences and post divorce adjustment. Females reported more negative consequences, used less effective problem solving strategies, were less successful in resolving their problems, and exhibited higher levels of post divorce stress. While not particularly surprising in and of 
itself, the "gender gap" in late life divorce was stronger and much more pervasive than anticipated.

Women were less happy in their marriages, but were less willing to end them. They reported more organizational activity, more interaction with friends and family, but were less positive about the support they received from those sources during the divorce process. Women reported more social censure and more negative feelings toward their spouses and others perceived as responsible for the divorce. After their divorce women were less likely to be dating, less enthusiastic about remarriage and less optimistic about the future. In retrospect the less than enthusiastic response with which older women greeted the possibility of divorce would seem an accurate reading of the real cost of divorce to them.

\section{AGE AND DIVORCE}

The significance of the gender gap reported above naturally leads to speculation as to whether the differences found were, in part, a function of age. Indeed, a general question to be addressed by this study was what role age did play in late life divorce. Alluding to previous studies, we had speculated that the methods of sampling and the small numbers of older persons included in the samples (because of their low rate of divorce) might be the reason that age differences were not found. Despite an increase in the size of our sample and a more restricted 
age range, we were unable to confirm our age related hypotheses.

In our sample, age appeared to play an insignificant role. Close examination of the data revealed almost no significant differences between age and other variables of interest. Age did not appear to be associated with those personal and marital characteristics related to divorce, the "causes" of divorce, the type of divorce experienced, the consequences endured as a result of divorce, nor adjustment subsequent to the divorce.

One reason age did not emerge as significant may be related to the way in which our age groups were defined. Although we attempted to select appropriate boundaries to our two stages in the life cycle and birth cohorts, we may have missed the mark by using chronological age alone to define these events.

The speculation about chronological age being an inadequate marker is fueled by an observation of the age differences evident in many of the couples involved in the divorce action. When a marriage between two people has endured for a long period of time, a certain amount of blurring of differences might be expected to occur. Such fading represents, in effect, a regression of sorts to a mean set of experiences and values. In point of fact, the social exchange model of Lewis and spanier (1979) implies this process of blurring is one way of successfully adapting to marriage. Although subjects in our sample may 
have been unable to "fade" enough to be successful in their marriage, they may have adapted enough--after a long marriage in particular--so that their age was no longer an accurate marker of events for them.

of course, it may be that age truly has little significance. Effects generated by stage in the life cycle or birth cohort may be overshadowed by major life events, particularly non-normative ones. Divorce may be a unifying event, much in the way that being a twin or being a victim of a violent crime acts to orient perspectives related to the shared trait. The main event was, after all, divorce.

The data provide some support for this interpretation. For the most part, apart from the role age may have played in deriving an anticipated cost based on what the past had been and what the future might bring, subjects ignored the issue of age. It was not a part of their responses to questions about what type of divorce experience they had, the consequences they bore as a result of the divorce or how they adjusted subsequently. In a word, they generally do not view age as that much of a factor in their divorce.

\section{Relationship Between Age and Sex}

We noted earlier that differences in the type of divorce experience, divorce, consequences and adjustment were often associated with sex. Further, the literature had suggested that older women in particular were likely to 
suffer more from divorce. Thus, we assumed that the females in our sample would show some age differences. Again our assumptions were not supported. Our findings did not show a decline in adjustment with advancing age for females. Rather, although not significant, we found those women under the age of 65 to have lower adjustment than those over the age of 65 .

One possible explanation for this finding is that those women under the age of 65 also had higher life stress scores. It may be they were coping with more stressful events at the time of their divorce. Further, the economic status of those women under age 65 was less stable than those over the age of 65 , resulting in greater financial strain subsequent to the divorce.

These findings are very suggestive. It may very well be that the relationship between age and post divorce adjustment is curvilinear. That is, after a low which occurs in mid life (45 - 65 years) females may be less affected by the divorce. Economic independence of sorts may be achieved through retirement, being alone is more common as other older women become widowed and decreasing parental responsibilities may provide more time or interest to develop roles apart from that of wife and mother.

STAGE II: PREDICTING ADJUSTMENT TO DIVORCE

The second part of this study was concerned with adjustment to divorce in late life. A divorce adjustment 
model was developed to predict which individuals would score lower on post divorce adjustment. This model, shown in Figure 3 (p. 54), suggested a set of relationships between five predictor variables--anticipated cost, divorce experience, consequences, time and sex--and the criterion variable, post divorce adjustment. We had hypothesized that a higher anticipated cost would result in a more negative divorce experience, that a negative divorce experience would result in higher negative consequences and that higher negative consequences would result in lower post divorce adjustment, with sex and time acting as intervening variables.

To test our model, we put forth seven hypotheses about the relationships the various components of the model had with one another, as well as with adjustment. In our analyses, we determined:

1) Marital risk and marital quality were related to type of divorce experience, al though not in the expected direction; further, they did not account for a significant portion of the variance in post divorce adjustment;

2) Life stress was not related to type of divorce experience, but did account for some small amount of variance in post divorce adjustment; this relationship was in the expected direction with those having higher life stress also having lower post divorce adjustment;

3) A negative divorce experience was associated with higher negative social, economic and psychological consequences; having a positive divorce experience resulted in higher legal consequences;

4) A negative divorce experience did help explain a significant portion of the variance in post 


\section{- divorce adjustment;}

5) Higher negative social, psychological and economic consequences were predictive of lower post divorce adjustment; higher overall consequences were associated with lower post divorce adjustment;

6) Sex accounted for the greatest amount of the variance in post divorce adjustment; and

7) The amount of time individuals had to respond to the divorce (prior to interview) was not a significant factor in post divorce adjustment scores.

Collectively, the findings provide evidence that the model was successful with 54 per cent of the variance in post divorce adjustment accounted for by five predictor variables.

\section{Discussion of the Divorce Adjustment Model}

The model did not, however, work exactly as we originally had hypothesized. The first component of the model, anticipated cost, composed of marital quality, marital risk and life stress variables, failed to work as expected. The absence of strong correlations among the three variables indicated that the index we had developed to measure anticipated cost would not work in the regression equation. Additional regression analysis indicated that life stress was associated with post divorce adjustment, while marital risk and marital quality showed no relationship with adjustment. In our final model, then, life stress was used to replace the anticipated cost variable in the multiple regression equation. 
The behavior of the marital risk and marital quality variables in the analysis was unexpected. Part of the difficulty may have been the result of measurement problems. The scales were constructed post hoc and may not have adequately represented the concept inherent in anticipated cost. In addition, it may be that subjects who had not divorced previously did not approach the termination of their marriage with the same ability to define their expectations for the experience as did those who had been involved in another divorce.

It may also be that individuals who reportedly had low risk, high quality marriages and also reported a more positve divorce experience were deluding themselves. We speculated that the delusion might be related to the investment the marriage represented. To devalue the marriage would be to devalue themselves and the time they had spent in it. Indeed, to do otherwise might signal that these subjects were so undesirable themselves they had to keep what they had regardless of the quality.

Another possible explanation is sex. This derived from the more positive ratings given to their marriage by men. We suggested that males who already had made a transition to a satisfying new heterosexual relationship (as had most in our sample) would not be likely to spend much time reviewing the warts and wrinkles of a marriage done and over with as far as they were concerned. The females in our sample generally had not developed new 
heterosexual relationships and were, in fact, still focused on the relationship which had failed.

Yet another explanation may be that those subjects who reported their marriages as being of high quality and their divorce as being a positive experience may be optimists. That is, those subjects may be individuals who look for the good in every situation and always view their world as "looking up."

A second divergence from the model was the positive association between high legal consequences and high post divorce adjustment. We had speculated that ritualized conflict provided through the judicial system allowed subjects to externalize some of the cost of divorce. One could feel blameless and virtuous regardless of the outcome. Another explanation might be a generational or cohort effect. That is, for this age group, seeking refuge in the legal dissolution of their marriage might have been the most appropriate response. One was expected to use a lawyer and to fight.

High legal consequences did not necessarily mean an involved or protracted fight over the divorce. In fact, just the opposite was true. Although time was not a significant variable in the regression model, generally the shorter the time the subjects had to adjust, the higher the post divorce adjustment tended to be. This finding contradicts findings in other studies. It might be that the long conflict which of ten preceded the contemplation of 
divorce resulted in most of the required emotional withdrawal taking place long before the subjects actually took any action to dissolve their marriage.

Despite the problems found in the original regression model, we found that sex, the type of divorce experience and overall consequences were predictive of post divorce adjustment. Taken tog $\epsilon$ ther these three variables accounted for one-half of the variance in post divorce adjustment scores. An indication of the strength of the model was found in the results of analysis conducted on several single variables found to be correlated with post divorce adjustment. Put into a regression model, single variables such as health status and fertility did not account for more than five per cent of the variance in post divorce adjustment.

While the type of divorce experience and overall consequences account for 20 per cent of the variance in post divorce adjustment, in each model we tested sex accounted for the greatest amount of variance in subject scores. Obviously sex only explains variance in the statistical sense. Females aren't necessarily born with less ability to adapt; indeed, the biological evidence indicates that they may be more able to adapt to change in their environment. If an innate difference doesn't explain the lowered capacity of females to adjust to divorce successfully, then, the question we must ask ourselves is what circumstances are responsible. 
The data would suggest the deck is stacked against the successful adjustment of older females in particular. Their chance of remarriage is low and they have almost no hope of establishing a satisfying heterosexual relationship even though that is perceived as the single most important ingredient necessary for successful adjustment. The need for friendships and organized activity is high, yet females often perceive themselves as shut out and being treated as unwelcome "fifth wheels." Females experience a heightened sense of personal failure yet they are less effective in resolving their problems, at least partially because they do not know how to marshall resouces in response to their problems.

\section{LIMITATIONS OF THE STUDY}

Before discussing the implications of our findings it is necessary to discuss the limitations of the study and how they might have affected the results we obtained. Some of the limitations are related to the method of sampling used. Our subjects represented the sampling universe for divorcing older persons in two counties in oregon, hence it was non-random. It was a purposive sample, selected in such a manner as to exclude individuals who occupied other marital roles (i.e., married, widowed). Further, our interview sample was found to have longer and more conflictive divorces than the initial sample from which they were taken. These differences may affect the 
generalizability of our findings.

A second limitation was the size of the sample and the restrictions thus imposed on the subsequent analysis. Although our sample represented the largest group of divorcing older persons studied to date, partitioning of the sample and the introduction of controls for other variables was somewhat limited by its size $(n=81)$.

The smallness of the sample also created added potential for data reduction problems. In developing the scales to be used in testing the adjustment model and its components we encountered a loss of cases due to missing data. Our ability to cross-validate results was hampered and, in a few cases, the cell size was sufficiently small as to create concern over the reliability of the statistical evidence.

Missing data also created a more generalized concern regarding the adjustment model. Questions must be asked regarding the randomness of the losses and whether a pattern in the rnissing data existed which would alter the outcome of the analysis. In addition, a fundamental question must be asked regarding the wisdom of trying to use such a complex model. Clearly, the use of a large number of variables in constructing the model's components caused a larger than expected loss of cases. Yet, as discussed above, complexity increased considerably the predictive power of the model.

Measurement represented another set of methodological 
problems we encountered. The data for this study were collected for another purpose. Most of the scales were constructed post hoc from the best available indicators. While we attempted to select items typically used to measure certain concepts and to verify the internal consistency of the scales so constructed, our scales suffer one major drawback. With the exception of the Langner Checklist, the scales have not benefited from repeated testing with other populations.

A final limitation may be said to rest in the conceptualization of the model. The underlying assumptions in the model are based on a view of humankind which assumes rationality. That is, the model assumed individuals would assess situations and respond in a manner most protective of their self interest. Obviously rationalism represents only one philosphical interpretation of human behavior. Some would argue, for example, that the conjugal family in which the bonds are primarily affectional - does not support a rationalistic interpretation. Our analysis, however, would suggest that at least some persons behaved according to a predictable and rational pattern. Perhaps the more interesting question is what characterizes the subjects who do not fit a rationalistic model.

Future research done on the topic of late life divorce might benefit from several changes in study design. This study suffered from the lack of control groups, longitudinal data and an inadequate sample size. Even 
though inferential statistics were used in the analysis, our ability to make causal statements about the findings are limited by these shortcomings.

\section{IMPLICATIONS OF THE STUDY}

The findings in this study have potential theoretical and policy implications. As noted in the previous paragraph, we have suggested that the philosophical view under which individuals operate may affect the way in which they respond to non-normative events such as divorce. In addition, models which are predicated on rationality may not work very well in predicting outcomes for individuals not accustomed to viewing the world in that mode. We must ask ourselves if a particular philosophical view predominates in a given culture and how alternative perspectives are to be accommodated by existing theoretical models.

Our findings point to other major implications as well. One implication is that the formalized, managed dissolution of marriage is important. If it did nothing else but signify the actual end of a marital union so that individuals could get on with building a new life, the divorce process would be important. But it apparently plays a more important role, allowing individuals to shift events in such a way as to sanitize any hint of culpability for the failure of their marriage. We could argue, in fact, that formalized dissolution is important enough that 
the movement to divorce by mail or mass trial may be potentially destructive even to individuals who think they agree on the need to dissolve their marriage. It is equally important, however, that the confrontation be skillfully managed. There was apparently very little gained by merely increasing the level of conflict in the divorce process.

The implications for the law in these findings are very suggestive. On the one hand, the data suggest that subjects ending their marriage need a method to argue for or against the termination of their marriage. Fault, or blame if you will, is a concept which is deeply rooted in the psyche of the individuals in our sample. Existing "no fault" divorce law does not appear to prevent individuals from attempting to externalize the blame for the failure of their marriage, but it does appear to cast them in a somewhat unfavorable light if the seek to do it publicly or legally. In other words, under no fault divorce the termination of the marriage is supposed to be a quiet, decorous event where all parties concerned amiably agree to all conditions. Unfortunately, this seldom is the case. Resistant parties now have few options but to go kicking and screaming into court where they may be treated either as objects of pity or as obdurate complainers.

The difficulty with family law issues, such as those presented by divorce, is that equity is not easily found for all involved. One potential solution is increased 
routine use of an arbitration or mediation process to negotiate outcomes in conflictive marriages. Such a process might provide a more positive way for individuals to work through the failure of their marriage.

Another implication is found in the lopsided effect of divorce in late life on women. While much has been said about the need for older men to expand their identity beyond work so that retirement is less traumatic for them, much less has been said about providing meaningful alternatives or expanding the number of roles available to older women. Many were not prepared to function in roles other than that of wife and mother. With their parental role reduced and their status as spouse taken away these women were ill prepared emotionally, financially or socially to adapt.

Worse yet there was little help available to older women. Often they did not feel comfortable with the type of assertive feminism practiced by younger displaced homemakers. Judges, lawyers, clergymen, professional counselors and social service workers appeared either as unknown or unhelpful figures. Their rage, fear and pain often seemed excessive, if not unseemly, even to themselves. Women such as these create an interesting dilemma for society. They reflect a socialization process which emphasized a set of expectations which are no longer held by the majority of society's members. Typically, since we do not really know what to do, we ignore them. 
clearly, we need to examine more closely some of the unique problems presented by divorce in late life. How should assets such as pensions be divided? How realistic is it to anticipate that minor "retooling" efforts will result in skilled, confident individuals able to generate a new life for themselves? Does society have the right to impose pre-divorce mediation when there are no minor children involved? These and other questions are ones which must be addressed in the near future. 


\section{FOOTNOTES}

lothers argue that the family is as much a causal agent in creating changes in American society as it is the victim of change (cf., Udry, 1971).

2 study in this area is greatly hampered by the lack of adequate vital statistics. Age specific divorce rates still are not uniformly reported; data are even more incomplete prior to 1960. Further, census data provide no clues as to marital history; only the current marital status is provided.

3 Several methods of calculating divorce statistics are used. These differences are apparent in the variety of terms used to report divorce rates. These terms include: 1) marriage to divorce rate expressed as the proportion of divorces to weddings in a given year; 2) crude divorce iate expressed as the numbe of divorces in given year per 1,000 persons in the population; 3) refined divorce rate expressed as the number of divorces in a given year per 1,000 married women; 4) age-specific divorce rate expressed as the number of divorces in a given year per 1,000 married women in specified age categories; and 5) life table analysis, which compares marital dissolution due to divorce with that due to the death of a spouse. Of the methods used, age-specific divorce rates and life table analysis are considered to be the most accurate, yet difficulties in obtaining necessary data and methodological problems have resulted in limited use of these two methods.

the Census.

$465+$ is the age category used by the u.s. Bureau of

5 It should be noted, however, that the sample was a purposive one selected to represent a marginally subsisting elderly population found in middle-size communities in the united states and thus may not be representative.

${ }^{6}$ Collusion is a mutual agreement between the parties to obtain a divorce by creating legal grounds for divorce.

7 The relationships depicted in the divorce adjustment model (shown in Figure 3, p. 54) are based on a set of rationalistic assumptions. That is, the model assumes that humans, consciously or unconsciously, view events and make decisions in terms of the costs and benefits to be derived 
from them. The linear nature of the model was dictated in part by the data to be used in the analysis. Deshane and Wilson's (1981b) data focused on three points in the divorce--prior, during and subsequent to the divorce. Although the data were collected using retrospective techniques with the subjects, and thus may be contaminated, it was possible to construct the time-bound concepts represented in the model. It should be noted that, generally, additional analysis undertaken confirm the relationships between individual components in the model.

${ }^{8}$ Data for this study were collected originally as part of a research project on late life divorce funded by AARP Andrus Foundation and conducted by the Institute on Aging, Portland state University, Portland, Oregon. Individuals interested in more descriptive information about what happens to individuals who seek divorce in late life are referred to the report published as part of that study, Dirorce in Late Life: Emerging Trends and Problems.

${ }^{9}$ Marriages may also be dissolved through desertion and separation. This study, however, focused exclusively upon those legally terminating their marriage.

IOMissing data in the court records on variables other than the six selected would have made further checks of limited value.

11 Conflicted divorce was measured as follows: 1) low conflict is equal to minimum time period, 1 or no lawyers, default hearing and amicable settlement (i.e., to each his own); 2) moderate conflict is equal to 3-9 month time period, 1 or 2 lawyers and precise property division; 3 ) high conflict is equal to 9 or more month time period, 2 lawyers, court appearances, legal orders.

12 Based on these correlational findings we must conclude that the scale "anticipated cost" does not work. This may be a function of the method (retrospective) used in the data collection process or the items used to construct the individual scales. We thus can expect that the component "anticipated cost" will have to be altered for the final regression equation. Additional analyses should reveal which, if any, of the concepts inherent in anticipated costs are relevant for post divorce adjustment.

13 It should be noted that this study attempted to distinguish between what subjects might expect to happen as a result of divorce based on their previous experiences ("anticipated cost") and what actually did happen to them as a result of the divorce ("real cost"). 


\section{BIBLIOGRAPHY}

Albrecht, S. L. Reactions and adjustments to divorce: Differenses in the experiences of males and females. Eamily Relations, 1980, 29, 59-68.

Babchuk, N. Primary friends and kin: $A$ study of the associations of middle class couples. Social Forces, May $1965,483-493$.

Becker, G. S., Landis, E. M., \& Michael, R. T. An economic analysis of marital instability. Journal of Political Economy, 1977, 85(6), 1141-1187.

Bell, R. R. Marriage and family interaction (Rev. ed.). Homewood, Ill.: The Dorsey Press, 1967.

Berman, W. H., \& Turk, D. C. Adaptation to divorce: Problems and coping strategies. Journal of Marriage and the Family, February 1981, 43, pp. 179-189.

Bernard, J. Remarriage of the widowed and the divorced. In Remarriage: A study of marriage. New York: The Dryden Press, 1956.

Bernard, J. Marital stability and pattern of status variables. Journal of Marriage and the Family, November $1966,28,421-439$.

Blood, R. O. Conflict, divorce \& readjustment. Conflict Resolution, June 1960, 4, 209-218.

Blood, Jr., R. 0 . Long-range causes and consequences of the employment of married women. Journal of Marriage and the Family, February 1965, 27, 43-47.

Blood, R. O. The Eamily. New York: The Free Press, 1972.

Blood, R. O., \& Wolfe, D. M. Husbands and wives: The dynamics of married living. New York: The Free Press, 1960 .

Bloom, B. L., Asher, S. J., \& White, S. W. Marital disruption as a stressor: $A$ review and analysis. Psychological Bulletin, 1978, 85(4), 867-894.

Bloom, B. L., \& Caldwell, R. A. Sex differences in 
adjustment during the process of marital adjustment. Journal of Marriage and the Family, August 1981, 43, 693-701.

Bohannon, P. Divorce and after. Garden City, N.Y.: Doubleday, 1970.

Brandwein, R. A., Brown, C. A., \& Fox, E. M. Women and children lost: The social situation of divorced mothers and their families. Journal of Marriage and the Family, May 1974, 36, 498-514.

Brown, C. A., Feldberg, R., Fox, E. M., \& Kohen, J. Divorce: Chance of a new lifetime. Journal of Social Issues, 1976, 32(1), 119-133.

Brown, G. W., \& Harris, T. Social origins of depression: A study of psychiatric disorder in women. New York: The Free Press, 1978.

Bumpass, L. L., \& Sweet, J. L. Differentials in marital instability: 1970. American Sociological Review, $1972,37,754-766$.

Burchinal, L. G., \& Chancellor, L. E. Survival rates among religiously homogamous and interreligious marriages. Social Forces, May 1963, 41, 353-362.

Burgess, E. W. The changing American family. Religious Education, May 1928, pp. 408-411.

Burgess, E. W., \& Wollin, P. Engagement and marriage. Philadelphia, Pa.: J. B. Lippincott Co., 1953.

Burr, W. R., Hill, R., Nye, F. I., \& Reiss, I. L. (Eds.). Contemporary theories about the family. New York: The Free Press, 1979.

Cain, L. D Age status and generational phenomena: The new old people in contemporary America. The Gerontologist, $1967, Z(2), 83-92$.

Cain, L. D Planning for the elderly of the future. Planning and the Urban Elderly--Today and Tomorrow. Los Angeles: The Gerontology Center, University of Southern California, 1971, 14-24.

Calhoun, A. W. A social history of the American family from colonial times to the present. New York: Barnes and Noble, 1945. (Originally published, 1917$. 
Carlson, E. Divorce rate fluctuation: A cohort phenomenon. Population studies, 1979, 33(3), 523536 .

Carter, H., \& Glick, P. C. Marriage and divorce: A social and economic study (Rev, ed.). Cambridge: Harvard University Press, 1976.

Carter, H., \& Plateris, A. Trends in divorce and family disruption. In R. F. Winch \& L. W. Goodman (Eds.), Selected studies in marriage and the family. New York: Holt, Rinehart and winston, Inc., 1968.

Cavan, R. S. The couple in old age. In Arnold M. Rose (Ed.), Human behavior and social processes. Boston: Houghton Mifflin Co., 1962.

Cavan, R. S. Marriage and family in the modern world (3rd ed.). New York: Thomas Y. Crowell Co., 1969.

Cherlin, A. Current and projected levels of divorce, separation and remarriage. Paper presented at the 32nd Annual Gerontological Society Meeting, Washington, D.C. November 1979.

Chiriboga, D. A. Marital separation and stress. Alternative Life Styles, 1979, 2, 461-470.

Chiriboga, D. A. Adaptation to marital separation in later and earlier life. Journal of Gerontology, 1982, 37(1), 109-114.

Chiriboga, D. A., Coho, A., Stein, J. A., \& Roberts, J. Divorce, stress and social supports: A study in helpseeking behavior. Journal of Divorce, 1979, 3(2), 121-135.

Chiriboga, D. A., \& Cutler, L. Stress responses among divorcing men and women. Journal of Divorce, 1979, 1. (3), 96-106.

Chiriboga, D. A., Roberts, J., \& Stein, J. A. Psychological well-being during marital separation. Journal of Diverce, 1978, 2, (1) 21-36.

Cleveland, $M$. Divorce in the middle years: The sexual dimension. Journal of Divorce, 1979, 3(2), 255-262.

Cleveland, W. P., \& Gianturco, D. T. Remarriage probability after widowhood: A prospective method. Journal of Gerontology, 1976, 3I, (1) 99-103. 
Colletta, N. D. Support systems after divorce: Incidence and impact. Journal of Marriage and the Family, $1979,41(6), 837-846$.

Crosby, J. F. A critique of divorce statistics and their interpretation. Family Relations, 1980, 29, 51-58.

Deckert, P., \& Langelier, R. The late divorce phenomena: The causes and impact of ending 20 year old or longer marriages. Journal of Divorce, 1978, 1(4), 381-390.

Deshane, M. R., \& Wilson, K. B. Divorce in late life: A call for research. Journal of Divorce, 1981a, $4(4)$, $81-91$.

Deshane, M. R., \& Wilson, R. B. Divorce in late life: Emerging trends and problems. Institute on Aging, Portland State University, November 1981b.

Eberstein, I. W., \& Frisbee, W. P. Differences in marital instability among Mexican Americans, Blacks and Anglos: 1960 and 1970. Social Problems, 1976, 23, $609-621$.

Edwards, J. N. The future of the family revisited. Journal of Marriage \& the Family, August 1967, 29, 505-511.

England, J. L., \& Kunz, P. R. The application of age specific rates to divorce. Journal of Marriage and the Family, February 1975, 37, 40-46.

Feneton, B. State variations in the united states divorce rates. Journal of Marriage and the Family, May 1972, $33,321-327$.

Finkelhor, D. Help for retirement marriages. Modern Maturity, April-May 1980, pp. 79-82.

Fried, E., \& Stern, K. The situation of the aged within the family. American Journal of orthopsychiatry, January $1948,28,31-54$.

Froiland, D. J., \& Hozeman, T. L. Counseling for constructive divorce. Personal counseling and Guidance Journal, September 1977, 55, 525-529.

Fullerton, G. P. Survival in marriage. New York: Holt, Rinehart \& Winston, 1972.

Glenn, N. D., \& Weaver, C. N. The contribution of marital happiness to global happiness. Journal of Marriage 
and the Family, February 1981, 43, 161-168.

Glick, P. Marital instability: Variations by size of place and region. The Millbank Memorial Fund Quarterly, January 1963, 41, 43-55.

Glick, P. C., \& Norton, A. J. Perspectives on the recent upturn in divorce and renarriage. Demography, August $1973,10(3), 301-314$.

Glick, P. C., \& Norton, A. J. Marrying, divorcing and living together in the U.S. today (Population Bulletin 32). Washington, D.C.: Population Reference Bureau, Inc., 1977.

Goode, W. J. Divorce as an escape mechanism. In After divorce. New York: The Free Press, 1956.

Goode, W. J. Marital satisfaction and instability: A cross-cultural class analysis of divorce rates. In Reinhard Bendix \& Seymore M. Lipset (Eds.), class status and power (2nd ed.). New York: The Free Press, 1966.

Goode, W. J. The role of the family in industrialization. In R. F. Winch \& L. W. Goodman (Eds.), Selected studies in marriage and the family ( 3 rd ed.). San Francisco: Holt, Rinehart \& Winston, Inc., 1968.

Granvold, D. K., \& welch, G. J. Intervention for postdivorce adjustment problems: The treatment seminar. Journal of Divorce, 1977, 1(1), 81 .

Granvold, D. K., Pedler, L. M., \& Schellie, S. G. A study of sex role expectancy and female post divorce adjustment. Journal of Divorce, $1979,3, \quad$ (2), 383-394.

Hannon, M. T., Tuma, N. B. \& Groenveld, L. P. Income and marital events: Evidence from an income-maintenance experiment. American Journal of Sociology, 1977, 84, $611-633$.

Heatherington, E. M., Cox, M., \& Cox, R. The aftermath of divorce. In J. H. Stevens, Jr. \& M. Mathews (Eds.), Mother-child, father-child relations. Washington, D.C.: National Association for the Education of Young Children, 1978.

Heatherington, E. M., Cox, M., \& Cox, R. Play and social interaction in children following divorce. Journal of Social Issues, $1979,35(4), 26$. 
Herrman, S. J. Divorce: A grief process. Perspectives in Psychiatric Care, 1974, 12, 108-112.

Hill, R. Families under stress. New York: Harper \& Row, 1949 .

Hillman, R. G. Marital instability and its relation to education, income and occupation: An analysis based on census data. In R. F. Winch, R. McGinnis \& H. R. Barringer (Eds.), Selected studies in marriage and the family. New York: Holt, Reinhart \& winston, 1962 .

Hobart, C. W. Commitment, value conflict and the future of the American family. Marriage and Family Living, November $1963,25$.

Holman, T. B., \& Burr, W. R. Beyond the beyond: The growth of family theories in the 1970's. Journal of Marriage and the Family, November 1980, 42, 729-740.

Holmes, T. H., \& Masuda, M. Life changes and illness susceptibility. In B. S. Dohrenwend \& B. P. Dohrenwend (Eds.), stressful life events: Their nature anā effects. New York: John Wiley \& Sons, 1974.

Houseknecht, S. K., \& Spanier, G. B. Marital disruption and higher education among women in the united States. Paper Presented at the conference on Women in Mid-Life Crisis, Ithaca, New York, October 1976.

Hunt, M., \& Hunt, B. The divorce experience. New York: MCGraw-Hill, 1977.

Jacobson, F. H. American marriage and divorce. New York: Rinehart \& CD., 1959.

Rauffman, L., \& Bycel, B. Divorce American style. The Center Magazine, 1980, 13(6).

Kelly, J. B., \& Wallerstein, J. S. Brief interventions with children in divorcing families. American Journal of Orthopsychiatry, January $1977,47(1)$, 23-39.

Kephart, $W$. M. The duration of marriage. American Sociological Review, June 1954, 19, 287-295.

Kephart, W. M. Occupational level and marital disruption. American Sociological Review, August 1955, 20, 456-465. 
Kerckhoff, A. C. Husband-wife expectations and reactions to retirement. journal of Gerontology, January 1964, $19,510-516$.

Kessler, S. The American way of divorce: Prescriptions for change. Chicago: NeIson-Hall, 1975.

Kitson, G. C. Attachment to spouse in divorce: A scale and its application. Journal of Marriage and the Family, May 1982, 44, 379-393.

Rrause, S. Family law in a nutshell. St. Paul, Minn.: West Publishing Co., 1977.

Krause, S. The crisis of divorce: Growth promoting or pathogenic. Journal of Divorce, 1979, $\underline{3}, \quad$ (1), 107-119.

Landis, J. T. Marriages of mixed and non-mixed religious faith. American Sociological Review, June 1949, 14, 401-407.

Langner, T. S. A twenty two item screening survey of psychiatric symptoms indicating impairment. Journal of Health and Human Behavior, 1962, 3(4), 291-301.

LeMasters, E. E. Holy deadlock: A study of unsuccessful marriages. Sociological ouarterly, 1959, 21, 86-91.

Lenthall, G. Marital satisfaction and marital stability. Journal of Marriage and Family Counseling, 1977, 3 , 25-32.

Leonard, F. The disillusionment of divorce for older women. In Grey Paper No. 6--Issues for Action. Oakland, Ca.: Older Women's League Educational Fund, August 1980.

Leslie, G. R. The family in social context (4th ed.). New York: oxford University Press, 1982.

Lewis, R. A., \& Spanier, G. B. Theorizing about the quality and stability of marriage. In W. R. Burr, R. Hill, F. I. Nye, \& I. L. Reiss (Eds.), contemporary theories about the family (Vol. 1). New York: The Free Press, 1979.

Linton, R. The study of man. New York: AppletonCentury-Crofts, 1936 .

Lipman, A. Role conceptions of couples in retirement. In Clark Tibbits \& Wilma Donahue (Eds.), Social and 
psychological aspects of aging. New York: Columbia University Press, 1962 .

Litwak, E. Divorce law as social control. Social Forces, March 1956, XXIV, 217-223.

Locksley, A. Social class and marital attitudes and behavior. Journal of Marriage and the Family, May $1982,44,427-440$.

Luckey, - Perceptual congruence of self and family concepts as related to marital interaction. Sociometry, September 1961, 24, 234-250.

McCubbin, H. I., Joy, C. B., Cauble, E. A., Corneau, J. R., Patterson, J. M., \& Needle, R. H. Family stress and coping: A decade review. Journal of Marriage and the Family, 1980, 42, 855-871.

Mckenry, P. C., White, P. N., \& Price-Bonham, S. The fractured conjugal family: A comparison of married and divorced dyads. Journal of Divorce, 1978, I, (3), 329-339.

Meyers, J. The adjustutent of women to marital separation: The effects of sex and role identification and of stage in family life as determined by age and presence or absence of dependent children. Journal of Marriage and Family, August 1976, 38, 615-627

Michael, R. T. The rise in divorce rates, 1960-1976: Age specific components. Demography, 1978, 15(2), $177-182$.

Milgram, S. The experience of living in cities. Science, 1970 , p. 167.

Moles, O. C., \& Levinger, G. Introduction. Journal of Social Issues, $1976, \underline{32(1)}, 1$.

Monahan, T. P. Is childlessness related to family stability? American Sociological Review, August 1955 , 20, 446-456.

Monahan, T. P. Divorce by occupational level. Marriage and Family Living, November 1955, 17, 322-324.

Monahan, T. P. Family fugitives. Marriage and Family Living, May 1958, 20, 146-151. Monahan, T. P., \& Kephart, W. M. Divorce and desertion by religious and mixed relizious groups. 
American Journal of Sociology, March 1954, 454-465.

Moore, B. Thoughts on the future of the family. In M. R. Stein, A. J. Vidich, \& D. M. White (Eds.), Identity and anxiety. New York: The Free Press, 1960.

Mudd, E. Conference on divorce (Series 9). Chicago: University of Chicago Law School, 1952.

National Center for Health Statistics. Monthly Vital Statistics Report, May 29 \& June $11,1981, \underline{30}(2,3)$.

Nimkoff, M. F. The American family. In R. S. Cavan (Ed.), Marriage and family in the modern world. New York: Thomas Y. Crowell Company, 1969.

Norton, A. J. The influence of divorce on traditional life-cycle measures. Journal of Marriage and the Family, February 1980, 42, 28-36.

Norton, A., \& Glick, P. C. Marital instability: Past, present and future. Journal of Social Issues, 1976, $32(1), 5-20$.

Nye, F. I., \& Berardo, F. M. The family: Its structure and interaction. New York: MacMillan, 1973.

ogburn, W. $F$. The changing functions of the family. In $R$. F. Winch \& L. W. Goodmn (Eds.), Selected studies in marriage and the family. New York: Holt, Rinehart \& Winston, Inc., 1968.

Ogburn, W. F., Nimkoff, M. F. Technology and the changing family. Boston: Houghton Mifflin Co., 1955.

O'Neill, W. L. Divorce in the progressive era. New Haven, Conn.: Yale University Press, 1967.

Pais, J., \& White, P. Family redefinition: A review of the literature toward a model of divorce adjustment. Journal of Divorce, 1979, $3(2), 271-278$.

Pang, H., \& Hanson, S. M. Highest divorce rates in the western states. Sociology and Social Research, 1968, 52, 228-236.

Park, R. E. Human communities: The city and human ecolㅇy. New York: The Free Press, 1952.

Parsons, T., \& Bales, R. F. Family, socialization and interaction process. Glencoe, Ill.: The Free Press, 1955. 
Pearlin, L. I., \& Johnson, J. S. Marital status, life strains and depression. American Sociological Review, October 1977, 42, 704-715.

Pearlin, L. \& Schooler, C. The structure of coping. Journal of Health and Social Behavior, 1978, 1.9, $2-21$.

Preston, S. H., \& MacDonald, J. The incidence of divorce within cohorts of American marriages contracted since the Civil War. Demography, 1979, 16(1), 1-25.

Price-Bonham, S., \& Balswick, J. O. The noninstitutions: Divorce, desertion and remarriage. Journal of Marriage and the Family, November 1980, 42, 959-972.

Raschke, H. J. The role of social participation in post separation and post divorce adjustment. Journal of Divorce, 1977,1 , (1), 129-139.

Raschke, H. The development of a post separation/post divorce problems and stress scale. Prepared for the National Council on Family Relations Annual Meeting, Philadelphia, Pennsylvania, October 1978.

Raschke, H. J., \& Barringer, K. D. Postdivorce adjustment in Parents-Without-Partners organizations. Family Perspective, 1978, 11, 23-24.

Reiss, I. L. The family system in America. San Francisco: Holt, Rinehart and Winston, Inc., 1971.

Reissman, L. The urban process. New York: The Free Press, 1964.

Ross, H., \& Sawhill, I. V. Time of transition: The growth of families headed by women. Washington, D.C.: The Urban Institute, 1975.

Scanzoni, J. Sexual bargaining: Power politics in the American marriage, Englewood Cliffs, N.J.: Prentice-Hall, 1972 .

Schoen, R., \& Nelson, V. E. Marriage, divorce and mortality: A life table analysis. Demography, 1974, $11(2), 267-290$.

Smith, P. The nation comes of age (Vol. IV). New York: McGraw Hill, 1981.

Spanier, G. B., \& Casto, R. F. Adjustment to separation and divorce: An analysis of 50 case studies. 
Journal of Divorce, 1979, $\underline{3}(2), 241$.

Spanier, G. B., \& Hanson, S. The role of extended kin in the adjustment to marital separation. Paper Presented at the Annual Meeting of the southern Sociological society, New Orleans, April 1978.

Spanier, G. B., Lewis, R. A., \& Cole, C. L. Marital adjustment over the family life cycle: The issue of curvilinearity. Journal of Marriage and the Family, May 1975, 37, 263-275.

Statistical bulletin. Metropolitan Life Insurance Co., July-September 1981, 62(3).

Sweeney, J. Sunset year survivors: Long-term marriages produce surprises. The sunday oregonian, July II, 1982 , p. 6 .

Terman, L. M. Psychological factors in marital happiness. New York: McGraw-Hill, 1938.

Thornton, A. Marital instability differentials and interactions: Insights from multivariable contingency table analysis. Sociology and social Research, 1978, 62, 572-595.

Treas, J., \& Van Hilst, A. Marriage and remarriage rates among older Americans. The Gerontologist, 1976, 16, 136-143.

Udry, J. R. Marital instability by race, sex, education, occupation and income using 1960 census data. In $R$. F. Winch \& L. W. Goodman (Eds.), selected studies in marriage and the family ( $3 \mathrm{rd}$ ed.). New York: Holt, Rinehart and Winston, 1968 .

Udry, R. The social context of marriage. Philadelphia, Pa.: J. B. Lippincott Co., 1971.

Uhlenberg, P., \& Meyers, M. A. P. Divorce and the elderly. The Gerontologist, 1981, 21, 276-282.

U.S. Bureau of the Census. Marital status and living arrangements: March, 1978. Current Population Reports, Series P-20, No. 33 .

U.S. Bureau of the Census. Historical statistics of the United States, Colonial Times to 1967. Washington, D.C.: 1960 .

Walster, E., Berscheid, E., \& Walster, G. W. New 
directions in equity research. Journal of Personality and Social Psychology, 1973, 25, 151-176.

Weeks, J. R. Population: An introduction to concepts and issues. Belmont, Ca.: Wadsworth Publishing Co., 1978 .

Weisman, R. S. Crisis theory and the process of divcrce. Social Casework, 1975, 56, 223-240.

Weiss, R. Marital separation. New York: Basic Books, 1975 .

Wilson, K. B., \& DeShane, M. R. The divorced elderly: A group at risk. Paper Presented at the 34 th Annual Gerontological Society Meeting, San Diego, California, November 1980.

Wilson, R. B., \& Schulz, R. Crisis intervention for the elderly: Effective designs and model programs. Institute on Aging, Portland State University, 1982.

Wirth, L. Urbanism as a way of life. American Journal of Sociology, 1938, XLIV, 1-24.

Zimmerman, C. C. Family and civilization. New York: Harper \& Brother, 1947. 